\title{
Synthesis, characterization and catalytic applications of organized mesoporous aluminas
}

Carlos Márquez-Alvarez ${ }^{1}$, Naděžda Žilková ${ }^{2}$ Joaquín Pérez-Pariente ${ }^{1}$ and Jiří Čejka ${ }^{2}$

${ }^{1}$ Institute of Catalysis and Petrochemistry (ICP), CSIC, C/ Marie Curie, 2. Cantoblanco 28049 Madrid, Spain

${ }^{2} J$. Heyrovský Institute of Physical Chemistry, Academy of Sciences of the Czech Republic, v.v.i., Dolejškova 3, CZ-182 23 Prague 8, Czech Republic

\begin{abstract}
The synthesis of organized mesoporous aluminas has opened a very interesting area for application of this type of materials, particularly as catalysts or catalyst supports. This review focuses on the individual synthesis routes to produce organized mesoporous aluminas with large surface areas and narrow pore size distributions, and on the evaluation of their textural, chemical and thermal properties. Second part outlines examples of catalytic applications of organized mesoporous alumina-based catalysts. We tried to rationalize the synthetic approaches to prepare organized mesoporous aluminas, to relate their properties to synthetic procedures used as well as to their catalytic behavior in different reactions. Utilization of various structure-directing agents for "cationic", "neutral", "anionic", "nanocasting" and special approaches leading to scaffolding and lathlike organized mesoporous aluminas is discussed in the first part of this review, as well as textural and structural characterization and thermal stability of mesoporous aluminas synthesized by different synthetic approaches. In the second part, catalytic applications of organized mesoporous aluminas described in the open literature are evaluated from the standpoint of the importance of these reactions for technological applications.
\end{abstract}

Keywords: Organized mesoporous alumina, Synthesis routes, Characterization, Catalytic applications, Metathesis, Hydrotreatment. 


\section{INTRODUCTION}

The first successful synthesis of mesoporous molecular sieves by Mobil researchers opened a new area in the research of inorganic porous materials with particular implications for adsorption, controlled desorption, and especially catalysis (14). With regard to that, materials possessing large surface areas, tailored pore sizes, high thermal stability, and allowing the modification with catalytically active species are of tremendous interest for both fundamental research and technological applications.

Alumina is the most frequently employed catalyst or catalytic support in the chemical industry (5). Therefore, any improvement of the alumina properties significant for their catalytic applications is extremely challenging. The synthesis of ordered mesoporous silicates and aluminosilicates, although without crystalline walls, initiated a great effort to synthesize similar materials based on different chemical compositions. Mesoporous alumina, titania and zirconia were the first targets in this area (6). However, it has been found that their synthesis is definitely not as straightforward as in the case of silicates of the M41S family. After several years of evaluating the synthesis approaches leading to organized mesoporous alumina at the end of twentieth century, the period of maturity in this area has been reached. This is documented by the available control of the pore size of organized mesoporous alumina as well as the formation of different types of active sites on their surface. This in a similar way as with mesoporous silicates and aluminosilicates (7) can lead to the various types of catalysts.

The successful synthesis of organized mesoporous aluminas, recently reviewed by Čejka (8), Pinnavaia (9), and Li and coworkers (10) (although in Chinese), represents an important improvement in textural properties of this type of mesoporous materials and a challenging area for their applications, particularly as catalysts and 
catalyst supports. The main advantages of organized mesoporous aluminas can be summarized as follows:

i) large surface areas, which depending on the synthesis, can reach more than $700 \mathrm{~m}^{2} / \mathrm{g}$,

ii) tuned pore size diameter from 2 to at least $10 \mathrm{~nm}$,

iii) possibility to change surface properties by properly chosen synthesis procedure.

In this paper the direct synthetic approaches to organized mesoporous aluminas are discussed in detail while no attention is paid to mesoporous alumina materials prepared by grafting of alumina on wide-pore mesostructured silicas, e.g. (11).

Recently published papers enlarged substantially the number of catalytic reactions being investigated using organized mesoporous aluminas as supports for catalytically active species. These reactions include e.g. hydrodesulfurization, dechlorination, metathesis, Tishchenko reaction and oxidation reactions depending on the way of alumina modification.

The objective of this review paper is to evaluate the relevant approaches to the synthesis of organized mesoporous aluminas and to describe their chemical, structural and textural properties. Particular attention is devoted to the catalytic results employing organized mesoporous aluminas of different types and structures in various chemical reactions. The rationalizations of the synthesis procedures with particular attention to the resulting textural properties of organized mesoporous aluminas and their catalytic behavior in different reactions with respect to textural and chemical properties were attempted. 


\section{SYNTHESIS OF ORGANIZED MESOPOROUS ALUMINAS}

Some effort devoted to the synthesis of organized mesoporous aluminas in early nineties mainly failed due to the necessity to modify the original synthetic approaches used for silica materials because of the different chemical behavior of the aluminum sources used. The first successful synthesis of organized mesoporous alumina was reported by Vaudry et al. (12) using long-chain carboxylic acids, while the previous attempts of Stucky's group led to the formation of lamellar systems only $(13,14)$. At present, various approaches to the synthesis of organized mesoporous aluminas have been described including "anionic", "cationic" and "neutral" procedures and also the nanocasting method. They all provide mesoporous aluminas with relatively high surface areas and narrow pore size distribution and offer interesting materials for application in catalysis.

The synthesis approaches reported in the literature for the formation of mesostructured aluminas are based on sol-gel processes in the presence of templates, both soft (surfactants and non-surfactant organic molecules) and hard (polymers and carbon molds) ones. Before reviewing these approaches, it is worth to briefly remind basic concepts of the chemistry of the alumina-water system and the structure of aluminum hydroxide and oxide hydroxide (for a detailed review see, e.g. ref. (15)). Aluminum oxide is highly soluble in water at $\mathrm{pH}$ below 4 and above 9 . The species in solution at $\mathrm{pH}<4$ are mainly $\mathrm{Al}\left(\mathrm{H}_{2} \mathrm{O}\right)_{6}{ }^{+}$cations. At higher $\mathrm{pH}$, deprotonation of water occurs, forming $\left[\mathrm{Al}(\mathrm{OH})\left(\mathrm{H}_{2} \mathrm{O}\right)_{5}\right]^{2+}$ ions that can produce dimeric or polymeric complexes by further deprotonation and loss of water molecules. At $\mathrm{pH}$ around the isoelectric point of alumina $(\mathrm{pH}=8-9)$, the predominant species in solution is $\mathrm{Al}(\mathrm{OH})_{4}{ }^{-}$ and, at higher $\mathrm{pH}, \mathrm{AlO}_{2}{ }^{-}$species occurs. At $\mathrm{pH}$ values in the range 4-8, precipitation of 
Al hydroxide takes place, often as a poorly ordered solid phase, that is transformed by ageing into crystalline aluminum hydroxide $\left(\mathrm{Al}(\mathrm{OH})_{3}\right)$ or oxide hydroxide $(\mathrm{AlOOH})$, depending on $\mathrm{pH}$ and temperature. Aluminum hydroxide occurs in three crystalline forms, namely gibbsite, bayerite and nordstrandite. $\mathrm{AlOOH}$ can be found in two crystalline modifications, like the metastable phase diaspore and boehmite, which crystallizes spontaneously by heating of aluminum hydroxide at temperatures from 100 to $300{ }^{\circ} \mathrm{C}$. Depending upon precipitation and ageing conditions, the most common hydroxides and oxide hydroxides produced are gibbsite, bayerite and boehmite, as well as pseudo-boehmite, a form of boehmite with higher $\mathrm{H}_{2} \mathrm{O}: \mathrm{Al}_{2} \mathrm{O}_{3}$ ratio (1.3-1.8, compared with 1 in boehmite) (16). All these structures are based on aluminum ions surrounded in six-fold coordination by oxygen and/or hydroxide ions. These coordination octahedra form layers that are linked by hydrogen bonds. As an example, the crystal structures of gibbsite and boehmite are depicted in Figure 1.

\subsection{Anionic surfactants}

Stucky et al. early extended the concept of cooperative formation of organicinorganic interfaces that led to the M41S molecular sieves, to the synthesis of a number of metal oxide, phosphate and sulfide mesophases (13). It was pointed out that organic bioarrays are generally based on anionic groups (such as carboxylate, phosphate or sulfate) that interact with cationic inorganic phases. Therefore, the formation of mesophases with anionic surfactants was explored. By properly adjusting the $\mathrm{pH}$ of the synthesis mixture, inorganic molecular species, both cationic $\left(\mathrm{I}^{+}\right)$and anionic $\left(\mathrm{I}^{-}\right)$, were obtained to promote the mesophase formation through an electrostatic interaction with anionic $\left(\mathrm{S}^{-}\right)$or cationic surfactants $\left(\mathrm{S}^{+}\right)(14)$. Besides these $\mathrm{SI}^{-}$and $\mathrm{S}^{+} \mathrm{I}^{-}$synthesis routes, 
also cation- $\left(\mathrm{M}^{+}\right)$and anion-mediated $\left(\mathrm{X}^{-}\right)$combinations of surfactant and inorganic species $\left(\mathrm{S}^{-} \mathrm{M}^{+} \mathrm{I}^{-}\right.$and $\left.\mathrm{S}^{+} \mathrm{X}^{-} \mathrm{I}^{+}\right)$were obtained. The synthesis of alumina mesophases was carried out by precipitation of aluminum hydroxide by adding an aqueous solution of aluminum nitrate to $\mathrm{NaOH}$ aqueous solutions containing alkylphosphates. However, these attempts resulted only in lamellar mesophases. Working at $\mathrm{pH}=5$ (below the isoelectric point of alumina), a mesophase with direct interaction between the surfactant and cationic inorganic species $\left(\mathrm{SI}^{-}\right)$was obtained, in which the presence of a bridging oxygen between $\mathrm{Al}$ and $\mathrm{P}$ (stemming from alkylphosphates) was identified. At $\mathrm{pH}>8$, sodium cations were incorporated at the interface between the surfactant and anionic aluminate species $\left(\mathrm{S}^{-} \mathrm{M}^{+} \mathrm{I}^{-}\right)$. In the later mesophase, the surfactant was hydrogen bonded to the aluminate framework.

Similarly, Yada et al. (17-19) used urea to obtain a homogeneous precipitation of aluminum hydroxide from aluminum nitrate aqueous solutions containing sodium dodecyl sulfate (SDS). Thermal decomposition of urea at temperatures around $70{ }^{\circ} \mathrm{C}$ was carried out for a controlled and homogeneous release of ammonia into the precursor solution, allowing a controlled increase in $\mathrm{pH}$ up to 8.5. Although at $\mathrm{pH}$ values ranging from 5.5 to nearly 7 the mesophases obtained were lamellar, hexagonal mesophases were also formed at $\mathrm{pH}>6$. Unfortunately, these mesophases collapsed after surfactant extraction with ethanol or acetone. Surfactant extraction with an ethanol solution of sodium acetate also led to mesophase collapse. In contrast, a mesoporous material with surface area as high as $660 \mathrm{~m}^{2} / \mathrm{g}$ was obtained (20) after surfactant extraction of a Ydoped alumina hexagonal mesophase. A mesoporous alumina was obtained, however, by calcination of the hexagonal alumina mesophase in air at $600^{\circ} \mathrm{C}$. The mesoporous alumina exhibited a narrow pore size distribution although the pore structure was 
disordered. Its BET surface area was not reported. Table 1 provides a list of mesoporous aluminas synthesized with anionic surfactants and their respective textural properties.

The investigations of Yada were followed by Sicard et al. (21) who investigated the mechanism of removal of the dodecyl sulfate surfactant from a mesostructured alumina by using thermal analysis. They showed that a strong interaction exists between the sulfate head groups and the alumina framework. This strong interaction caused probably a ready sintering and collapse of the alumina framework upon surfactant removal by calcination, as previously proposed by Valange et al. (22). The mechanism of this mesostructured alumina templating has been recently investigated in detail by Caragheorgheopol et al. using NMR self-diffusion and spin and fluorescence probe techniques (23). The authors observed that hexagonally structured alumina was formed over a large range of concentrations of the $\mathrm{SDS} / \mathrm{Al}\left(\mathrm{NO}_{3}\right)_{3} /$ water/urea starting solution. According to the proposed precipitation mechanism, the $\mathrm{pH}$ increase due to urea decomposition caused the $\mathrm{Al}^{3+}$ concentration to decrease as charged hydroxoaluminum species were formed. This led to the destabilization of the micellar phase and formation of the dodecyl sulfate-Al hexagonal structure. All synthesized alumina samples showed, however, poor thermal stability and removal of the surfactant led to the collapse of the structure. These results are in a good agreement with those of Sicard et al. (24) investigating the mechanism of formation of mesostructured hexagonal alumina by means of fluorescence probing technique. The authors showed that transformation of the complex formed by growing alumina polymer and dodecyl sulfate micelles into an organized material proceeded before or during precipitation of the organized solid.

Based on the early attempts to prepare organized mesoporous aluminas using dodecyl sulphate as structure-directing agent it seemes that, although hexagonal alumina is formed during the synthesis, the removal of the surfactant resulted in a breakdown of 
the mesoporous structure. This is probably due to the formation of a strong complex between cationic alumina species and the sulfate group. Thermogravimetric analysis (TGA) of dodecylsulfate-alumina mesophases, reported in ref. (21), indicated dodecyl sulfate content close to $55 \mathrm{wt} \%$. This loading of the structure directing agent (SDA) corresponds to an $\mathrm{Al} / \mathrm{SDA}$ ratio as low as ca. 3. Therefore, the main reason for collapse of the structure during calcination probably lies in a low average Al-O-Al connectivity due to the high surfactant content. This conclusion stresses the importance of determining the fraction of organic material in order to properly evaluate the stability of alumina mesophases. However, this parameter is usually not reported. Furthermore, the textural properties of mesostructured aluminas may strongly depend on the calcination protocol used to remove the template. Yada et al. (19) reported a decrease in the BET surface area from 120 to $43 \mathrm{~m}^{2} / \mathrm{g}$ for aluminas calcined at $600{ }^{\circ} \mathrm{C}$ when the heating rate was increased from 1 to $5{ }^{\circ} \mathrm{C} / \mathrm{min}$, and the dwell time from 3 to $10 \mathrm{~h}$ (Table 1). Ray et al. (25) reproduced the synthesis conditions of Yada et al. and reported BET surface area of $77 \mathrm{~m}^{2} / \mathrm{g}$ for alumina calcined at $500{ }^{\circ} \mathrm{C}$ for $4 \mathrm{~h}$, however, the heating rate was not reported. Ray et al. (25) also carried out the synthesis of alumina mesophase using sodium dodecylsulfate and aluminum nitrate, similar to that reported by Valange et al. (22). The authors reported a BET surface area as low as $27 \mathrm{~m}^{2} / \mathrm{g}$ for the alumina calcined at $500{ }^{\circ} \mathrm{C}$ for $4 \mathrm{~h}$, while Valange et al. reported a value as high as $443 \mathrm{~m}^{2} / \mathrm{g}$ after calcination at $450^{\circ} \mathrm{C}$ for $2 \mathrm{~h}$, when the surfactant was decomposed in a nitrogen stream at $450{ }^{\circ} \mathrm{C}$ prior to calcination (Table 1). These results evidence that rationalization of results reported for the synthesis of mesostructured alumina requires a detailed description of the synthesis and calcination protocols employed.

Valange et al. (22) reported several synthesis routes in aqueous medium with different inorganic aluminum sources and anionic surfactants. X-ray powder diffraction 
data showed that hexagonal mesophases were obtained using $\mathrm{Al}_{13}$ Keggin polycations and carboxylic acids in slightly acidic medium. Control of $\mathrm{pH}$ around 6 was required in order to lower the high positive charge density of the Keggin cations and to avoid the formation of lamellar mesophases. The mesostructures prepared, however, became disordered upon calcination at $450{ }^{\circ} \mathrm{C}$. Alumina sintering occurred upon calcination, which was attributed to the strong interaction between the sulfate groups and the positive charges of the alumina surface. A microporous alumina with surface area of $707 \mathrm{~m}^{2} / \mathrm{g}$ was obtained using $\mathrm{Na}$ laurate at $\mathrm{pH}$. It was suggested that at $\mathrm{pH}$ values below 7, microporous aluminas would tend to be formed because of the low curvature alumina sheets. Therefore, to obtain mesoporous aluminas, it was proposed that small amounts of cationic surfactants should be added in order to get a better charge density matching when working at $\mathrm{pH}$ close to 7 . The mesophase obtained with a mixture of $\mathrm{Na}$ palmitate and cetyltrimethylammonium bromide at $\mathrm{pH} 6.5$ was also hexagonal. Calcination at $450{ }^{\circ} \mathrm{C}$ rendered a disordered mesoporous alumina with high surface area $\left(810 \mathrm{~m}^{2} / \mathrm{g}\right)$ and pore size of $2.7 \mathrm{~nm}$.

Davis et al. (12) obtained mesophases by hydrolysis of aluminum alkoxide precursors in low molecular weight alcohol solutions, using $\mathrm{C}_{5}$ to $\mathrm{C}_{18}$ carboxylic acid surfactants. The amount of water used (molar ratio $\mathrm{H}_{2} \mathrm{O} / \mathrm{Al}$ alkoxide $=3.2$ ) was slightly higher than the stoichiometric amount required for a complete hydrolysis of the alkoxide to produce aluminum hydroxide (Eq. [1]):

$$
\mathrm{Al}(\mathrm{OR})_{3}+3 \mathrm{H}_{2} \mathrm{O} \rightarrow \mathrm{Al}(\mathrm{OH})_{3}+3 \mathrm{ROH} \quad \text { [Eq. 1] }
$$

Mesoporous aluminas with relatively narrow pore size distribution and a disordered pore structure were produced after calcination in air at $430{ }^{\circ} \mathrm{C}$ for $2 \mathrm{~h}$. The 
alumina samples exhibited BET surface areas as high as $710 \mathrm{~m}^{2} / \mathrm{g}$. However, the thermal stability of these samples was low as surface areas substantially decreased to less than $360 \mathrm{~m}^{2} / \mathrm{g}$ when the calcination temperature was increased to $500{ }^{\circ} \mathrm{C}$. As shown in Table 1, the surface areas correspond to aluminas templated with the same surfactant (lauric acid) but aged at different temperatures (110 and $138{ }^{\circ} \mathrm{C}$, respectively). Nonetheless, Ray et al. (25) carried out similar synthesis, with ageing at $100{ }^{\circ} \mathrm{C}$, and reported a surface area of $412 \mathrm{~m}^{2} / \mathrm{g}$ for a sample calcined at $500{ }^{\circ} \mathrm{C}$ for $4 \mathrm{~h}$. One possible reason for the low thermal stability is that the mesophases obtained possess an aluminum oxide hydroxide framework with low Al-O-Al connectivity, due to the monoand bidentate coordination of carboxylate species with aluminum, and the relatively high surfactant content (TGA suggests a lauric acid/Al molar ratio around 0.3) (12).

Čejka et al. $(26,27)$ modified slightly the former procedure to synthesize mesoporous aluminas in order to carry out a detailed textural characterization by $\mathrm{N}_{2}$ sorption measurements. Samples were templated with lauric and stearic acid in 1propanol solution. Samples calcined at $420{ }^{\circ} \mathrm{C}$ exhibited mesoporous surface areas of $475 \mathrm{~m}^{2} / \mathrm{g}$ (lauric acid) and around $700 \mathrm{~m}^{2} / \mathrm{g}$ (stearic acid), and BJH pore size distributions with maxima at around $3.5 \mathrm{~nm}$. This work was later extended to obtain high resolution sorption isotherms in the region of low relative pressures (down to $10^{-6}$ ) (28). The investigation proved that stearic acid-templated samples calcined at temperatures between 420 and $1000{ }^{\circ} \mathrm{C}$ (as well as several block copolymers-templated samples) did not possess any detectable amount of micropores. It was also shown (29) by combination of X-ray diffraction (Figure 2) and TEM (Figure 3) that these materials calcined at low temperature do not exhibit a crystalline structure. However, during calcination at temperatures between 600 and $1000{ }^{\circ} \mathrm{C}$, these aluminas were transformed into crystalline phase, showing a packing of $\delta$-alumina nanoparticles. 
Kim et al. (30) recently reported the synthesis of mesoporous aluminas loaded with Ni nanoparticles using lauric acid as template in 2-butanol solutions containing $\mathrm{Ni}^{2+}$ cations. Different porosity was observed when the hydrolysis of the aluminum secbutoxide precursor was carried out in the presence of the surfactant or prior to the addition to the surfactant solution. The former hydrolysis method rendered aluminas with framework mesoporosity, while the later procedure gave rise to textural porosity. Furthermore, weaker interaction between nickel and alumina was found when the prehydrolysis method was used, leading to a higher degree of Ni reduction. The effect of $\mathrm{pH}$ and water content on the textural properties of mesoporous aluminas templated by stearic acid was also reported (31). Aluminas were prepared by hydrolysis of aluminum sec-butoxide in 2-butanol solutions containing stearic acid (surfactant:Al molar ratio = 0.2 ) at room temperature, and $\mathrm{pH}$ regulated in the range 6-8 using $1 \mathrm{M} \mathrm{HNO}_{3}$ solution. After calcination at $450{ }^{\circ} \mathrm{C}$, mesoporous aluminas with wormhole-like pore structure were obtained in all cases. The pore size of aluminas synthesized using $\mathrm{H}_{2} \mathrm{O}$ : $\mathrm{Al}$ ratio equal or lower than 8 was $3.5 \mathrm{~nm}$, and surface area increased with $\mathrm{H}_{2} \mathrm{O}$ : $\mathrm{Al}$ ratio up to $485 \mathrm{~m}^{2} / \mathrm{g}$. For $\mathrm{H}_{2} \mathrm{O}: \mathrm{Al}$ ratios higher than 16 (both butanol and water are considered as cosolvents in these cases), mesoporous aluminas with wider pores (7.1-7.7 nm) and slightly smaller surface area $\left(370-390 \mathrm{~m}^{2} / \mathrm{g}\right)$ were obtained.

The attempts to synthesize organized mesoporous aluminas using long-chain carboxylic acids can be summarized as follows:

i) mesoporous alumina can be readily prepared in alcoholic media,

ii) surface areas can reach values as large as $700 \mathrm{~m}^{2} / \mathrm{g}$,

iii) the size of the pores depends on the size of micelles (length of the hydrophobic chain of long-chain carboxylic acids), 
iv) syntheses carried out in aqueous solutions usually provide mesoporous aluminas with lower surface areas compared with those performed in alcoholic media.

\subsection{Cationic surfactants}

Certain analogy to the typical synthesis procedures well established for the synthesis of mesoporous molecular sieves of M41S family can be found in the synthesis of organized mesoporous aluminas synthesized using alkyltrimethylammonium surfactants (Table 2). However, a number of the reported syntheses of these alumina mesophases are not expected to follow a direct $\mathrm{S}+\mathrm{I}-$ interaction route. For syntheses carried out in aqueous solution at $\mathrm{pH}$ below the isoelectric point of alumina or by hydrolysis of aluminum alkoxides in organic media, the inorganic species in solution would be cationic and, therefore, an anion-mediated $\mathrm{S}+\mathrm{X}-\mathrm{I}+$ interaction would drive mesophase formation.

Acosta et al. (32) published the first report on the synthesis of aluminum hydroxide-cationic surfactant mesophases, using alkyltrimethylammonium bromide in aqueous solution. Aluminum chloride was used as precursor and the precipitation was controlled by addition of urea and mild heating, to reach a $\mathrm{pH}$ value close to 7 . Gelation was carried out at $80-90{ }^{\circ} \mathrm{C}$. The concentration of the aqueous surfactant solutions was varied from 20 to $50 \mathrm{wt} \%$ aiming to explore both isotropic and hexagonal mesophase regions. However, disordered mesophases, showing a single low angle X-ray diffraction line, were obtained in all cases. Heating in a stream of nitrogen at $450{ }^{\circ} \mathrm{C}$ followed by calcination in air at the same temperature to remove the surfactant rendered poorly crystalline mesoporous transition aluminas. The textural properties were reported for samples obtained using a $32 \mathrm{wt} \%$ surfactant concentration. Only small differences were found for the sample prepared using octyltrimethylammonium bromide compared to a 
sample obtained without surfactant. It seems that in a similar way as in the synthesis of ordered mesoporous silica, octyltrimethylammonium cation is a poor structure-directing agent (probably due to a short hydrophobic hydrocarbon chain). Significant increases in BET surface area (from 430 to $485 \mathrm{~m}^{2} / \mathrm{g}$ ), pore volume (from 0.29 to $0.66 \mathrm{~cm}^{3} / \mathrm{g}$ ) and average pore size (from 2.7 to $5.5 \mathrm{~nm}$ ) were reported, however, for tetradecyltrimethylammonium-templated aluminas. A small decrease in the surface area was reported when the calcination temperature was increased for the octyltrimethylammonium-templated alumina, for which BET surface areas around 340 and $270 \mathrm{~m}^{2} / \mathrm{g}$ were measured after calcination at 650 and $800{ }^{\circ} \mathrm{C}$, respectively.

The synthesis of mesophase precursors of mesoporous aluminas and other oxides in aqueous solutions of alkyltrimethylammonium surfactants has been also reported using atrane complexes as precursors $(33,34)$. This amine-trialkoxo complexes were obtained by a transesterification of a metal alkoxide with triethanolamine (TEA) aiming to slow down the hydrolysis of the precursor. Mesoporous aluminas rendered by calcination at $500{ }^{\circ} \mathrm{C}$ of mesophases prepared using cetyltrimethylammonium (CTA) bromide as surfactant exhibited a wormhole-like porous structure. The water/TEA ratio was found to affect both BET surface area and BJH pore size. Thus, increasing the water/TEA molar ratio from 7.4 to 44.5 led to a decrease in the BET surface area from 340 to $250 \mathrm{~m}^{2} / \mathrm{g}$, while the pore size increased from 3.3 to $6.0 \mathrm{~nm}$. These results suggest that porosity is originated by the agglomeration of small alumina crystallites. Complexation of the aluminum precursor with TEA is probably limiting the growth of those crystallites. An increase in water/TEA molar ratio might lessen such effect and promote formation of larger crystallites, which would be reflected in the observed changes in textural properties. 
Deng et al. (35) also investigated this reaction system using aluminum secbutoxide as precursor. It is worth noting that despite the high reactivity of aluminum alkoxides, aluminum sec-butoxide is expected to hydrolyze with a lower rate than the more commonly used isopropoxide. Indeed, even though no chemical modification of the aluminum alkoxide was carried out to retard hydrolysis, mesostructured amorphous aluminas were obtained. It was observed that the presence of limited amounts of ethanol as co-solvent, promoted the formation of macropores. The macroporous-mesoporous aluminas exhibited a regular array of unidirectional macropores of around $300 \mathrm{~nm}$ in diameter when the synthesis was carried out at room temperature in a $30 \mathrm{vol} \%$ ethanol/water mixture. The samples, however, were not homogenous and not all particles exhibited hierarchical pore structure. No explanation of the mechanism involved in the regular macroporous structure formation was provided.

The synthesis of mesoporous alumina in aqueous solutions is still rather challenging and not so well understood compared with syntheses in other solvents. However, it should be stressed that textural properties of these aluminas are usually of lower quality compared with alcoholic solutions. The synthesis carried out in 1-butanol has been reported (36), using a water to aluminum sec-butoxide molar ratio of 2 . This corresponds to the stoichiometric amount required for aluminum oxide hydroxide formation (Eq. [2]) and, therefore, it is expected to prevent formation of aluminum hydroxide:

$$
\mathrm{Al}(\mathrm{OR})_{3}+2 \mathrm{H}_{2} \mathrm{O} \rightarrow \mathrm{AlO}(\mathrm{OH})+3 \mathrm{ROH}
$$

The precipitates were submitted to hydrothermal treatment at $100{ }^{\circ} \mathrm{C}$ for $24 \mathrm{~h}$. The samples calcined at $500{ }^{\circ} \mathrm{C}$ showed disordered mesoporous structure and textural 
properties similar to samples previously synthesized in aqueous medium. The addition of formamide to the synthesis gel was claimed to allow the control of the pore size (37). The $\mathrm{N}_{2}$ sorption isotherms reported for samples calcined at $500{ }^{\circ} \mathrm{C}$ showed, however, that these materials loose the mesoscopic order with increasing amount of formamide. Ray et al. (25) modified the synthesis procedure used by Kim et al. (36) and showed that the change of solvent from 1-butanol to 2-butanol led to an increase in the BET surface area of samples calcined at $500{ }^{\circ} \mathrm{C}$, from 401 to $475 \mathrm{~m}^{2} / \mathrm{g}$, and pore volume from 0.46 to $0.67 \mathrm{~cm}^{3} / \mathrm{g}$ (Table 2). Furthermore, decreasing the amount of cetyltrimethylammonium in the synthesis medium from a surfactant:Al molar ratio of 0.5 to 0.3 , gave rise to a further increase of both BET surface area $\left(506 \mathrm{~m}^{2} / \mathrm{g}\right)$ and pore volume $\left(0.83 \mathrm{~cm}^{3} / \mathrm{g}\right)$. The latter sample showed a relatively high thermal stability (Table 2).

\subsection{Non-ionic surfactants}

The first report on the synthesis of non-ionic $\left(\mathrm{N}^{0}\right)$ surfactant-alumina mesophases stable to calcination was published in the middle of 1990's by Bagshaw et al. $(38,39)$. The surfactants used were either diblock R-(EO) copolymers (Tergitol, Igepal, Triton) containing a hydrophilic poly(ethylene oxide) chain (PEO) with $n$ ethylene oxide (EO) units and a hydrophobic hydrocarbon moiety (R) or triblock $(\mathrm{EO})_{\mathrm{n}}(\mathrm{PO})_{\mathrm{m}}(\mathrm{EO})_{\mathrm{n}}$ copolymers (Pluronics), where the hydrophobic part corresponds to a poly(propylene oxide) chain (PPO) with $m$ propylene oxide (PO) units linked to two poly(ethylene oxide) chains. The emulsifying properties of such copolymers can be predicted from their hydrophilic-lipophilic balance (HLB), which value ranges from 0 to 20 and is calculated as the weight percentage of the PEO chain divided by 5 . Thus, the 
higher the HLB value, the more water-soluble the surfactant. In this case, it is expected that oxygen atoms of the PEO chain interact via hydrogen bonding with the hydroxyl groups bonded to $\mathrm{Al}$ or even at bare $\mathrm{Al}$ having available coordination sites (Figure 4). The precursor used was an alkoxide (aluminum sec-butoxide) and its hydrolysis was carried out in 2-butanol solution with a 2:1 water:alkoxide molar ratio. Surfactant removal by calcination of the solid phase in a stream of air at $500{ }^{\circ} \mathrm{C}$ for $4 \mathrm{~h}$ resulted in mesoporous aluminas with surface areas ranging from 420 to $535 \mathrm{~m}^{2} / \mathrm{g}$, BJH pore size from 2.4 to $4.7 \mathrm{~nm}$ and mesopore volume from 0.21 to $0.68 \mathrm{~cm}^{3} / \mathrm{g}$ (Table 3), with no long-distance ordering of mesopores. These results showed a clear advantage in using the non-ionic surfactants in contrast to charged (both cationic and anionic) surfactants for the synthesis of high surface area aluminas. No details (e.g. heating rate) were given on the exact thermal treatment employed for surfactant removal. However, it should be stressed that this treatment might have enormous influence on the final textural properties from at least two reasons. First, the surfactant combustion is highly exothermic. As mesophases contain a high amount of surfactant, careful calcination is required in order to avoid temperature overshoots that might cause a structural collapse. Usually, solvent-extraction and/or thermal decomposition of the organic phase in inert atmosphere is performed prior to the calcination in air. Second, further condensation of Al-O-Al bridges during early stages of this temperature treatment is probably critical to achieve stable mesoporous alumina. Later on, Zhang and Pinnavaia (40) indicated that these materials possessed a relatively low thermal stability, which led to a significant loss of surface area when the calcination temperature was increased from 500 to $600{ }^{\circ} \mathrm{C}$. The authors proposed that addition of $\mathrm{Ce}$ or La to the synthesis gel increases thermal stability. The decrease in BET surface area of ca. $32 \%$ (from 530 to $360 \mathrm{~m}^{2} / \mathrm{g}$ ) for a Cecontaining sample was reported. However, this result was compared to a non-doped 
mesoporous alumina with a BET surface area lower than that of the samples reported in the previous paper after calcination at $500{ }^{\circ} \mathrm{C}\left(390 \mathrm{~m}^{2} / \mathrm{g}\right)$, which decreased to a similar extent ( $31 \%$ loss of surface area) when the calcination temperature was increased to 600 ${ }^{\circ} \mathrm{C}$. Amphiphilic triblock copolymers were used also to synthesize organized mesoporous aluminas with a pore diameter of $10 \mathrm{~nm}$ and surface areas around $360 \mathrm{~m}^{2} / \mathrm{g}$ by Luo et al. (41). The shape of synthesized alumina particles was spherical with a size from 100 to $900 \mathrm{~nm}$ depending on the synthesis conditions.

Following this approach, González-Peña et al. $(42,43)$ synthesized mesoporous aluminas using aluminum sec-butoxide as precursor and Tergitol and Triton-type of surfactants as templates in 2-butanol solution. Profound examination of TEM images published in ref. (42) suggests the presence of thin platelet-like crystals, very much resembling those currently observed in sol-gel aluminas obtained in the absence of surfactants (Figure 5). Hence, the surfactant PEO chain seems to favour a partial breaking of the hydrogen bonds that hold the boehmite-like layers together, and contribute additionally to limit the crystal growth along the $a$ and $c$ directions as well. Individual platelets were identified, with a surface around $5 \times 5 \mathrm{~nm}^{2}$ and ca. $2 \mathrm{~nm}$ thickness, that is, close to $3 / 2$ times the $b_{0}$ unit cell parameter (which corresponds to the packing of three boehmite-like $\mathrm{AlOOH}$ layers). It is worth noting that the reported BET surface area $\left(520 \mathrm{~m}^{2} / \mathrm{g}\right)$ agrees with the value expected for such small particles, as shown in Figure 6. This figure displays a sharp increase in the surface area per unit mass estimated for boehmite crystals with this aspect ratio as the crystal size decreases below ca. $5 \mathrm{~nm}$. Prompted by these conclusions, González-Peña et al. $(42,43)$ have worked out a method to decrease further the crystal growth of the boehmite layers, as well as to gain control on the pore size. This method consists of the use of amines together with non-ionic surfactants. It has been reported that the use of long-chain n- 
alkylamines increases the micelle size, and therefore increases as well the pore size of siliceous MCM-41 (44). On the other hand, it is well known that long-chain $n$ alkylamines penetrate into the interlayer space of layered compounds, leading to the effective separation of layers. This effect has been widely used to prepare the precursors of pillared clay materials $(45,46)$. It was shown (42) that addition of amines to the synthesis gel improved thermal stability of mesoporous aluminas. BET surface areas over $500 \mathrm{~m}^{2} / \mathrm{g}$ were reported for materials calcined at $550{ }^{\circ} \mathrm{C}$. The BET surface area reported for samples calcined at $600{ }^{\circ} \mathrm{C}$ was as high as $415 \mathrm{~m}^{2} / \mathrm{g}$, for a sample obtained using Triton X-114 and hexylamine (10:1:1 = Al:surfactant:amine molar ratio). The authors also observed that pore size and volume increased with the number of ethylene oxide (EO) units of the surfactant when 1,4-dioxane was used as solvent (47). The reported pore diameters for samples synthesized at room temperature with Triton X-114 (8 EO units), Tergitol 15-S-9 (9 EO units) and Tergitol 15-S-15 (15 EO units) were 3.5, 4.8 and $5.2 \mathrm{~nm}$, respectively. In contrast, no correlation was observed when the solvent used was 2-butanol. This was attributed to the inability of the surfactants to form micelles in 2-butanol. It was reported that the mesoporous aluminas synthesized using both solvents exhibited an intricate stacking of amorphous aluminum oxihydroxide platelets, from which the porous structure originates (Figure 5), and that most of the aluminum was octahedrally coordinated $(42,47)$. Indeed, it has been reported that poly(ethylene oxide) alkylphenyl surfactants of Triton family do not aggregate into micelles in ethanol or methanol, whereas micelles are formed in solvents like, among others, ethyleneglycol, 1,4-butanediol, ethylenediamine $(48,49)$ or dioxane $(50,51)$. Surprisingly, this observation has been generally overlooked, but it could allow to conclude that in most of the syntheses reported in the literature using non-ionic surfactants, the textural properties of the final alumina material were not determined by 
micellar chemistry. On the contrary, the surfactant would be located in the interlayer space, the oxygen atoms of the PEO hydrophilic chain interacting with the $\mathrm{OH}$ groups of the inorganic layers by H-bond. Several of these boehmite-surfactant "sandwiches" could be packed, which would partially collapse upon calcination.

To summarize, these results show that the boehmite-surfactant interaction is not strong enough to overcome the basic anisotropy of the Al-(O,OH)-Al network, and hence the basic layered morphology of boehmite is retained. Therefore, the control of hydrolysis and condensation reactions was also attempted by means of chemical modification of the alkoxide precursor with chelating ligands $(47,52)$. It was found that the development of structural porosity was promoted, though at the expense of lower surface areas and smaller pore volumes. Simultaneously, a large increase in the concentration of tetra- and pentacoordinated aluminum was observed (Figure 7). Nitrogen sorption studies of samples calcined at $550{ }^{\circ} \mathrm{C}$ showed that the ethylene glycol-modified precursor led to alumina samples containing slit mesopores while modification with ethyl acetoacetate and triethanolamine produced microporous aluminas with irregularly shaped pore channels. Calcination at $600{ }^{\circ} \mathrm{C}$ led to the development of mesoporosity but the pore structure was retained. TEM images combined with stochastic reconstruction methods (53-55) showed that these microporous aluminas had a disordered but isotropic porous structure (Figure 8). It was concluded that triethanolamine modification led to alumina samples with a network of cylindrical pores with very high connectivity, whereas modification with ethyl acetoacetate led to a material with lower accessibility of the pores due to their higher tortuosity.

Stucky et al. (56) synthesized mesostructured aluminas and other metal oxides in ethanol solution with large mesopores using the triblock copolymer Pluronic P123, as 
structure directing agent. The alumina sample was prepared from aluminum trichloride dissolved in a $10 \mathrm{wt} \% \mathrm{P} 123$ ethanolic solution, and gellation was carried out at $40{ }^{\circ} \mathrm{C}$ for several days. The recovered solids were calcined at $400{ }^{\circ} \mathrm{C}$ to remove the surfactant. A notably large pore size $(14 \mathrm{~nm})$ and a relatively low BET surface area $\left(300 \mathrm{~m}^{2} / \mathrm{g}\right)$ were reported for this material (Table 4). The authors did not report any evidences of an ordered mesostructure.

Cruise et al. (57) used a monoolein-water bicontinuous cubic phase as a template for the synthesis of mesoporous alumina using aluminum nitrate as precursor. The cubic phase region was identified in a ternary phase diagram water-aluminum nitratemonoolein by ${ }^{1} \mathrm{H}$ NMR. TEM and electron diffraction analysis of a sample calcined at $500{ }^{\circ} \mathrm{C}$ showed the presence of $\gamma-\mathrm{Al}_{2} \mathrm{O}_{3}$ nanoparticles within an amorphous matrix. The material exhibited poor textural properties.

Multiple quantum (MQ) MAS NMR and thermogravimetric analysis were employed by Deng et al. (58) to investigate the stability of the structure of mesoporous aluminas produced by non-ionic supramolecular templating. Aluminas were synthesized in a butanol solution of Pluronic 64L using aluminum sec-butoxide as alumina source. MQMAS NMR data allowed to accurately quantifying the populations of four-, fiveand six-coordinated Al sites in calcined samples. All samples calcined at $500{ }^{\circ} \mathrm{C}$ possessed around $5 \%$ of pentacoordinated $\mathrm{Al}$. The ratio $\mathrm{Al}^{\mathrm{VI}} / \mathrm{Al}^{\mathrm{IV}}$ decreased as the synthesis temperature increased, from 3.5 at $25^{\circ} \mathrm{C}$, to 2.7 at $50{ }^{\circ} \mathrm{C}$, and further to 2.2 at 70 and $90{ }^{\circ} \mathrm{C}$. Nonetheless, it was concluded that the synthesis temperature did not affect the thermal evolution from the aluminum hydroxide to transitional alumina nor the thermal stability of the later one.

Bronstein et al. (59) used a poly(ethylene oxide) block copolymer (SE 1010) along with anionic and cationic microgels containing noble metal nanoparticles as 
templates for obtaining mesoporous metal-loaded aluminas in one step. Microgel aqueous solutions derived from sulfonated polystyrene and poly(ethylmethacryl)tetramethylammonium chloride, containing $\mathrm{Pd}$ and $\mathrm{Pt}$ nanoparticles, were mixed at $5{ }^{\circ} \mathrm{C}$ with a solution of the block copolymer and aluminum sec-butoxide in tetrahydrofuran, vigorously stirred and submitted to vacuum. The resultant powders were calcined at $500{ }^{\circ} \mathrm{C}$ to remove the organic templates. The mesoporous materials obtained exhibited $\gamma-\mathrm{Al}_{2} \mathrm{O}_{3}$ nanofibers embedded in a porous network. Larger pores $(8.0 \mathrm{~nm}$ compared to $3.8 \mathrm{~nm})$ were formed with cationic microgels, which were attributed to their association with the growing anionic alumina species.

Caragheorgheopol et al. (60) synthesized mesoporous aluminas using triblock copolymers Pluronic P123 and PE 10400 and the diblock copolymer Tergitol 15-S-12 as templates, in acetonitrile and 2-butanol solutions. The analysis of the ESR spectra of the spin probe 5-doxyl stearic acid showed that washing of the as-synthesized samples with different solvents (water, acetonitrile, ethanol and 2-butanol) at room temperature changes the surfactant aggregates organization. This, in turn, modifies the alumina pore structure, leading to variations in surface area, mesopore volume and mesopore diameter of the calcined aluminas (Tables 3 and 4). The final materials exhibited BET surface areas in the range $270-450 \mathrm{~m}^{2} / \mathrm{g}$, mesopore volumes from 0.5 to $1.3 \mathrm{~cm}^{3} / \mathrm{g}$, and pore sizes from 4.3 to $8.9 \mathrm{~nm}$. Heating the as-synthesized materials at $120{ }^{\circ} \mathrm{C}$ for $24 \mathrm{~h}$ before the washing treatment, however, stabilized the mesostructure.

The recent paper by Somorjai and coworkers (61) was the first report on the synthesis of a mesoporous alumina with an ordered pore arrangement. A sample with a hexagonal arrangement or mesopore channels was obtained using Pluronic P123 as template, and a low surfactant:Al ratio (0.017). This is the first report showing TEM 
images of organized mesoporous alumina very similar to those known for wellorganized MCM-41 structures. For the synthesis of this material, an alumina sol was prepared at $40^{\circ} \mathrm{C}$ by mixing a solution of P123 in ethanol and another solution obtained adding aluminum tert-butoxide to a mixture of concentrated $\mathrm{HCl}$ and ethanol. The sol was aged at $40{ }^{\circ} \mathrm{C}$ for 3 days and the product was calcined at $400{ }^{\circ} \mathrm{C}$. Water content had a strong influence on the final structure as the formation of the ordered structure was observed only for a water:Al ratio of 6 , as shown by TEM and SAXS techniques. The sample had a pore size around $6.8 \mathrm{~nm}$, pore wall thickness of $2.9 \mathrm{~nm}$, and BET surface area of $410 \mathrm{~m}^{2} / \mathrm{g}$.

Crystalline ordered mesoporous $\gamma-\mathrm{Al}_{2} \mathrm{O}_{3}$ has been prepared both as films (62) and powder (63) by combining block copolymer templating and evaporation-induced self assembly. The precursor solutions used were obtained by dissolving aluminum chloride and poly(ethylene-co-butylene)-block-poly(ethylene oxide) (KLE-type block copolymer) in ethanol, and adding a small amount of diluted aqueous ammonia solution. Films were prepared by dip-coating in the precursor solution. The hydrated frameworks showed a perfect $f c c$ mesostructure at room temperature, but a progressive lattice contraction during thermal treatment in air. Amorphous mesoporous alumina films were obtained after calcination at $400{ }^{\circ} \mathrm{C}$, exhibiting interconnected ellipsoidal disk-shaped pores arranged in a contracted fcc mesostructure. The inorganic framework progressively transformed into nanocrystalline $\gamma-\mathrm{Al}_{2} \mathrm{O}_{3}$ in the temperature range from 400 to $900{ }^{\circ} \mathrm{C}$, with a further small contraction of the $f c c$ mesostructure. From water adsorption-desorption isotherms, the accessible porosity of these mesoporous $\gamma-\mathrm{Al}_{2} \mathrm{O}_{3}$ films was estimated to be $55 \%$, with no microporosity. The dimensions of the ellipsoidal pores and interconnections were dependent on the size of the spherical micelles of surfactant and the thermal treatment used. Thus, disk-shaped pores of 3.3 by 
$13 \mathrm{~nm}$ (with windows $2 \mathrm{~nm}$ in diameter) and 6 by $24 \mathrm{~nm}$ (with windows $5 \mathrm{~nm}$ in diameter) were reported for samples obtained using the block copolymers KLE22 (average molecular weight $6900 \mathrm{~g} / \mathrm{mol}, 89$ EO units) and KLE23 (average molecular weight $37000 \mathrm{~g} / \mathrm{mol}, 568 \mathrm{EO}$ units), respectively, calcined at $900{ }^{\circ} \mathrm{C}$. At higher calcination temperature, $\gamma-\mathrm{Al}_{2} \mathrm{O}_{3}$ particles coalesced into larger $\delta-\mathrm{Al}_{2} \mathrm{O}_{3}$ crystalline particles, and produced a degradation of the mesostructure. Alumina powder was prepared by spray drying from a precursor solution containing a KLE surfactant with a PEO chain composed of 86 EO units (average molecular weight $6600 \mathrm{~g} / \mathrm{mol}$ ). The calcined samples consisted of sub-micrometer particles exhibiting a regular mesostructure, with a compact packing of spherical pores. The material was amorphous and contained a large fraction of aluminum cations in 4-fold and 5-fold coordination for calcination temperatures below $900{ }^{\circ} \mathrm{C}$. After calcination at $700{ }^{\circ} \mathrm{C}$ for $30 \mathrm{~min}$, a mesoporous alumina with spherical pores $13 \mathrm{~nm}$ in diameter, BET surface area as high as $403 \mathrm{~m}^{2} / \mathrm{g}$ and a pore volume of $0.56 \mathrm{~cm}^{3} / \mathrm{g}$ were obtained. Subsequent calcination at $900{ }^{\circ} \mathrm{C}$ for $30 \mathrm{~min}$ led to formation of crystalline $\gamma-\mathrm{Al}_{2} \mathrm{O}_{3}$ particles $6 \mathrm{~nm}$ in size, while retaining the mesostructure. Pore volume and surface area reduced to $0.34 \mathrm{~cm}^{3} / \mathrm{g}$ and $134 \mathrm{~m}^{2} / \mathrm{g}$, respectively.

As stated above, the processes involved in the surfactant-templating of aluminas are extremely complex and not yet well understood. A large number of syntheses of mesostructured aluminas assisted by non-ionic surfactants have been reported, using different reactants, surfactants, solvents and thermal treatments (Tables 3 and 4). However, there is a general lack of detailed characterization that makes difficult to correlate textural properties and porous structure with the synthetic procedures used. Nonetheless, some attempts to provide a deeper knowledge of these processes have been reported. 


\subsection{Non-surfactant templates and nanocasting}

The results shown in previous sections demonstrate that it is possible to influence the textural properties of aluminas by using compounds that are able to interact either with the aluminum atoms or with the oxygen atoms or hydroxyl groups attached to the alumina, in conditions where the formation of micelles from surfactantcontaining synthesis media is not particularly favoured. Therefore, several synthesis routes have been reported, which made use of the hydrogen bonding ability of OH-rich additives, or employed well known aluminum chelating capabilities of some organic molecules (Table 5).

The use of water soluble organic polymers to control both the pore volume and the pore size distribution of porous alumina was reported long ago by Basmadjian in an early work (64). The organic polymers were added either to alumina gels after precipitation or to the aluminum nitrate precursor solution and precipitating the gel in the presence of the additive. Removal of the template was carried out by calcination at 500-600 ${ }^{\circ} \mathrm{C}$. Mercury intrusion porosimetry showed that polyethylene glycols and polyethylene oxides led to a large increase in the pore volume in the pore size range 2$100 \mathrm{~nm}$, while methyl cellulose compounds formed mainly macropores, and polyvinyl alcohols and polyacrylamides increased the pore volume in the entire meso- and macropores range. Total pore volumes of as high as $5 \mathrm{~cm}^{3} / \mathrm{g}$, and surface areas up to 360 $\mathrm{m}^{2} / \mathrm{g}$ were reported.

Ji et al. (65) investigated acetylacetone as an additive to prepare gels precursors of high surface area aluminas in the absence of surfactant templates. The gels were obtained by hydrolysis of aluminum sec-butoxide in 2-propanol solution catalysed by nitric acid at room temperature, using various acetylacetone/alkoxide ratios. A 
maximum in the surface area of samples calcined at $400{ }^{\circ} \mathrm{C}$ was found for a chelating agent/aluminum alkoxide molar ratio in the range 0.3-0.4. BET surface areas as high as $560 \mathrm{~m}^{2} / \mathrm{g}$ were reported for gels calcined at $400^{\circ} \mathrm{C}$, but the pore volumes were relatively low.

You et al. (66) reported on the synthesis of mesoporous alumina by a reverse microemulsion route. By hydrolysis of aluminum isopropoxide in water in isooctane microemulsion stabilized with polyethylene glycol and n-propanol, hydrothermal treatment of the precipitate at $150{ }^{\circ} \mathrm{C}$ and calcination at $500{ }^{\circ} \mathrm{C}$, uniform rod-shaped $\gamma$ $\mathrm{Al}_{2} \mathrm{O}_{3}$ nanoparticles were obtained. The sample showed a disordered porous structure due to the stacking of nanoparticles, with a pore volume close to $0.9 \mathrm{~cm}^{3} / \mathrm{g}$, a uniform pore size around $5.5 \mathrm{~nm}$, but relatively low surface area $\left(263 \mathrm{~m}^{2} / \mathrm{g}\right)$.

Shan et al. (67) described the use of tetraethylene glycol (TEG) as a template of mesostructured aluminas. Amorphous mesoporous aluminas with surface areas up to $530 \mathrm{~m}^{2} / \mathrm{g}$ were produced by calcination at $600{ }^{\circ} \mathrm{C}$ of solid gels obtained by hydrolysis of aluminum isopropoxide in an ethanol/2-propanol solution containing TEG (1:1:2 TEG:Al: $\mathrm{H}_{2} \mathrm{O}$ molar ratio). It was reported that mesopore size slightly increased with the temperature and/or time of heating of the solid gel in autoclave before calcination.

Jan and Shantz (68) have recently reported that folded polypeptide chains have a templating effect in aluminas. Aluminum chloride was added to an acidic aqueous solution containing helical poly-L-glutamic acid to obtain a precipitate. It was shown that the polypeptide remained in a folded state during the synthesis. After template removal by calcination at $400{ }^{\circ} \mathrm{C}$, amorphous alumina nanoparticles, ca. $50 \mathrm{~nm}$ in size, were formed. The material was not mesostructured and had relatively poor textural properties (BET surface area of $340 \mathrm{~m}^{2} / \mathrm{g}$, total pore volume of $0.19 \mathrm{~cm}^{3} / \mathrm{g}$ and 0.1 $\mathrm{cm}^{3} / \mathrm{g}$ micropore volume). 
In a recent report, Liu et al. (69) synthesized mesoporous alumina templated with tartaric acid derivatives, using aluminum sec-butoxide as precursor in ethanol solution. Samples calcined at $400{ }^{\circ} \mathrm{C}$ consisted of poorly crystalline $\gamma-\mathrm{Al}_{2} \mathrm{O}_{3}$. More crystalline mesoporous $\gamma-\mathrm{Al}_{2} \mathrm{O}_{3}$ was obtained from mixtures of a boehmite sol and tartaric and other hydroxy-carboxylic acids, after calcination at $500{ }^{\circ} \mathrm{C}(70)$. The drying temperature of the boehmite-template mixture had a significant effect on the final pore structure. It was proposed that the strong coordination interaction between the hydrocarboxylic acid and boehmite particles induces the arrangement of the later into different structures depending on the drying temperature. Uniform mesostructures were obtained at $100{ }^{\circ} \mathrm{C}$ while bimodal mesoporous structures and micro-mesoporous materials were produced at 30 and $150{ }^{\circ} \mathrm{C}$, respectively.

Green and coworkers (71) recently disclosed the use of glucose as a template for mesostructured alumina synthesis in aqueous medium. Aluminum isopropoxide was used as aluminum source and the $\mathrm{pH}$ was adjusted with a nitric acid solution. Using a glucose/Al molar ratio of 1 at $\mathrm{pH} 5.0$ and a calcination temperature of $600{ }^{\circ} \mathrm{C}$, an amorphous mesoporous alumina with a wormhole-like structure was obtained. The reported BET surface area and pore volume were relatively high $\left(422 \mathrm{~m}^{2} / \mathrm{g}\right.$ and 0.66 $\mathrm{cm}^{3} / \mathrm{g}$, respectively) and the BJH pore size distribution was narrow with maximum at $5.1 \mathrm{~nm}$. Slightly poorer textural properties were reported, however, for samples prepared at $\mathrm{pH}$ values of 4.5 and 5.5.

The first successful synthesis of mesoporous alumina using ionic liquids as templates has been very recently published by Žilková et al. (72). The syntheses were carried out in aqueous medium using aluminum chlorhydrate as aluminum source and 1-methyl-3-octylimidazolium chloride as structure-directing agent. Samples calcined at $560{ }^{\circ} \mathrm{C}$ were crystalline $\gamma$-alumina particles with a disordered porous structure and 
showed surface areas around $270 \mathrm{~m}^{2} / \mathrm{g}$ and a narrow pore size distribution with pores of nearly $4 \mathrm{~nm}$ in size. More recently, Park et al. (73) reported the synthesis of mesoporous alumina in propanol solution, using 1-hexadecyl-3-methylimidazolium chloride as template. The synthesis was carried out at $\mathrm{pH}=10$, using aluminum sec-butoxide as aluminum source, with a molar ratio $\mathrm{H}_{2} \mathrm{O}: \mathrm{Al}=6.4$. Mesoporous alumina exhibiting wide pores $(9.9 \mathrm{~nm})$ and a large pore volume $\left(1.46 \mathrm{~cm}^{3} / \mathrm{g}\right)$ was obtained by calcination at $550{ }^{\circ} \mathrm{C}$. The sample retained much of the textural properties after calcination at 700 and $800{ }^{\circ} \mathrm{C}$ (Table 5).

Zhang et al. (74) reported the synthesis of hierarchically porous alumina beads using polymer scaffolds. Samples were prepared by calcination at $520{ }^{\circ} \mathrm{C}$ of inorganicpolymer composites prepared by immersion of porous poly(acrylamide) beads in an aluminum sec-butoxide solution. Porous alumina beads with a trimodal pore size distribution $(4.0 \mu \mathrm{m}, 0.08 \mu \mathrm{m}$ and $4.0 \mathrm{~nm})$ were reported.

Nanocasting has also been successfully applied to the synthesis of mesostructured aluminas (Table 5). A nanocasting strategy making use of a carbon aerogel as a hard template to synthesize mesoporous alumina has recently been reported by Schüth and col. (75). The carbon aerogel was impregnated with an aqueous solution of aluminum nitrate, then dried at $50{ }^{\circ} \mathrm{C}$ and finally calcined at $600{ }^{\circ} \mathrm{C}$. Amorphous alumina granules, a few millimeters in size were obtained with BET surface areas up to $365 \mathrm{~m}^{2} / \mathrm{g}$ and pore volume of $1.55 \mathrm{~cm}^{3} / \mathrm{g}$. The samples showed no regular mesopore structure. Partial collapse of the pore structure was observed for low aluminum loadings $\left(\mathrm{Al}_{2} \mathrm{O}_{3} / \mathrm{C}<0.2\right)$. For $\mathrm{Al}_{2} \mathrm{O}_{3} / \mathrm{C}>0.3$, a bimodal pore system with maxima of the pore size distribution at 8 and 20-30 nm was obtained. Previously, Schüth et al. (76) reported the use of repeated nanocasting to obtain mesoporous alumina. A CMK-3 carbon mold was chosen to nanocast alumina, using aluminum alcoholates as aluminum source. This 
carbon mold, obtained as an inverse replica of mesoporous silica SBA-15, is formed by uniform-sized, interconnected carbon rods in a hexagonal arrangement. Despite the regular structure of the carbon mold used, the alumina samples showed a disordered pore network. In sharp contrast with these results, Liu et al. have reported recently the successful synthesis of a highly ordered mesoporous alumina via nanocasting with CMK-3 carbon (77). The carbon mold was first impregnated with ethanol solution of aluminum nitrate and then filled with ammonia in order to precipitate aluminum hydroxide. The aluminum precursor loading was controlled by repeating several times of these two steps. Subsequent calcination of this sample in air at $550{ }^{\circ} \mathrm{C}$ rendered a crystalline $\gamma-\mathrm{Al}_{2} \mathrm{O}_{3}$ material with a long-range two-dimensional hexagonal mesostructure, which exhibited a BET surface area of $396 \mathrm{~m}^{2} / \mathrm{g}$, pore volume of 0.46 $\mathrm{cm}^{3} / \mathrm{g}$ and a narrow pore size distribution with maximum at $4.6 \mathrm{~nm}$. It was observed that the pore structure strongly depended on the aluminum precursor loading of carbon and the thermal treatment used. Thus, the ordered material was obtained from a precursor containing around $2.7 \mathrm{~g}$ of $\mathrm{Al}_{2} \mathrm{O}_{3}$ per $\mathrm{g}$ of carbon (estimated from the reported thermogravimetric analyses), i.e. an $\mathrm{Al}_{2} \mathrm{O}_{3} / \mathrm{C}$ molar ratio of 0.32 , while lower loading rendered a disordered mesoporous alumina. Furthermore, alumina crystallization (carried out by heating at $750^{\circ} \mathrm{C}$ under nitrogen) prior to carbon combustion was required to retain the ordered mesostructure.

The non-surfactant synthesis and nanocasting approaches to prepare organized mesoporous aluminas show a very broad diversity of resulting alumina materials, which can be synthesized. The remaining open question is the role of various organic structure-directing agents on the final textural properties of mesoporous aluminas. As indicated in previous chapters, final textural properties of individual organized mesoporous alumina samples depend both on the way of preparation and on subsequent 
thermal treatment (calcination). Unfortunately, no clear conclusions can be drawn at the moment as the individual authors use different thermal treatments and not all data are always available.

\subsection{Lathlike and scaffolding frameworks}

Organized mesoporous aluminas can be prepared not only with exclusively amorphous walls as demonstrated in the above examples but also with partly crystalline walls. Zhu et al. (78) reported the synthesis of $\gamma-\mathrm{Al}_{2} \mathrm{O}_{3}$ nanofibers using non-ionic poly(ethylene oxide) surfactants to control the crystal growth of a boehmite precursor. The precursor aluminum hydrate colloids were obtained from sodium aluminate, mixed with the surfactant and heated in autoclaves at $100{ }^{\circ} \mathrm{C}$. Fibrous $\gamma-\mathrm{Al}_{2} \mathrm{O}_{3}$ obtained by calcination at $500{ }^{\circ} \mathrm{C}$ was not mesostructured but the low contact area between the fibers gave rise to very large porosity (pore volumes up to $1.9 \mathrm{~cm}^{3} / \mathrm{g}$ ). Recently, Zhu et al. (79) have shown that temperature treatment and $\mathrm{pH}$ of aluminum hydrate-surfactant cake, as well as the organic template, controlled the morphology and crystallinity of the boehmite nanoparticles. Thin mesoporous plates were obtained, at $200{ }^{\circ} \mathrm{C}$, with neutral or basic reaction mixtures while porous laths resulted from acidic mixtures. By calcination at $500{ }^{\circ} \mathrm{C}$, the boehmite transformed into nanocrystalline $\gamma-\mathrm{Al}_{2} \mathrm{O}_{3}$ while retaining the morphology.

Pinnavaia and coworkers have synthesized also mesostructured $\gamma-\mathrm{Al}_{2} \mathrm{O}_{3}$ with lathlike and scaffoldlike framework structures $(80,81)$. The synthesis method was based on the formation of a mesostructured surfactant-boehmite precursor that was transformed into mesostructured $\gamma-\mathrm{Al}_{2} \mathrm{O}_{3}$ by calcination at $550{ }^{\circ} \mathrm{C}$. Surfactant-boehmite mesostructures were assembled by means of hydrolysis of different aluminum compounds in the presence of diblock and triblock copolymers. Scaffoldlike 
mesostructured $\gamma-\mathrm{Al}_{2} \mathrm{O}_{3}$ was obtained using aluminum sec-butoxide while the use of $\mathrm{Al}_{13}$ oligocations led to lathlike mesostructures. These aluminas exhibited relatively high surface areas (over $300 \mathrm{~m}^{2} / \mathrm{g}$ ) and pore volumes up to $1.5 \mathrm{~cm}^{3} / \mathrm{g}$. Hicks and Pinnavaia (82) also obtained mesoporous crystalline boehmite with a scaffoldlike structure by hydrolysing aluminum sec-butoxide in ethanol-water solutions of amine surfactants. The as-prepared samples showed an intergrowth of boehmite nanofibers with uniform size. This scaffold structure was retained after surfactant removal by calcination at $325{ }^{\circ} \mathrm{C}$. Calcination at $500{ }^{\circ} \mathrm{C}$ transformed the boehmite into mesostructured $\gamma-\mathrm{Al}_{2} \mathrm{O}_{3}$ with high surface area (up to $529 \mathrm{~m}^{2} / \mathrm{g}$ ) and pore volumes close to $1 \mathrm{~cm}^{3} / \mathrm{g}$.

As the extension of the synthetic effort with mesoporous aluminas Ren et al. (83) reported the synthesis of hierarchical mesoporous-macroporous crystalline boehmite and $\gamma-\mathrm{Al}_{2} \mathrm{O}_{3}$, with a scaffoldlike aggregation of nanofibers. The samples were prepared by hydrolysis of aluminum sec-butoxide in a $\mathrm{H}_{2} \mathrm{SO}_{4}$ aqueous solution containing a poly(ethylene oxide) block copolymer (Brij 56) as a template, and hydrothermal treatment at $80{ }^{\circ} \mathrm{C}$. Microwave heating facilitated the crystallization of boehmite and led to a more uniform macroporous structure. Calcination at $300{ }^{\circ} \mathrm{C}$ did not alter the boehmite crystalline structure. Transformation to $\gamma-\mathrm{Al}_{2} \mathrm{O}_{3}$ occurred at a calcination temperature of $400{ }^{\circ} \mathrm{C}$ with retaining the hierarchical meso-macroporous structure.

Lathlike structures of $\gamma-\mathrm{Al}_{2} \mathrm{O}_{3}$ were also obtained using cationic surfactants (84). Hydrolysis of aluminum sec-butoxide was carried out in the presence of alkyltrimethylammonium surfactants in 1-butanol solution, the precipitates were submitted to hydrothermal treatment at $150{ }^{\circ} \mathrm{C}$ and the samples finally calcined at 500 ${ }^{\circ} \mathrm{C}$. The water:Al ratio had a major effect on the morphology. For water:Al ratios of 10 
and 20, lathlike mesostructures were obtained, while the ratio of 2 gave rise to the characteristic wormhole-like type of pore structure. Lee et al. (85) also reported a strong effect on particle morphology when the hydrolysis of aluminum sec-butoxide in the presence of surfactants was carried out without addition of any organic solvent. The precipitates were submitted to hydrothermal treatment at $150{ }^{\circ} \mathrm{C}$ for $72 \mathrm{~h}$, rendering boehmite materials, which were transformed into $\gamma-\mathrm{Al}_{2} \mathrm{O}_{3}$ after calcination at $500{ }^{\circ} \mathrm{C}$. Several unidirectional crystalline $\gamma-\mathrm{Al}_{2} \mathrm{O}_{3}$ nanostructures were obtained depending on the type of surfactant used. With cationic and non-ionic surfactants, isolated individual and branched nanotubes were produced, while anionic and neutral surfactants rendered fibers and rods, respectively.

Yao et al. (86) obtained a mesoporous $\gamma-\mathrm{Al}_{2} \mathrm{O}_{3}$ with narrow pore size distribution using no templates. The precursor alumina sol was prepared at room temperature by ultrasonic treatment of an aqueous suspension of freshly precipitated aluminum hydroxide, acidified with nitric acid. The vacuum drying of this sol rendered a white gel constituted by needle-like pseudoboehmite particles, which transformed into spherical $\gamma-\mathrm{Al}_{2} \mathrm{O}_{3}$ particles after calcination at $550{ }^{\circ} \mathrm{C}$ for $10 \mathrm{~h}$. Although its pore size distribution was narrow, the sample exhibited poor textural properties (BET surface area of 158 $\mathrm{m}^{2} / \mathrm{g}$ and mesopore volume of $0.13 \mathrm{~cm}^{3} / \mathrm{g}$ ). At lower calcination temperatures, part of the pseudoboehmite particles were retained, leading to the development of microporosity and a slightly larger surface area.

\subsection{Rationalization of synthetic approaches}

Since Stucky and coworkers extended the method of synthesis of M41S materials to obtain non-silica-based mesostructured materials $(13,14)$, a plethora of 
synthetic approaches to prepare organized mesoporous aluminas has been reported, making use of different templating routes:

i) neutral

ii) anionic

iii) cationic

iv) non-surfactant

v) nanocasting

The vast majority of the reported synthetic approaches led to aluminas with a disordered mesoporous structure. Only few reports have been published very recently on the preparation of ordered mesoporous aluminas, both via non ionic surfactant templating (61-63) and nanocasting (77). Nonetheless, from the point of view of the use of these aluminas as catalysts or catalyst supports, the main added value provided by these synthesis routes would not be related to their organized structure. It is their ability to produce aluminas with high surface areas and narrow pore size distributions as well as to tune the pore size which would provide a major benefit to different catalytic applications.

The individual aluminas prepared by various methods differ in their textural properties, which is mainly due to different synthesis conditions, variation of type and strength of interaction between organic and inorganic species in the synthesis mixture and, last but not least, conditions of post-synthesis treatment. As a rough rule, it can be summarized that synthesis carried out with ionic surfactants in aqueous media tend to produce aluminas with poorer textural properties than in alcohols solutions, and, in general, higher surface areas are obtained with non ionic as compared to ionic surfactants. However, it should be stressed that porosity of aluminas strongly depend not only on the intermediate hydroxide/oxyhydroxide, but also on the conditions of 
drying and particularly conditions of calcinations (16). The number of parameters that can be modified in the whole set of steps involved in the preparation of mesostructured aluminas, from the precipitation of the intermediate phases to the final calcination, is immense. Our analysis of the open literature let us to conclude that reliable rationalization of the synthetic approaches used to prepare mesostructured aluminas would require a deep systematic study and detailed information on the synthesis, ageing and thermal treatment steps, which are usually lacking in many papers published. Some experimental details on the preparation of the hydroxide/oxyhydroxide intermediates, including a key parameter such as $\mathrm{pH}$, are not reported for many syntheses. Also, characterization of the intermediate phases is usually not carried out. The actual washing procedure for these intermediates should be fully described as it has been shown that it may affect the final textural properties (60). The use of different ageing and drying conditions makes also difficult to compare results from different laboratories. We have found that details on the final calcination step, such us the heating rate used and previous thermal decomposition of templates, are very often missing, despite their strong effect on the final textural properties.

Thermal stability, particularly under reaction conditions, is another important issue still to be fully investigated. Based on several detailed studies (e.g. that of Caragheorgheopol et al. (23)) it seems to be clear that condensation of Al-O-Al, which is required to stabilize the framework, proceeds still during the first calcination steps. This is in agreement with ${ }^{27} \mathrm{Al}$ MAS NMR data (Figure 9) showing a substantial shift from Al-octahedral to Al-tetrahedral arrangement after calcination. In general, with increasing temperature of calcination, surface areas and void volumes of organized mesoporous aluminas decrease while the apparent pore sizes increase. In this case, the information provided by X-ray diffraction patterns and nitrogen adsorption data are not 
sufficient to assess unambiguously all details of the pore architecture and framework structure.. TEM images can provide clear evidence on the reconstruction of organized mesoporous aluminas from amorphous to crystalline transition aluminas still retaining relatively large surface areas. The unambiguous conclusions on the structure of transition aluminas, crystallinity and type of the materials can be drawn from X-ray diffraction patterns recorded at higher angles (Figure 2).

\section{CATALYTIC APPLICATIONS}

There exist only a limited number of examples showing catalytic properties of catalysts based on organized mesoporous aluminas. These include mainly hydrodesulfurization, hydrodechlorination, metathesis, and some oxidation reactions. In all of these reactions catalysts based on organized mesoporous aluminas synthesized by different approaches exhibit higher catalytic activities in comparison with conventional aluminas.

\subsection{Hydrodesulfurization}

Hydrodesulfurization is one of the most important reactions in nowadays large scale technologies removing sulfur from organic compounds to decrease substantially the rate of deactivation of different catalysts used in further processes. In addition, sulfur obtained by this reaction represents the main raw material for the production of sulfuric acid. Čejka et al. $(87,88)$ investigated catalytic properties of molybdenum oxide supported on organized mesoporous aluminas of different pore diameters in hydrodesulfurization of thiophene. The catalysts were prepared using conventional 
impregnation and thermal spreading method performed at $550{ }^{\circ} \mathrm{C}$ for several hours. Figure 10 shows the comparison of three catalysts based on organized mesoporous alumina with a commercial catalyst. No diffraction lines of molybdenum oxide were discernible on the X-ray diffraction pattern after calcinations providing nice evidence on the well-dispersed molybdenum oxide particles. Three important conclusions can be envisaged from this Figure:

i) up to $30 \mathrm{wt}$. \% of molybdenum oxide can be spread over the organized mesoporous alumina (surface areas $400-450 \mathrm{~m}^{2} / \mathrm{g}$ ) without any loss of activity related to one molybdenum atom,

ii) all three catalysts supported on mesoporous alumina exhibited a higher thiophene conversion compared with commercial catalyst,

iii) both conventional impregnation as well as thermal spreading methods were found to be convenient for the preparation of highly active hydrodesulfurization catalysts,

iv) the size of mesoporous alumina pores seems to influence the transport of reactants as with increasing size the conversion of thiophene increases as well although the loading of molybdenum oxide is the same.

Despite the substantially higher conversion of thiophene over mesoporous alumina based catalyst, the rate of deactivation was similar to the rate of deactivation over commercial BASF catalyst (88).

Further investigations of catalytic activity of mesoporous alumina in hydrodesulfurization reactions were performed by Pinnavaia and his group (89) employing mesostructured $\gamma$-alumina in hydrodesulfurization of dibenzothiophene. The catalysts comprised both Mo and Co in contrast to the study of Čejka et al. $(87,88)$. Incipient wetness impregnation was used to modify the mesostructured alumina. Resulting conversions depended on the loading and morphology of different 
mesostructured aluminas but were comparable with those obtained for commercial HDS catalysts.

The results of hydrodesulfurization reactions over organized mesoporous alumina based catalysts stress the importance of producing alumina supports with large surface areas. The alumina supports enabled high loadings of transition metal oxide active phases at least up to $30 \mathrm{wt} . \%$, which is substantially higher compared with conventional alumina supports. On the other hand, it should be noted that both thiophene and dibenzothiophene were used as pure reactants and the activity of these novel hydrodesulfurization catalysts should be proved using real feadstocks after scalling up of the synthesis.

\subsection{Hydrodechlorination}

Mesoporous alumina modified with $\mathrm{Ni}$ was investigated in hydrodechlorination of different chlorinated hydrocarbons, which belong to the most hazardous organic compounds (90-93). Complete dechlorination of carbon tetrachloride was observed at temperatures above $350{ }^{\circ} \mathrm{C}$ in the presence of water (93). The presence of sufficient amount of water vapor seems to be critical for inhibiting the formation of elemental carbon, chlorine or $\mathrm{COCl}_{2}$. The effect of water vapor was explained on the basis of facile creation and regeneration of reactive hydroxyl groups on the alumina surface during the reaction. In the case of hydrodechlorination of 1,2-dichloropropane (90) by mesoporous alumina prepared with stearic acid as structure-directing agent and modified with Ni via impregnation or vapor deposition, it was clearly shown that much higher conversion was reached over the catalyst prepared by vapor deposition. Detailed textural analysis provided clear evidence that mesoporous structure after vapor 
deposition was retained with only a small decrease in surface area and void volume in comparison with impregnation method. As the impregnation was carried out with aqueous solution of nickel nitrate the deteriorating role of water on the mesoporosity of mesoporous alumina is expected (90). Modification of mesoporous aluminas with metals for hydrodechlorination can be also performed during the synthesis (92). Magnesium stearate and nickel nitrate were added to the synthesis mixture to prepare mesoporous alumina catalysts for o-dichlorobenzene hydrodechlorination. It was found that mesoporous alumina retained a homogeneously mixed metallic state of $\mathrm{Ni}$ and $\mathrm{Mg}$ and was also resistant against deactivation.

\subsection{Metathesis}

New type of heterogeneous catalysts for metathesis of linear olefins and their functional derivatives have been developed in the J. Heyrovský Institute of Physical Chemistry, Prague $(94,95)$. Organized mesoporous aluminas (OMA) with wormholelike pore structure and narrow pore size distribution with different pore sizes were used for supporting of rhenium(VII) oxide. The catalysts were tested in metathesis of linear 1- and 2-olefins, cycloolefins, as well as allyl anisole or di-allyl-diethyl malonate. List of substrates with reaction conditions and resulting activities and selectivities is provided in Table 6 . Figure 11 shows the comparison of catalytic activity of organized mesoporous aluminas modified with rhenium oxide with conventional alumina (all catalysts with $12 \mathrm{wt} \%$ of Re) in 1-decene metathesis (Scheme 1). 
$2 \mathrm{CH}_{3}\left(\mathrm{CH}_{2}\right)_{7} \mathrm{CH}=\mathrm{CH}_{2} \leftrightarrows \mathrm{CH}_{2}=\mathrm{CH}_{2}+\mathrm{CH}_{3}\left(\mathrm{CH}_{2}\right)_{7} \mathrm{CH}=\mathrm{CH}\left(\mathrm{CH}_{2}\right)_{7} \mathrm{CH}_{3}$

Scheme 1. Metathesis of 1-decene

From Figure 11 it is seen that

i) organized mesoporous alumina based catalysts exhibited higher activity than both catalysts with conventional supports,

ii) catalysts prepared from mesoporous alumina with larger pores are more active than that possessing narrower pores.

The selectivity to 9 -octadecene is in all cases higher than $95 \%$. Similar results showing the superiority of nanostructured mesoporous aluminas supported $\operatorname{Re}(\mathrm{VII})$ oxide catalysts in alkene metathesis were obtained simultaneously by other groups as well (96-98).

The experiments carried out with organized mesoporous alumina modified with different amount of rhenium oxide showed that the optimum catalyst loading found was $9 \mathrm{wt} \% \operatorname{Re}$ (Figure 12). However, for rhenium(VII) oxide supported on conventional $\gamma$ alumina (99), an exponential increase in the reaction rate in 1-decene metathesis was observed until approx. 14 wt \% of Re. This loading value corresponds to the formation of a monolayer on the catalyst surface (one Re atom per $0.35 \mathrm{~nm}^{2}$ ) (99). In contrast to molybdenum oxide, rhenium oxide does not incline to the formation of polyanions and isolated $\mathrm{ReO}_{4}$ species are proposed to be present on the surface of alumina. Also X-ray diffraction confirmed the absence of crystallites even at high loadings (99). Similar results were reported also by Onaka et al. (96) and Oikawa et al. (97). These authors also described superior catalytic activity of Re-oxide supported on mesoporous alumina in comparison with conventional $\gamma$-alumina at the same loading of the active oxide 
phase. However, it is still not clear if higher catalytic activity of Re-oxide over organized mesoporous alumina is due to a larger surface area or different interaction of the oxide phase with the support. This is due to the fact that increase in the activity of these catalysts is not linear with increasing concentration of the active phase. Mol reported that only a small amount of Re-oxide (probably in a lower valence state) is catalytically active in metathesis reaction (100).

Detailed study of the surface properties of parent mesoporous alumina supports and catalysts prepared via modification with Re-oxide revealed the presence of a significant amount of Lewis acid sites. This was evidenced by FTIR investigation using pyridine as probe molecule (98). The amount of Lewis sites was considerably higher compared with convential aluminas. The remarkable performance of both ordered mesoporous catalysts was ascribed to the presence of these strong Lewis acid sites, likely stemming from the interaction of linked rhenium species with the weak Lewis acid sites of the support.

Table 6 provides a list of substrates, which were tested in alkene, alkadiene and cycloalkene metathesis carried out over supported Re(VII) oxide catalysts. In all cases, Re/OMAs exhibited higher activity in comparison with Re/Alcoa and Re/Condea at the same loading of Re-oxide. In some cases, activity of Re/OMA having a pore size of 6.5 $\mathrm{nm}$ was found higher than that of Re/OMA with pores of $3.5 \mathrm{~nm}$ (1-decene, 1,7octadiene, 1,9-decadiene). In the case of 1,9-decadiene, the product distribution depended strongly on the catalyst pore size. The higher population of ADMET trimers, tetramers and higher oligomers was obtained using catalyst with higher pores. This provides an example of pore size controlled catalyst selectivity.

Detailed investigation of textural and chemical properties of organized mesoporous aluminas modified with rhenium(VII) oxide using MAS NMR, FTIR 
spectroscopy of adsorbed pyridine, elemental analysis, nitrogen adsorption and catalytic behavior in 1-decene metathesis revealed the following differences between organized mesoporous aluminas and conventional supports and catalysts based on them (101):

(a) the presence of pentacoordinated $\mathrm{Al}$ atoms in OMA, which can represent coordinatively unsaturated sites able to coordinate Re oxide species,

(b) higher concentration of Lewis acid sites in OMA catalysts,

(c) lower fraction of basic $\mathrm{OH}$ groups in OMA supports.

Although all of these features can explain the improved catalytic activity, the unequivocal relationship between them and the enhanced activity of mesoporous alumina based catalysts has not been drawn yet.

In addition, X-ray photoelectron spectroscopy (Figure 13) proved that during activation in $\mathrm{Ar}$ at $500{ }^{\circ} \mathrm{C}$, Re in all catalysts tested was reduced in a substantial extent to the oxidation states +6 and +4 . The assignment of the $\operatorname{Re}(4 \mathrm{f} 7 / 2)$ peaks at binding energies of 46.6, 44.4 and $42.5 \mathrm{eV}$ to $\operatorname{Re}(\mathrm{VII}), \operatorname{Re}(\mathrm{VI})$ and $\mathrm{Re}(\mathrm{IV})$, respectively, was made according to the NIST database and in accord with Okal et al. (102). It was inferred that catalytically active centres are formed only from Re(IV) species (101).

Further extension of this work on metathesis over mesoporous alumina based catalysts was focused on the activity of these catalysts in transformations of functional unsaturated hydrocarbons. Re(VII) oxide on alumina is known to catalyze also the metathesis of oxygen-containing substrates, however, only with $\mathrm{Me}_{4} \mathrm{Sn}$ cocatalyst (99). The presence of $\mathrm{Me}_{4} \mathrm{Sn}$ was found to be critical also for Re/OMA catalysts if used in metathesis of unsaturated esters and ethers (103). Table 7 provides a list of substrates tested in metathesis over mesoporous alumina based catalysts with respective catalytic results. The catalysts were particularly investigated in metathesis of $p$-allyl anisole (Scheme 2) and di-allyl-di-ethyl malonate (Scheme 3). 


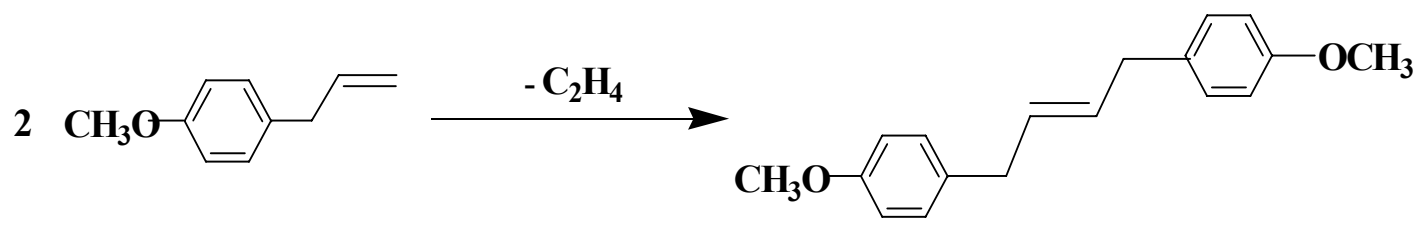

Scheme 2 Metathesis of $p$-allyl anisole
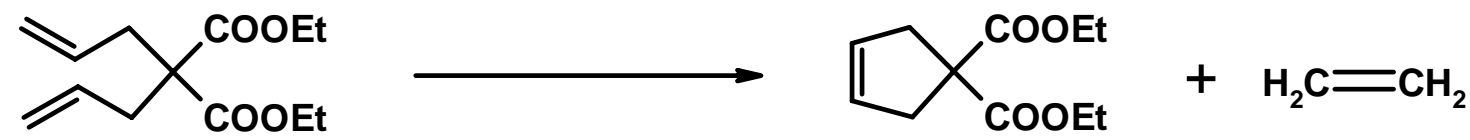

Scheme 3 Metathesis of di-allyl-di-ethyl malonate

It is seen that a high selectivity to the desired products was achieved with all catalysts used. The yields, however, depended on the catalyst used and considerably decreased in the order Re/OMA5 $>$ Re/Condea $>$ Re/OMA3.5 > Re/Alcoa (103). Generally, the specific activity (TON) is lower in comparison with unsubstituted substrates, suggesting a competition between metathesis and catalysts deactivation by polar substrates. For comparison, lathlike and scaffolded mesostructured $\gamma$-aluminas were tested in these reactions and compared with organized mesoporous aluminas containing amorphous walls (103). Figure 14 provides nice evidence that the crucial factor for high activity of these catalysts in metathesis of functionalized unsaturated hydrocarbons is the pore size (metathesis of $p$-allyl anisole). For catalysts with the same loading of $\mathrm{Re}$ oxide the activities were very similar with the exception of catalyst prepared from mesoporous alumina with the smallest pore size diameter $(3.5 \mathrm{~nm})$. It can be inferred that organized mesoporous as well as crystalline mesostructured aluminas 
exhibit similar surface chemical properties, which result in the similar interaction with Re oxide.

\subsection{Oxidation reactions}

Basicity of organized mesoporous aluminas plays an important role in stabilizing gold particles for epoxidations of styrene (104). It was observed that dispersion and average size of gold particles are dependent on the number of surface basic sites of alumina support. $\mathrm{CO}_{2}$ temperature programmed desorption combining with FTIR measurements provided a clear evidence that mesoporous alumina possesses more abundant surface basic sites in comparison with $\gamma$-alumina. The conversion of styrene over gold nanoparticles supported on mesoporous alumina at the reaction temperature of $82{ }^{\circ} \mathrm{C}$ was in the range of $70-85 \%$ while gold on $\gamma$-alumina exhibited a conversion of 65 $\%$. Pure organized mesoporous aluminas provided conversions between 38 and $50 \%$ (104). For gold loading of $2.0 \%$ the selectivity to styrene oxide was about $65-70 \%$, however, with increasing gold loading $(3.5 \%)$ the conversion of styrene increased to $100 \%$ with a substantial decrease in the selectivity to styrene oxide at the expense of benzaldehyde and benzoic acid. Oxidation properties of gold nanoparticles on mesoporous alumina were reported also for carbon monoxide oxidation at low reaction temperatures (105).

Partial oxidation of methane in syn-gas at the reaction temperature of $700{ }^{\circ} \mathrm{C}$ was investigated over $\mathrm{Ni} /$ mesoporous alumina catalysts prepared by addition of $\mathrm{Ni}$ nitrate to the synthesis mixture (lauric acid was employed as structure directing agent) or by post-synthesis impregnation. $\mathrm{Ni}$ /mesoporous alumina catalyst exhibited stronger metal-support interaction and a more favorable catalyst structure for obtaining finely 
dispersed nickel particles, compared to the Ni-impregnated catalyst. The deactivation of catalysts examined in this work was mainly due to the formation of carbon deposits. The Ni/mesoporous alumina catalyst having smaller nickel particles and lower levels of carbon deposition had a more stable catalytic activity than the Ni-impregnated catalyst (106).

While zeolites or siliceous mesoporous molecular sieves are well know for immobilization of organometallic complexes (for recent review see (107)) only very little is known about the properties of mesoporous alumina for immobilizing $\mathrm{Mn}$ (III) and Co(II)-salen complexes. Chaube et al. (108) immobilized these complexes on the surface of mesoporous alumina, which resulted in the preparation of a highly stable, as for the activity and also against leaching, heterogenized catalyst for olefin epoxidations. The functionalized metal-salen complexes investigated in a liquid phase oxidation of styrene and cyclohexene gave clear evidence that the functionalized salen complexes can be more active and selective than the corresponding neat metal complexes (108).

Mesoporous alumina modified with $\mathrm{V}$ and Mo was successfully tested in oxidative dehydrogenation of ethane (109). The catalytic results showed that Vcontaining mesoporous alumina was four times more active than the Mo-analog. The highest activity was achieved with a V-Mo alumina catalyst indicating a synergistic

effect between V and Mo. All these alumina based catalysts (V, Mo, V-Mo) were more active and selective in oxidative dehydrogenation of ethane than the same catalysts prepared from $\gamma$-alumina (109).

\subsection{Miscellaneous}

Organized mesoporous alumina synthesized using $\mathrm{Al}_{13}$-Keggin units and modified with $\mathrm{Cu}$ were employed for the hydrogenation of cinnamaldehyde to cinnamyl 
alcohol (110). The authors reported on the remarkably high activity of this mesoporous alumina-based catalysts due to a high surface area of the mesoporous support. It seems that organized mesoporous alumina was able to stabilize properly $\mathrm{Cu}^{0}$ clusters, which exhibited high catalytic activity in hydrogenation reactions. This study was further extended by the same authors (111) showing the one-step preparation of highly selective hydrogenation catalyst composed of sub-nanometric $\mathrm{Cu}_{2} \mathrm{O}$ particles supported on mesoporous alumina.

Very recently, organized mesoporous alumina was utilized as a support for finely dispersed $\mathrm{Pd}-\mathrm{Zn}$ catalysts for hydrogen production by methanol steam reforming (112). Detailed characterization of prepared catalyst was performed combining X-ray diffraction, sorption experiments, X-ray photoelectron spectroscopy, infrared spectroscopy and atomic absorption spectrometry. The catalyst was found to be active in oxidative steam reforming of methanol, in the temperatures between 100 and $400{ }^{\circ} \mathrm{C}$ with a production of hydrogen/ $\mathrm{CO}_{2}$ mixtures with a low concentration of $\mathrm{CO}$. A catalytic performance of this type is rather unusual, particularly taking into consideration the low active metal loading used (1.7 wt\%) (112).

Zhao et al. (113) investigated the surface properties of mesoporous aluminas synthesized with triblock copolymers for carbon disulfide hydrolysis. Both weak acid sites as well as weak-medium basic sites were identified on the surface of mesoporous alumina, which exhibited much higher catalytic activity than conventional $\gamma$-alumina. Conversion of carbon disulfide of $90 \%$ was achieved on mesoporous alumina at about $200{ }^{\circ} \mathrm{C}$ while the reaction temperature required to reach the same conversion over $\gamma$ alumina was ca. $330{ }^{\circ} \mathrm{C}$.

New strong base catalysts prepared from mesoporous alumina was described by Seki and Onaka (114). This sulfated mesoporous alumina was tested in the Tishchenko 
reaction, which is transformation of o-phthalaldehyde into the respective phthalide (Scheme 4).
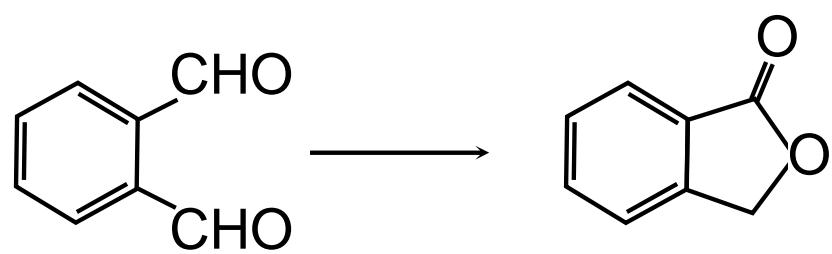

Scheme 4 Tishchenko reaction

The most active catalysts exhibited surface areas between 530 and $570 \mathrm{~m}^{2} / \mathrm{g}$. Even non-modified mesoporous alumina synthesized from Al-sec-butoxide was rather active in this reaction with further increase in the activity after modification with sulfate groups (114). Addition of tetrahydrofuran as co-solvent resulted in a remarkable increase in the reaction rate particularly under supercritical conditions in $\mathrm{CO}_{2}$ (115). When mesoporous alumina was modified with sodium, a strong base catalyst was prepared, exhibiting a high activity in double bond shift reactions, e.g. isomerization of $\alpha$-pinene to $\beta$-pinene (116). In this case, particularly the selectivity to $\beta$-pinene was much higher compared with the conventional catalyst $(93-96 \%$ vs. 58 or $89 \%$, respectively). These results on preparation, characterization and catalytic testing of base catalysts originating from organized mesoporous aluminas were reviewed in ref. (117).

Mesoporous alumina prepared using cetyltrimethylammonium bromide with surface area around $400 \mathrm{~m}^{2} / \mathrm{g}$ and modified with Pt provided an excellent catalytic activity in the reduction of NO with propylene compared with conventional alumina (Condea, $180 \mathrm{~m}^{2} / \mathrm{g}$ ). In this case the increase in the surface area of mesoporous alumina played probably the key role in the activity enhancement (118). 


\subsection{The role of textural properties for catalytic reactions}

Although still relatively scattered are the papers on catalytic properties of organized mesoporous aluminas supported catalysts it is evident that their improved catalytic behavior compared with conventional aluminas (mainly $\gamma$-alumina) stems from the following textural and chemical properties

i) higher surface areas compared with conventional aluminas (nicely shown for hydrodesulfurization of thiophene or dibenzothiophene (87-89)).

ii) the absence of micropores, which allows much better dispersion of the transition metal oxide phase and does not allow to hide part of the oxide in the micropores being not accessible for substrate molecules (e.g. in metathesis $(94,95))$.

iii) a high concentration of basic sites providing an opportunity to stabilize small metal particles via strong metal-support interaction, which leads to a high activity in oxidation reactions (104).

iv) different coordination of aluminum at the surface of channel walls, which can substantially influence the interaction of catalytically active species with the surface of alumina walls.

In Chapter 2.6. we tried to rationalize the synthesis approaches and postsynthesis treatments and to relate them to textural properties of organized mesoporous aluminas. No general relationships were achieved as important details on synthesis and further treatmens are usually missing in the papers. Even more complicated was our effort to correlate textural properties with catalytic behavior of catalysts based on mesoporous aluminas. The items i) to iv) represents the basic evaluation of the textural 
properties with respect to catalytic data but it is more than evident that further and deep investigations are needed.

\section{SUMMARY AND OUTLOOK}

Organized mesoporous aluminas have been synthesized up-to-now using four different synthetic approaches, which can be summarized as follows:

(i) cationic surfactant routes;

(ii) anionic surfactant routes;

(iii) non-ionic surfactant methods;

(iv) non-surfactant and nanocasting approaches.

These synthetic approaches enable preparation of organized mesoporous aluminas differing in the surface areas, pore sizes and void volumes. Detailed investigation of the synthesis mechanisms leading to organized mesoporous aluminas revealed that after the synthesis the Al-O-Al connectivity is not yet fully developed and further condensation of Al-O-Al bonds proceeds during the early stages of the calcination treatment. This is in contrast to the synthesis of mesoporous silicates, where the condensation is practically finished during the synthesis. This finding decreases the importance of the role of the synthetic approach on the final textural properties of organized mesoporous aluminas, as these can be substantially influenced by the temperature treatment.

Organized mesoporous aluminas are a new family of porous materials, the properties of which significantly extend the properties of conventional aluminas, due to possibilities of tailoring surface areas, void volumes and pore sizes. Their properties predetermine organized mesoporous aluminas for application in catalysis enabling 
various ways of addition of catalytically active phases. Clear examples have been reported in the literature showing higher activities of heterogeneous catalysts with organized mesoporous alumina supports compared with conventional alumina supports. Hydrodesulfurization and particularly metathesis provided interesting examples.

Higher activities of some catalysts based on organized mesoporous aluminas are usually related to larger surface areas, which enable to accommodate higher amounts of catalytically active species. The thermal spreading method, used for modification with $\mathrm{MoO}_{3}$ and $\mathrm{Re}_{2} \mathrm{O}_{7}$, is a relatively easy method being carried out at temperatures of 500$550{ }^{\circ} \mathrm{C}$ for several hours. This method results in a spreading of the oxides on the alumina surface and X-ray diffraction clearly evidence the absence of "visible" crystals of these oxides. No water is needed for modification. Conventional impregnation can be used as well at least for the synthesis of hydrodesulfurization catalysts. From the practical point of view, physical mixing of support and precursor of active phase (transition metal oxides) followed by heat treatment is an easy and efficient method.

On the other hand, the chemical surface properties of organized mesoporous aluminas have not yet been investigated in detail. Thus, no evidences are provided on differences or similarities of chemical structure of alumina surfaces. This could be an important factor, which should control the interaction of active species with alumina surface. Based on some FTIR investigations, acidic, neutral as well as basic hydroxyl groups are present on the surface of organized mesoporous aluminas and the type and concentration of them control in some respect the spreading of transition metal oxides on the surface. In this respect, substantial changes of the aluminum coordination were described for as-synthesized and calcined samples. The increasing concentration of tetrahedrally coordinated aluminum after calcination evidences proceeding condensation during thermal treatment. It can be inferred that particularly the 
coordination of surface $\mathrm{Al}$ atoms is critical for interaction with oxide species or organic ligands. More intense and complete research work would be required to understand the relationship between synthesis procedures and chemical surface properties of the resulting alumina materials.

The vast majority of synthesized organized mesoporous aluminas exhibit lower ordering in comparison with mesoporous silicates of MCM-41 type. Thus, it is rather challenging to try to prepare mesoporous aluminas possessing well-ordered hexagonal structure. Even more interesting would be the synthesis of cubic mesoporous aluminas or those with cages connected with pores like in the case of siliceous SBA-16, which could be extended further to the other known topologies of silica-based materials. Synthesis of mesoporous aluminas in microwave has also not yet been reported.

Alumina is also frequently used as catalyst binder, e.g. in the preparation of zeolite catalysts. In this respect, the utilization of zeolite seeds as a building block for the preparation of organized mesoporous aluminas with enhanced acidic properties could be an interesting target in the field of the synthesis of new materials.

For future catalytic investigations or even industrial applications it is desirable to

i) increase the number of reactions being tested,

ii) increase the broadness of synthesis procedures employed in the preparation of catalysts,

iii) go deeply into the chemical characterization of the alumina surface,

iv) investigate the possibilities of immobilization of highly active homogeneous catalysts on the alumina surface.

The understanding of all of these aspects should enable to describe in a rational way the relationships among synthesis conditions, post-synthesis treatments, preparation of final catalysts and activity and selectivity in a chosen reaction. Successful 
design of those steps should result in the development of new highly active heterogeneous catalysts with a potential for industrial applications.

\section{Acknowledgement}

N.Ž. and J.Č thank the Grant Agency of the Academy of Sciences of the Czech Republic (A4040411) and the Ministry of Industry and Trade of the Czech Republic (FTA/042) for a financial support of this research. J.Č. also thanks the European Community for the project (SES6-CT-2005-020133). C.M.A. and J.P.P. thank the Ministry of Science and Education of Spain (MAT2003-07769-C02-02) for financial support. Czech-Spanish project between the Academy of Sciences of the Czech Republic and the Spanish Council for Scientific Research (2006CZ0027) is also acknowledged.

\section{REFERENCES}

[1] Kresge, C.T.; Leonowicz, M.E.; Roth, W.J.; Vartuli, J.C.; Beck, J.S. (1992) Ordered mesoporous molecular-sieves synthesized by a liquid-crystal template mechanism. Nature, 359: 710-712.

[2] Beck, J.S.; Vartuli, J.C.; Roth, W.J.; Leonowicz, M.E.; Kresge, C.T.; Schmitt, K.D.; Chu, C.T.W.; Olson, D.H.; Sheppard, E.W.; McCullen, S.B.; Higgins, J.B.; Schlenker, J.L. (1992) A new family of mesoporous molecular-sieves prepared with liquid-crystal templates. J. Am. Chem. Soc., 114: 10834-10843.

[3] Corma, A. (1997) From microporous to mesoporous molecular sieve materials and their use in catalysis. Chem. Rev., 97: 2373-2419.

[4] Taguchi, A.; Schüth, F. (2005) Ordered mesoporous materials in catalysis. Microporous Mesoporous Mater., 77: 1-45.

[5] Misra, C. (1986) Industrial Alumina Chemicals. ACS Monograph, 184; American Chemical Society: Washington.

[6] Ying, J.Y.; Mehnert, C.P.; Wong, M.S. (1999) Synthesis and applications of supramolecular-templated mesoporous materials. Angew. Chem. Int. Ed., 38: 5677. 
[7] Schüth, F. (2005) Engineered porous catalytic materials. Ann. Rev. Mater. Res., 35: 209-238.

[8] Čejka, J. (2003) Organized mesoporous alumina: synthesis, structure and potential in catalysis. Appl. Catal. A, 254: 327-338.

[9] Pinnavaia, T.J.; Zhang, Z.R.; Hicks, R.W. (2005) An overview of mesostructured forms of alumina with crystalline framework walls. In Nanoporous materials IV. Sayari, A., Jaroniec, M.; Eds. Elsevier: Amsterdam. Stud. Surf. Sci. Catal., 156: $1-10$.

[10] Li, C.R.; Feng, Y.S.; Yang, Q.H. (2006) The research progress of mesoporous alumina. Progr. Chem., 18: 1482-1488.

[11] Landau, M.V.; Dafa, E.; Kaliya, M.L.; Sen, T.; Herskowitz, M. (2001) Mesoporous alumina catalytic material prepared by grafting wide-pore MCM-41 with an alumina multilayer. Microporous Mesoporous Mater., 49: 65-81.

[12] Vaudry, F.; Khodabandeh, S.; Davis, M.E. (1996) Synthesis of pure alumina mesoporous materials. Chem. Mater., 8: 1451-1464.

[13] Huo, Q.S.; Margolese, D.I.; Ciesla, U.; Demuth, D.G.; Feng, P.Y.; Gier, T.E.; Sieger, P.; Firouzi, A.; Chmelka, B.F.; Schüth, F.; Stucky, G.D. (1994) Organization of organic-molecules with inorganic molecular-species into nanocomposite biphase arrays. Chem. Mater., 6: 1176-1191.

[14] Huo, Q.S.; Margolese, D.I.; Ciesla, U.; Feng, P.Y.; Gier, T.E.; Sieger, P.; Leon, R.; Petroff, P.M.; Schüth, F.; Stucky, G.D. (1994) Generalized synthesis of periodic surfactant inorganic composite-materials. Nature, 368: 317-321.

[15] Wefers, K. (1990) Nomenclature, preparation and properties of aluminum oxides, oxide hydroxides and trihydroxides. In Alumina Chemicals: science and technology handbook. Hart, L.D.; Ed. The American Ceramic Society: Westerville. 13-22.

[16] Trimm, D.L.; Stanislaus, A. (1986) The control of pore size in alumina catalyst supports: a review. Appl. Catal., 21: 215-238.

[17] Yada, M.; Machida, M.; Kijima, T. (1996) Synthesis and deorganization of an aluminium-based dodecyl sulfate mesophase with a hexagonal structure. Chem. Commun., 769-770.

[18] Yada, M.; Kitamura, H.; Machida, M.; Kijima, T. (1997) Biomimetic surface patterns of layered aluminum oxide mesophases templated by mixed surfactant assemblies. Langmuir, 13: 5252-5257.

[19] Yada, M.; Hiyoshi, H.; Ohe, K.; Machida, M.; Kijima, T. (1997) Synthesis of aluminum-based surfactant mesophases morphologically controlled through a layer to hexagonal transition. Inorg. Chem., 36: 5565-5569. 
[20] Yada, M.; Ohya, M.; Machida, M.; Kijima, T. (1998) Synthesis of porous yttrium aluminium oxide templated by dodecyl sulfate assemblies. Chem. Commun., 1941-1942.

[21] Sicard, L.; Llewellyn, P.L.; Patarin, J.; Kolenda, F. (2001) Investigation of the mechanism of the surfactant removal from a mesoporous alumina prepared in the presence of sodium dodecylsulfate. Microporous Mesoporous Mater., 44: 195-201.

[22] Valange, S.; Guth, J.L.; Kolenda, F.; Lacombe, S.; Gabelica, Z. (2000) Synthesis strategies leading to surfactant-assisted aluminas with controlled mesoporosity in aqueous media. Microporous Mesoporous Mater., 35-6: 597-607.

[23] Caragheorgheopol, A.; Caldararu, H.; Vasilescu, M.; Khan, A.; Angelescu, D.; Žilková, N.; Čejka, J. (2004) Structural characterization of micellar aggregates in sodium dodecyl sulfate/aluminum nitrate/urea/water system in the synthesis of mesoporous alumina. J. Phys. Chem. B, 108: 7735-7743.

[24] Sicard, L.; Lebeau, B.; Patarin, J.; Zana, R. (2002) Study of the mechanism of formation of a mesostructured hexagonal alumina by means of fluorescence probing techniques. Langmuir, 18: 74-82.

[25] Ray, J.C.; You, K.S.; Ahn, J.W.; Ahn, W.S. (2007) Mesoporous alumina (I): Comparison of synthesis schemes using anionic, cationic, and non-ionic surfactants. Microporous Mesoporous Mater., 100: 183-190.

[26] Čejka, J.; Žilková, N.; Rathouský, J.; Zukal, A. (2001) Nitrogen adsorption study of organised mesoporous alumina. Phys. Chem. Chem. Phys., 3: 50765081.

[27] Čejka, J.; Veselá, L.; Rathouský, J.; Zukal, A. (2002) Adsorption of nitrogen on organized mesoporous alumina. In Nanoporous materials III. Sayari, A., Jaroniec, M.; Eds. Elsevier: Amsterdam. Stud. Surf. Sci. Catal., 141: 429-436.

[28] Čejka, J.; Žilková, N.; Rathouský, J.; Zukal, A.; Jagiello, J. (2004) Highresolution adsorption of nitrogen on mesoporous alumina. Langmuir, 20: 75327539.

[29] Čejka, J.; Kooyman, P.J.; Veselá, L.; Rathouský, J.; Zukal, A. (2002) Hightemperature transformations of organised mesoporous alumina. Phys. Chem. Chem. Phys., 4: 4823-4829.

[30] Kim, P.; Joo, J.B.; Kim, H.; Kim, W.; Kim, Y.; Song, I.K.; Yi, J. (2005) Preparation of Mesoporous Ni-alumina Catalyst by One-step Sol-gel Method: Control of Textural Properties and Catalytic Application to the Hydrodechlorination of o-dichlorobenzene. Catal. Lett., 104: 181-189.

[31] Kim, Y.; Kim, C.; Kim, P.; Yi, J. (2005) Effect of preparation conditions on the phase transformation of mesoporous alumina. J. Non-Cryst. Sol., 351: 550-556.

[32] Acosta, S.; Ayral, A.; Guizard, C.; Cot, L. (1996) Synthesis of alumina gels in amphiphilic media. J. Sol-Gel. Sci. Technol., 8: 195-199. 
[33] Cabrera, S.; El Haskouri, J.; Alamo, J.; Beltran, A.; Beltran, D.; Mendioroz, S.; Marcos, M.D.; Amorós, P. (1999) Surfactant-assisted synthesis of mesoporous alumina showing continuously adjustable pore sizes. Adv. Mater., 11: 379-381.

[34] Cabrera, S.; El Haskouri, J.; Guillem, C.; Latorre, J.; Beltrán-Porter, A.; BeltránPorter, D.; Marcos, M.D.; Amorós, P. (2000) Generalised syntheses of ordered mesoporous oxides: the atrane route. Solid State Sci., 2: 405-420.

[35] Deng, W.H.; Toepke, M.W.; Shanks, B.H. (2003) Surfactant-assisted synthesis of alumina with hierarchical nanopores. Adv. Funct. Mater., 13: 61-65.

[36] Kim, H.J.; Lee, H.C.; Choo, D.H.; Lee, H.C.; Chung, S.H.; Lee, K.H.; Lee, J.S. (2003) Synthesis and characterization of mesoporous alumina molecular sieves using cationic surfactants. In Nanotechnology in mesostructured materials. Park, S.E., Ryoo, R., Ahn, W.S., Lee, C.W., Chang, J.S.; Eds. Elsevier: Amsterdam. Stud. Surf. Sci. Catal., 146: 213-216.

[37] Kim, Y.; Kim, C.; Choi, J.W.; Kim, P.; Yi, J. (2003) Synthesis of mesoporous gamma-aluminas of controlled pore properties using alkyl carboxylate assisted method. In Nanotechnology in mesostructured materials. Park, S.E., Ryoo, R., Ahn, W.S., Lee, C.W., Chang, J.S.; Eds. Elsevier: Amsterdam. Stud. Surf. Sci. Catal., 146: 209-212.

[38] Bagshaw, S.A.; Prouzet, E.; Pinnavaia, T.J. (1995) Templating of mesoporous molecular-sieves by nonionic polyethylene oxide surfactants. Science, 269: 1242-1244.

[39] Bagshaw, S.A.; Pinnavaia, T.J. (1996) Mesoporous alumina molecular sieves. Angew. Chem. Int. Ed. Engl., 35: 1102-1105.

[40] Zhang, W.Z.; Pinnavaia, T.J. (1998) Rare earth stabilization of mesoporous alumina molecular sieves assembled through an $\mathrm{N}^{\circ} \mathrm{I}^{\mathrm{o}}$ pathway. Chem. Commun., $1185-1186$.

[41] Luo, Q.; Li, L.; Xue, Z.; Zhao, D. (2000) Synthesis of nanometer-sized mesoporous silica and alumina spheres. In Nanoporous materials II. Sayari, A., Jaroniec, M., Pinnavaia, T.J.; Eds. Elsevier: Amsterdam. Stud. Surf. Sci. Catal., 129: $37-43$.

[42] González-Peña, V.; Díaz, I.; Márquez-Alvarez, C.; Sastre, E.; Pérez-Pariente, J. (2001) Thermally stable mesoporous alumina synthesized with non-ionic surfactants in the presence of amines. Microporous Mesoporous Mater., 44: 203-210.

[43] González-Peña, V.; Márquez-Alvarez, C.; Sastre, E.; Pérez-Pariente, J. (2001) Improved Thermal Stability of Mesoporous Alumina Support of Catalysts for the Isomerization of Light Paraffins. In Zeolites and mesoporous materials at the down of the 21st century. Galameau, A., di Renso, F., Fajula, F., Védrine, J.; Eds. Elsevier: Amsterdam. Stud. Surf. Sci. Catal., 135: 1072-1079. 
[44] Sayari, A.; Yang, Y.; Kruk, M.; Jaroniec, M. (1999) Expanding the pore size of MCM-41 silicas: Use of amines as expanders in direct synthesis and postsynthesis procedures. J. Phys. Chem. B, 103: 3651-3658.

[45] Wittingham, M.S.; Jacobson, A.J.; Eds. (1982) Intercalation Chemistry. Academic Press: New York.

[46] Dresselhaus, G.; Dresselhaus, M.S. (1986) Intercalation in layered materials: Proceedings of the 10th course of the Erice summer school on intercalation layered materials, [International School of Materials Science and Technology], held july 5-15, 1986, in Erice, Sicily, Italy. Dresselhaus, M.S.; Ed. NATO ASI Ser. B, 148; Plenum Press: New York.

[47] González-Peña, V.; Márquez-Alvarez, C.; Sastre, E.; Pérez-Pariente, J. (2002) Synthesis of ordered mesoporous and microporous aluminas: strategies for tailoring texture and aluminum coordination. In Impact of zeolites and other porous materials on the new technologies at the beginning of the new millennium. Aiello, R., Giordano, G., Testa, F.; Eds. Elsevier: Amsterdam. Stud. Surf. Sci. Catal., 142: 1283-1290.

[48] Ray, A. (1971) Solvophobic interactions and micelle formation in structure forming nonaqueous solvents. Nature, 231: 313-315.

[49] Ray, A.; Nemethy, G. (1971) Micelle formation by nonionic detergents in waterethylene glycol mixtures. J. Phys. Chem., 75: 809-815.

[50] Becher, P. (1965) Nonionic surface-active compounds. X. Effect of solvent on micellar properties. J. Colloid Sci., 20: 728-731.

[51] Becher, P.; Trifiletti, S.E. (1973) Nonionic surface-active agents .12. Effect of solvent on thermodynamics of micellization. J. Colloid Interf. Sci., 43: 485-490.

[52] González-Peña, V.; Márquez-Alvarez, C.; Díaz, I.; Grande, M.; Blasco, T.; Pérez-Pariente, J. (2005) Sol-gel synthesis of mesostructured aluminas from chemically modified aluminum sec-butoxide using non-ionic surfactant templating. Microporous Mesoporous Mater., 80: 173-182.

[53] Díaz, I.; González-Peña, V.; Márquez-Alvarez, C.; Pérez-Pariente, J. (2003) Transmission electron microscopy study of the porous structure of aluminas synthesized by non-ionic surfactant templating route. Collect. Czech. Chem. Commun., 68: 1937-1948.

[54] Díaz, I.; González-Peña, V.; Márquez-Alvarez, C.; Kikkinides, E.S. (2004) Transmission electron microscopy combined with stochastic reconstruction methods for structural characterization of porous alumina synthesized via nonionic surfactant-templating route. Microporous Mesoporous Mater., 68: 11-19.

[55] Díaz, I.; González-Peña, V.; Márquez-Alvarez, C.; Pérez-Pariente, J.; Kikkinides, E.S. (2005) Investigation of organised porous aluminas by transmission electron microscopy. In Molecular Sieves: from basic research to industrial applications. Čejka, J., Žilková, N., Nachtigall, P.; Eds. Elsevier: Amsterdam. Stud. Surf. Sci. Catal., 158: 541-548. 
[56] Yang, P.D.; Zhao, D.Y.; Margolese, D.I.; Chmelka, B.F.; Stucky, G.D. (1998) Generalized syntheses of large-pore mesoporous metal oxides with semicrystalline frameworks. Nature, 396: 152-155.

[57] Cruise, N.; Jansson, K.; Holmberg, K. (2001) Mesoporous alumina made from a bicontinuous liquid crystalline phase. J. Colloid Interf. Sci., 241: 527-529.

[58] Deng, W.; Bodart, P.; Pruski, M.; Shanks, B.H. (2002) Characterization of mesoporous alumina molecular sieves synthesized by nonionic templating. Microporous Mesoporous Mater., 52: 169-177.

[59] Bronstein, L.M.; Chernyshov, D.M.; Karlinsey, R.; Zwanziger, J.W.; Matveeva, V.G.; Sulman, E.M.; Demidenko, G.N.; Hentze, H.P.; Antonietti, M. (2003) Mesoporous alumina and aluminosilica with Pd and Pt nanoparticles: Structure and catalytic properties. Chem. Mater., 15: 2623-2631.

[60] Caragheorgheopol, A.; Caldararu, H.; Ionita, G.; Savonea, F.; Žilková, N.; Zukal, A.; Čejka, J. (2005) Solvent-induced textural changes of as-synthesized mesoporous alumina, as reported by spin probe electron spin resonance spectroscopy. Langmuir, 21: 2591-2597.

[61] Niesz, K.; Yang, P.D.; Somorjai, G.A. (2005) Sol-gel synthesis of ordered mesoporous alumina. Chem. Commun., 1986-1987.

[62] Kuemmel, M.; Grosso, D.; Boissière, C.; Smarsly, B.; Brezesinski, T.; Albouy, P.A.; Amenitsch, H.; Sanchez, C. (2005) Thermally stable nanocrystalline gamma-alumina layers with highly ordered 3D mesoporosity. Angew. Chem., 44: 4589-4592.

[63] Boissière, C.; Nicole, L.; Gervais, C.; Babonneau, F.; Antonietti, M.; Amenitsch, H.; Sanchez, C.; Grosso, D. (2006) Nanocrystalline mesoporous gamma-alumina powders "UPMC1 material" gathers thermal and chemical stability with high surface area. Chem. Mater., 18: 5238-5243.

[64] Basmadjian, D.; Fulford, G.N.; Parsons, B.I.; Montgomery, D.S. (1962) The control of the pore volume and pore size distribution in alumina and silica gels by the addition of water soluble organic polymers. J. Catal., 1: 547-563.

[65] Ji, L.; Lin, J.; Tan, K.L.; Zeng, H.C. (2000) Synthesis of high-surface-area alumina using aluminum tri-sec-butoxide-2,4-pentanedione-2-propanol-nitric acid precursors. Chem. Mater., 12: 931-939.

[66] You, Z.X.; Balint, I.; Aika, K. (2003) Mesostructured alumina nanocomposites synthesized via reverse microemulsion route. Chem. Lett., 32: 630-631.

[67] Shan, Z.; Jansen, J.C.; Zhou, W.; Maschmeyer, T. (2003) Al-TUD-1, stable mesoporous aluminas with high surface areas. Appl. Catal. A, 254: 339-343.

[68] Jan, J.S.; Shantz, D.F. (2005) Helical poly-L-glutamic acid templated nanoporous aluminium oxides. Chem. Commun., 2137-2139. 
[69] Liu, X.; Wei, Y.; Jin, D.; Shih, W.H. (2000) Synthesis of mesoporous aluminum oxide with aluminum alkoxide and tartaric acid. Mater. Lett., 42: 143-149.

[70] Liu, Q.; Wang, A.; Wang, X.; Zhang, T. (2006) Mesoporous [gamma]-alumina synthesized by hydro-carboxylic acid as structure-directing agent. Microporous Mesoporous Mater., 92: 10-21.

[71] Xu, B.; Xiao, T.; Yan, Z.; Sun, X.; Sloan, J.; González-Cortés, S.L.; Alshahrani, F.; Green, M.L.H. (2006) Synthesis of mesoporous alumina with highly thermal stability using glucose template in aqueous system. Microporous Mesoporous Mater., 91: 293-295.

[72] Žilková, N.; Zukal, A.; Čejka, J. (2006) Synthesis of organized mesoporous alumina templated with ionic liquids. Microporous Mesoporous Mater., 95: 176179.

[73] Park, H.S.; Yang, S.H.; Jun, Y.S.; Hong, W.H.; Kang, J.K. (2007) Facile route to synthesize large-mesoporous $\gamma$-alumina by room temperature ionic liquids. Chem. Mater., 19: 535-542.

[74] Zhang, H.; Hardy, G.C.; Khimyak, Y.Z.; Rosseinsky, M.J.; Cooper, A.I. (2004) Synthesis of hierarchically porous silica and metal oxide beads using emulsiontemplated polymer scaffolds. Chem. Mater., 16: 4245-4256.

[75] Li, W.C.; Lu, A.H.; Schmidt, W.; Schüth, F. (2005) High surface area, mesoporous, glassy alumina with a controllable pore size by nanocasting from carbon aerogels. Chem. Eur. J., 11: 1658-1664.

[76] Schüth, F.; Czuryskiewicz, T.; Kleitz, F.; Linden, M.; Lu, A.H.; Rosenholm, J.; Schmidt, W.; Taguchi, A. (2003) Expanding horizons of mesoporous materials to non-siliceous systems. In Nanotechnology in mesostructured materials. Park, S.E., Ryoo, R., Ahn, W.S., Lee, C.W., Chang, J.S.; Eds. Elsevier: Amsterdam. Stud. Surf. Sci. Catal., 146: 399-406.

[77] Liu, Q.; Wang, A.; Wang, X.; Zhang, T. (2006) Ordered crystalline alumina molecular sieves synthesized via a nanocasting route. Chem. Mater., 18: 51535155.

[78] Zhu, H.Y.; Riches, J.D.; Barry, J.C. (2002) gamma-alumina nanofibers prepared from aluminum hydrate with poly(ethylene oxide) surfactant. Chem. Mater., 14: 2086-2093.

[79] Zhu, H.Y.; Gao, X.P.; Song, D.Y.; Ringer, S.P.; Xi, Y.X.; Frost, R.L. (2005) Manipulating the size and morphology of aluminum hydrous oxide nanoparticles by soft-chemistry approaches. Microporous Mesoporous Mater., 85: 226-233.

[80] Zhang, Z.; Hicks, R.W.; Pauly, T.R.; Pinnavaia, T.J. (2002) Mesostructured forms of gamma-Al2O3. J. Am. Chem. Soc., 124: 1592-1593.

[81] Zhang, Z.; Pinnavaia, T.J. (2002) Mesostructured gamma-A12O3 with a Lathlike Framework Morphology. J. Am. Chem. Soc., 124: 12294-12301. 
[82] Hicks, R.W.; Pinnavaia, T.J. (2003) Nanoparticle assembly of mesoporous AlOOH (boehmite). Chem. Mater., 15: 78-82.

[83] Ren, T.Z.; Yuan, Z.Y.; Su, B.L. (2004) Microwave-assisted preparation of hierarchical mesoporous-macroporous boehmite $\mathrm{AlOOH}$ and gamma-Al2O3. Langmuir, 20: 1531-1534.

[84] Lee, H.C.; Kim, H.J.; Rhee, C.H.; Lee, K.H.; Lee, J.S.; Chung, S.H. (2005) Synthesis of nanostructured gamma-alumina with a cationic surfactant and controlled amounts of water. Microporous Mesoporous Mater., 79: 61-68.

[85] Lee, H.C.; Kim, H.J.; Chung, S.H.; Lee, K.H.; Lee, H.C.; Lee, J.S. (2003) Synthesis of Unidirectional Alumina Nanostructures without Added Organic Solvents. J. Am. Chem. Soc., 125: 2882-2883.

[86] Yao, N.; Xiong, G.X.; Zhang, Y.H.; He, M.Y.; Yang, W.S. (2001) Preparation of novel uniform mesoporous alumina catalysts by the sol-gel method. Catal. Today, 68: 97-109.

[87] Čejka, J.; Žilková, N.; Kaluža, L.; Zdražil, M. (2002) Mesoporous alumina as a support for hydrodesulfurization catalysts. In Nanoporous materials III. Sayari, A., Jaroniec, M.; Eds. Elsevier: Amsterdam. Stud. Surf. Sci. Catal., 141: 243250 .

[88] Kaluža, L.; Zdražil, M.; Žilková, N.; Čejka, J. (2002) High activity of highly loaded MoS2 hydrodesulfurization catalysts supported on organised mesoporous alumina. Catal. Commun., 3: 151-157.

[89] Hicks, R.W.; Castagnola, N.B.; Zhang, Z.R.; Pinnavaia, T.J.; Marshall, C.L. (2003) Lathlike mesostructured gamma-alumina as a hydrodesulfurization catalyst support. Appl. Catal. A, 254: 311-317.

[90] Kim, P.; Kim, Y.; Kim, C.; Kim, H.; Park, Y.; Lee, J.H.; Song, I.K.; Yi, J. (2003) Synthesis and characterization of mesoporous alumina as a catalyst support for hydrodechlorination of 1,2-dichloropropane: effect of catalyst preparation method. Catal. Lett., 89: 185-192.

[91] Kim, P.; Kim, Y.; Kim, H.; Song, I.K.; Yi, J. (2004) Synthesis and characterization of mesoporous alumina for use as a catalyst support in the hydrodechlorination of 1,2-dichloropropane: effect of preparation condition of mesoporous alumina. J. Mol. Catal. A, 219: 87-95.

[92] Kim, P.; Kim, Y.; Kim, H.; Song, I.K.; Yi, J. (2005) Preparation, characterization, and catalytic activity of $\mathrm{NiMg}$ catalysts supported on mesoporous alumina for hydrodechlorination of o-dichlorobenzene. J. Mol. Catal. A, 231: 247-254.

[93] Khaleel, A. (2006) Catalytic activity of mesoporous alumina for the hydrolysis and dechlorination of carbon tetrachloride. Microporous Mesoporous Mater., 91: 53-58. 
[94] Balcar, H.; Hamtil, R.; Žilková, N.; Čejka, J. (2004) Rhenium oxide supported on mesoporous organized alumina as a catalyst for metathesis of 1-alkenes. Catal. Lett., 97: 25-29.

[95] Hamtil, R.; Žilková, N.; Balcar, H.; Čejka, J. (2006) Rhenium oxide supported on organized mesoporous alumina - A highly active and versatile catalyst for alkene, diene, and cycloalkene metathesis. Appl. Catal. A, 302: 193-200.

[96] Onaka, M.; Oikawa, T. (2002) Olefin metathesis over mesoporous aluminasupported rhenium oxide catalyst. Chem. Lett., 850-851.

[97] Oikawa, T.; Ookoshi, T.; Tanaka, T.; Yamamoto, T.; Onaka, M. (2004) A new heterogeneous olefin metathesis catalyst composed of rhenium oxide and mesoporous alumina. Microporous Mesoporous Mater., 74: 93-103.

[98] Aguado, J.; Escola, J.M.; Castro, M.C.; Paredes, B. (2005) Metathesis of 1hexene over rhenium oxide supported on ordered mesoporous aluminas: comparison with Re2O7/gamma-A12O3. Appl. Catal. A, 284: 47-57.

[99] Mol, J.C. (1999) Olefin metathesis over supported rhenium oxide catalysts. Catal. Today, 51: 289-299.

[100] Mol, J.C. (2002) Application of olefin metathesis in oleochemistry: an example of green chemistry. Green Chem., 4: 5-13.

[101] Balcar, H.; Žilková, N.; Bastl, Z.; Dědeček, J.; Hamtil, R.; Brabec, L.; Zukal, A.; Čejka, J. (2007) Characterization of textural and surface properties of mesoporous metathesis catalysts. In Proceedings of the 15th International Zeolite Conference. Elsevier: Amsterdam. Stud. Surf. Sci. Catal., in press.

[102] Okal, J.; Kępiński, L.; Krajczyk, L.; Tylus, W. (2003) Oxidation and redispersion of a low-loaded $\mathrm{Re} / \gamma-\mathrm{Al}_{2} \mathrm{O}_{3}$ catalyst. J. Catal., 219: 362-371.

[103] Balcar, H.; Hamtil, R.; Žilková, N.; Zhang, Z.; Pinnavaia, T.J.; Čejka, J. (2007) Metathesis of olefin functional derivatives over rhenium supported on organized mesoporous alumina. Appl. Catal. A, 320: 56-63.

[104] Yin, D.H.; Qin, L.S.; Liu, H.F.; Li, C.Y.; Jin, Y. (2005) Gold nanoparticles deposited on mesoporous alumina for epoxidation of styrene: Effects of the surface basicity of the supports. J. Mol. Catal. A, 240: 40-48.

[105] Qin, L.S.; Yin, D.H.; Liu, J.F.; Li, C.Y. (2005) Mesoporous alumina-supported nano-Au catalysts for carbon monoxide oxidation at low temperature. Chin. J. Catal., 26: 714-718.

[106] Kim, P.; Kim, Y.; Kim, H.; Song, I.K.; Yi, J. (2004) Synthesis and characterization of mesoporous alumina with nickel incorporated for use in the partial oxidation of methane into synthesis gas. Appl. Catal. A, 272: 157-166.

[107] Jacobs, P.A. (2005) An evaluation of the potential of the Ship-in-Bottle approach for catalyst immobilization in microporous supports. In Zeolites and 
ordered mesoporous materials: progress and prospects. Čejka, J., van Bekkum, H.; Eds. Elsevier: Amsterdam. Stud. Surf. Sci. Catal., 157: 289-310.

[108] Chaube, V.D.; Shylesh, S.; Singh, A.P. (2005) Synthesis, characterization and catalytic activity of Mn(III)- and Co(II)-salen complexes immobilized mesoporous alumina. J. Mol. Catal. A, 241: 79-87.

[109] Solsona, B.; Dejoz, A.; García, T.; Concepción, P.; Lopez Nieto, J.M.; Vázquez, M.I.; Navarro, M.T. (2006) Molybdenum-vanadium supported on mesoporous alumina catalysts for the oxidative dehydrogenation of ethane. Catal. Today, 117: 228-233.

[110] Valange, S.; Barrault, J.; Derouault, A.; Gabelica, Z. (2001) Binary Cu-Al mesophases precursors to uniformly sized copper particles highly dispersed on mesoporous alumina. Microporous Mesoporous Mater., 44: 211-220.

[111] Valange, S.; Derouault, A.; Barrault, J.; Gabelica, Z. (2005) One-step generation of highly selective hydrogenation catalysts involving sub-nanometric $\mathrm{Cu} 2 \mathrm{O}$ supported on mesoporous alumina: strategies to control their size and dispersion. J. Mol. Catal. A, 228: 255-266.

[112] Lenarda, M.; Moretti, E.; Storaro, L.; Patrono, P.; Pinzari, F.; RodríguezCastellón, E.; Jiménez-López, A.; Busca, G.; Finocchio, E.; Montanari, T.; Frattini, R. (2006) Finely dispersed Pd-Zn catalyst supported on an organized mesoporous alumina for hydrogen production by methanol steam reforming. Appl. Catal. A, 312: 220-228.

[113] Zhao, X.P.; Yue, Y.H.; Zhang, Y.; Hua, W.M.; Gao, Z. (2003) Mesoporous alumina molecular sieves: characterization and catalytic activity in hydrolysis of carbon disulfide. Catal. Lett., 89: 41-47.

[114] Seki, T.; Onaka, M. (2005) Strong base catalysis of sulfated mesoporous alumina for the Tishchenko reaction in supercritical carbon dioxide. Chem. Lett., 34: $262-263$.

[115] Seki, T.; Onaka, M. (2006) Sulfated mesoporous alumina: A highly effective solid strong base catalyst for the Tishchenko reaction in supercritical carbon dioxide. J. Phys. Chem. B, 110: 1240-1248.

[116] Seki, T.; Ikeda, S.; Onaka, M. (2006) Synthesis of sodium-doped mesoporous alumina and its strong base catalysis for double bond migration of olefins. Microporous Mesoporous Mater., 96: 121-126.

[117] Seki, T.; Onaka, M. (2006) Heterogeneous strong base catalysis in supercritical carbon dioxide by mesoporous alumina and sulfated mesoporous alumina. Catal. Surv. Asia, 10: 138-150.

[118] Zhang, X.; Zhang, F.; Chan, K.Y. (2004) The synthesis of large mesopores alumina by microemulsion templating, their characterization and properties as catalyst support. Mater. Lett., 58: 2872-2877. 
[119] Lee, H.C.; Kim, H.J.; Choo, D.H.; Lee, H.C.; Chung, S.H.; Lee, K.H.; Lee, J.S. (2003) Synthesis and characterization of mesoporous alumina molecular sieves with cationic surfactants in the presence of formamide. In Nanotechnology in mesostructured materials. Park, S.E., Ryoo, R., Ahn, W.S., Lee, C.W., Chang, J.S.; Eds. Elsevier: Amsterdam. Stud. Surf. Sci. Catal., 146: 217-220. 
TABLE 1. Organized mesoporous aluminas templated by anionic surfactants ( $\left.\mathrm{S}^{-}\right)$

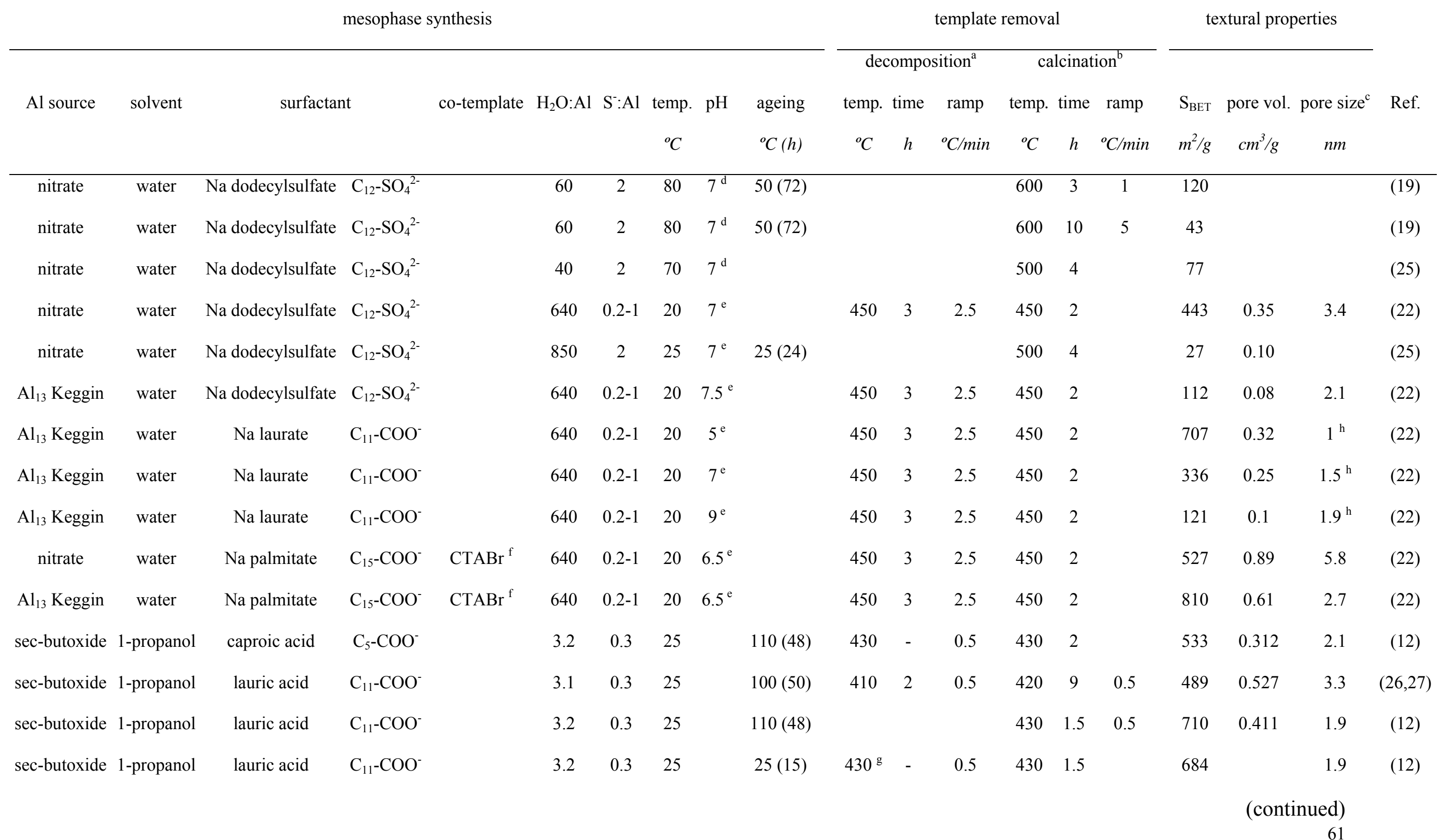




\begin{tabular}{|c|c|c|c|c|c|c|c|c|c|c|c|c|c|c|c|c|c|c|c|}
\hline \multirow{3}{*}{ Al source } & \multirow{3}{*}{ solvent } & \multirow{3}{*}{\multicolumn{2}{|c|}{ surfactant }} & \multirow{3}{*}{ co-template } & \multirow{3}{*}{$\mathrm{H}_{2} \mathrm{O}: \mathrm{Al}$} & \multirow{3}{*}{$\mathrm{S}^{-}: \mathrm{Al}$} & \multirow[b]{2}{*}{ temp. } & \multirow{3}{*}{$\mathrm{pH}$} & \multirow{3}{*}{$\begin{array}{l}\text { ageing } \\
{ }^{o} \mathrm{C}(h)\end{array}$} & \multicolumn{3}{|c|}{ decomposition $^{\mathrm{a}}$} & \multicolumn{3}{|c|}{ calcination $^{b}$} & \multirow[b]{2}{*}{$\mathrm{S}_{\mathrm{BET}}$} & \multirow[b]{2}{*}{ pore vol. } & \multirow[b]{2}{*}{ pore size ${ }^{c}$} & \multirow{3}{*}{ Ref. } \\
\hline & & & & & & & & & & temp. & time & ramp & temp. & time & ramp & & & & \\
\hline & & & & & & & ${ }^{\circ} \mathrm{C}$ & & & ${ }^{\circ} \mathrm{C}$ & $h$ & ${ }^{\circ} \mathrm{C} / \mathrm{min}$ & ${ }^{\circ} \mathrm{C}$ & $h$ & ${ }^{\circ} \mathrm{C} / \mathrm{min}$ & $\mathrm{m}^{2} / \mathrm{g}$ & $\mathrm{cm}^{3} / \mathrm{g}$ & $n m$ & \\
\hline sec-butoxide & 1-propanol & lauric acid & $\mathrm{C}_{11}-\mathrm{COO}^{-}$ & dodecane & 4.6 & 0.13 & 25 & & $100(50)$ & 410 & 2 & 1 & 495 & 9 & 1 & 459 & & 5.7 & $(26,27)$ \\
\hline sec-butoxide & 1-propanol & lauric acid & $\mathrm{C}_{11}-\mathrm{COO}^{-}$ & & 3.2 & 0.3 & 25 & & $138(48)$ & $500^{g}$ & - & 0.5 & 500 & 1 & & 357 & & 3.5 & $(12)$ \\
\hline sec-butoxide & 1-propanol & lauric acid & $\mathrm{C}_{11}-\mathrm{COO}^{-}$ & & 3.0 & 0.3 & 25 & & $100(24)$ & & & & 500 & 4 & & 412 & 0.44 & $4.2^{\mathrm{i}}$ & $(25)$ \\
\hline sec-butoxide & 1-propanol & lauric acid & $\mathrm{C}_{11}-\mathrm{COO}^{-}$ & & 3.1 & 0.3 & 25 & & $100(50)$ & 410 & 2 & 0.5 & 600 & 6 & 0.5 & 313 & 0.477 & 4.4 & $(26,27)$ \\
\hline sec-butoxide & 1-propanol & lauric acid & $\mathrm{C}_{11}-\mathrm{COO}^{-}$ & & 3.1 & 0.3 & 25 & & $100(50)$ & 410 & 2 & 0.5 & 800 & 6 & 0.5 & 223 & 0.409 & 5.1 & $(26,27)$ \\
\hline sec-butoxide & 1-propanol & stearic acid & $\mathrm{C}_{17}-\mathrm{COO}^{-}$ & & 3 & 0.32 & 25 & & $100(50)$ & 410 & 2 & 0.5 & 420 & 9 & 0.5 & 758 & 0.681 & 3.7 & $(26,27)$ \\
\hline sec-butoxide & 1-propanol & stearic acid & $\mathrm{C}_{17}-\mathrm{COO}^{-}$ & & 3.1 & 0.32 & 25 & & $100(50)$ & 410 & 2 & 0.5 & 420 & 9 & 0.5 & 707 & 0.588 & 2.5 & $(26,27)$ \\
\hline sec-butoxide & 1-propanol & stearic acid & $\mathrm{C}_{17}-\mathrm{COO}^{-}$ & & 3.2 & 0.3 & 25 & & $110(48)$ & & & & 430 & 6 & 0.5 & 702 & 0.41 & 2.1 & (12) \\
\hline sec-butoxide & 2-butanol & stearic acid & $\mathrm{C}_{17}-\mathrm{COO}^{-}$ & & 48 & 0.2 & 25 & 7 & $25(24)$ & & & & 450 & 3 & & 386 & 1 & 7.7 & $(31)$ \\
\hline sec-butoxide & 2-butanol & stearic acid & $\mathrm{C}_{17}-\mathrm{COO}^{-}$ & & 32 & 0.2 & 25 & 7 & $25(24)$ & & & & 450 & 3 & & 377 & 1 & 7.7 & $(31)$ \\
\hline sec-butoxide & 2-butanol & stearic acid & $\mathrm{C}_{17}-\mathrm{COO}^{-}$ & & 16 & 0.2 & 25 & 7 & $25(24)$ & & & & 450 & 3 & & 369 & 0.9 & 7.1 & $(31)$ \\
\hline sec-butoxide & 2-butanol & stearic acid & $\mathrm{C}_{17}-\mathrm{COO}^{-}$ & & 8 & 0.2 & 25 & 7 & $25(24)$ & & & & 450 & 3 & & 485 & 0.5 & 3.5 & $(31)$ \\
\hline sec-butoxide & 2-butanol & stearic acid & $\mathrm{C}_{17}-\mathrm{COO}^{-}$ & & 4 & 0.2 & 25 & 7 & $25(24)$ & & & & 450 & 3 & & 420 & 0.6 & 3.5 & $(31)$ \\
\hline sec-butoxide & 2-butanol & stearic acid & $\mathrm{C}_{17}-\mathrm{COO}^{-}$ & & 1.5 & 0.2 & 25 & 7 & $25(24)$ & & & & 450 & 3 & & 264 & 0.2 & 3.5 & $(31)$ \\
\hline sec-butoxide & 1-propanol & stearic acid & $\mathrm{C}_{17}-\mathrm{COO}^{-}$ & & 3.1 & 0.32 & 25 & & $100(50)$ & 410 & 2 & 0.5 & 450 & 19 & 0.5 & 397 & 0.633 & 4.7 & $(26,27)$ \\
\hline sec-butoxide & pentane & lauric acid & $\mathrm{C}_{11}-\mathrm{COO}^{-}$ & & 3 & 0.32 & 25 & & $25(15)$ & $430^{g}$ & - & 0.5 & 430 & 2 & & 645 & & $2.1,3.6^{\mathrm{j}}$ & (12) \\
\hline sec-butoxide & none & palmitic acid & $\mathrm{C}_{15}-\mathrm{COO}^{-}$ & & 2 & 0.5 & 25 & & $150(72)$ & & & & 500 & 4 & & 282 & 0.34 & 2.8 & (85) \\
\hline
\end{tabular}


${ }^{\mathrm{a}}$ In nitrogen. ${ }^{\mathrm{b}}$ In air. ${ }^{\mathrm{c}} \mathrm{BJH}$ pore size distribution. ${ }^{\mathrm{d}}$ Thermal decomposition of urea. ${ }^{\mathrm{e}}$ Addition of NaOH. ${ }^{\mathrm{f}}$ Cetyltrimethylammonium bromide. ${ }^{\mathrm{g}}$ In nitrogen or air. ${ }^{\mathrm{h}}$ Contains micropores. ${ }^{\mathrm{i}}$ Mean pore diameter. ${ }^{\mathrm{j}}$ Bimodal pore size distribution. 
TABLE 2. Organized mesoporous aluminas templated by cationic $\left(\mathrm{S}^{+}\right)$alkyltrimethylammonium surfactants

mesophase synthesis

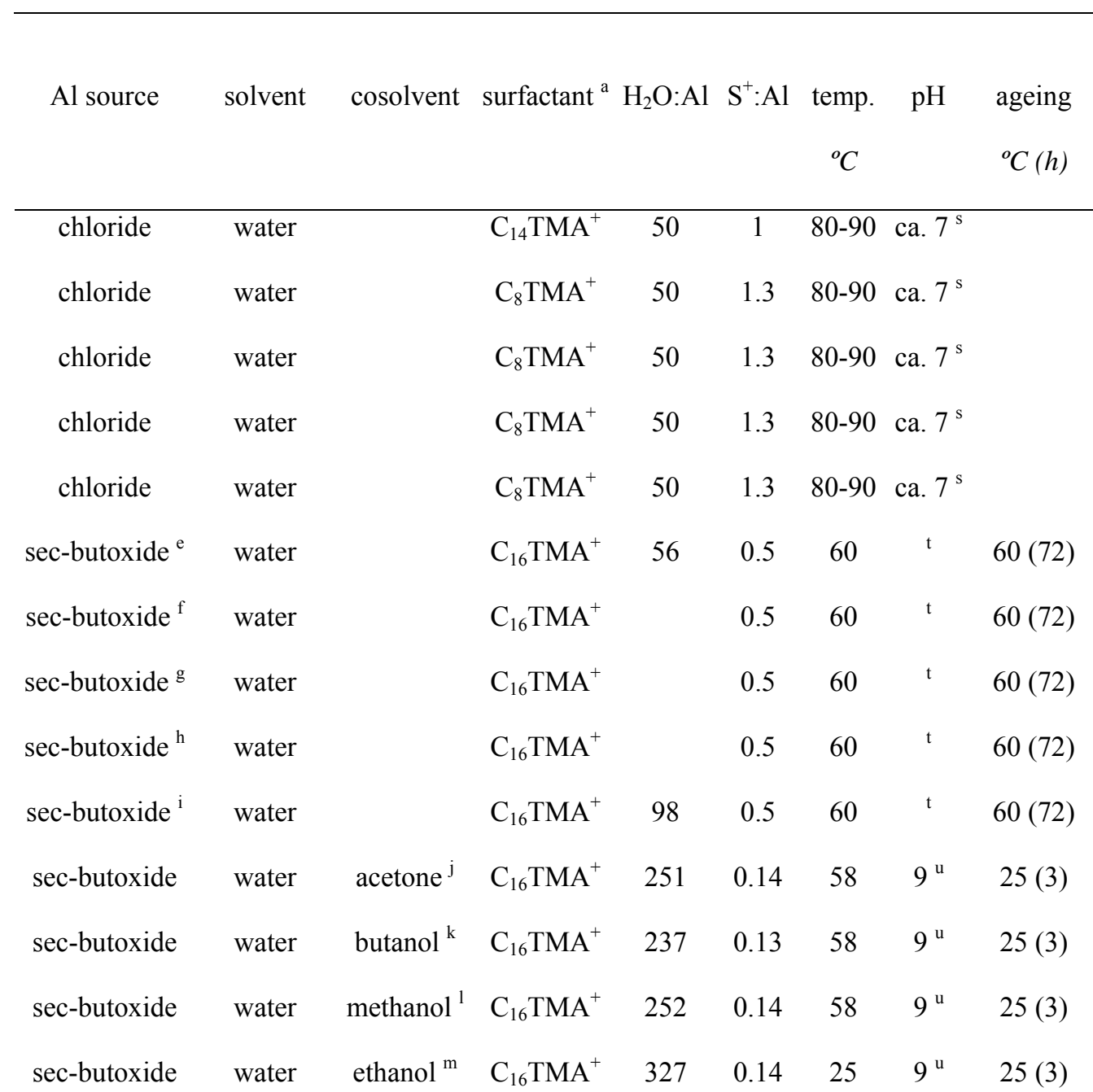

template removal

textural properties

decomposition $^{\mathrm{b}} \quad$ calcination $^{\mathrm{c}}$

temp. ramp temp. time ramp $S_{\text {BET }}$ pore vol. pore size ${ }^{d}$ Ref.

${ }^{\circ} \mathrm{C} \quad{ }^{\circ} \mathrm{C} / \mathrm{min} \quad{ }^{\circ} \mathrm{C} \quad h \quad{ }^{\circ} \mathrm{C} / \mathrm{min} \quad \mathrm{m}^{2} / \mathrm{g} \quad \mathrm{cm}^{3} / \mathrm{g} \quad \mathrm{nm}$

\begin{tabular}{|c|c|c|c|c|c|c|c|c|}
\hline 450 & 1 & 450 & 2 & & 485 & 0.66 & 5.5 & (32) \\
\hline 450 & 1 & 450 & 2 & & 460 & 0.33 & 2.9 & (32) \\
\hline 450 & 1 & 650 & 2 & & 340 & 0.31 & 3.5 & (32) \\
\hline 450 & 1 & 800 & 2 & & 270 & 0.29 & 4 & (32) \\
\hline \multirow[t]{10}{*}{450} & 1 & 1000 & 2 & & 130 & 0.16 & 4.5 & (32) \\
\hline & & 500 & 5 & & 340 & & 3.3 & (33) \\
\hline & & 500 & 5 & & 327 & & 3.9 & (33) \\
\hline & & 500 & 5 & & 318 & & 4.1 & (33) \\
\hline & & 500 & 5 & & 315 & & 5.1 & (33) \\
\hline & & 500 & 5 & & 250 & & 6 & (33) \\
\hline & & 500 & 5.5 & 2 & 350 & 0.38 & 4.2 & (35) \\
\hline & & 500 & 5.5 & 2 & 420 & 0.46 & 4.3 & (35) \\
\hline & & 500 & 5.5 & 2 & 430 & 0.44 & $3.9,350^{\mathrm{w}}$ & $(35)$ \\
\hline & & 500 & 5.5 & 2 & 300 & 0.28 & $3.7,400^{\mathrm{w}}$ & $(35)$ \\
\hline
\end{tabular}




\begin{tabular}{|c|c|c|c|c|c|c|c|c|c|c|c|c|c|c|c|c|c|}
\hline \multirow{3}{*}{ Al source } & \multirow{3}{*}{ solvent } & \multirow{3}{*}{ cosolvent } & \multirow{3}{*}{ surfactant $^{\mathrm{a}}$} & \multirow{3}{*}{$\mathrm{H}_{2} \mathrm{O}: \mathrm{Al}$} & \multirow{3}{*}{$\mathrm{S}^{+}: \mathrm{Al}$} & \multirow[b]{2}{*}{ temp. } & \multirow{3}{*}{$\mathrm{pH}$} & \multirow{3}{*}{$\begin{array}{l}\text { ageing } \\
{ }^{\circ} C(h)\end{array}$} & \multicolumn{2}{|c|}{ decomposition $^{\mathrm{b}}$} & \multicolumn{3}{|c|}{ calcination $^{\mathrm{c}}$} & \multirow{3}{*}{$\begin{array}{l}\mathrm{S}_{\mathrm{BET}} \\
\mathrm{m}^{2} / \mathrm{g}\end{array}$} & \multirow{3}{*}{$\begin{array}{l}\text { pore vol. } \\
\qquad \mathrm{cm}^{3} / \mathrm{g}\end{array}$} & \multirow{3}{*}{$\begin{array}{c}\text { pore size }^{\mathrm{d}} \\
n m\end{array}$} & \multirow{3}{*}{ Ref. } \\
\hline & & & & & & & & & temp. & ramp & temp. & time & ramp & & & & \\
\hline & & & & & & ${ }^{\circ} \mathrm{C}$ & & & ${ }^{\circ} \mathrm{C}$ & ${ }^{\circ} \mathrm{C} / \mathrm{min}$ & ${ }^{\circ} \mathrm{C}$ & $h$ & ${ }^{\circ} \mathrm{C} / \mathrm{min}$ & & & & \\
\hline sec-butoxide & water & ethanol $^{\mathrm{n}}$ & $\mathrm{C}_{16} \mathrm{TMA}^{+}$ & 229 & 0.32 & 25 & $9^{u}$ & $25(3)$ & & & 500 & 5.5 & 2 & 460 & 0.56 & $4.7,400^{w}$ & (35) \\
\hline sec-butoxide & water & ethanol $^{\mathrm{n}}$ & $\mathrm{C}_{16} \mathrm{TMA}^{+}$ & 248 & 0.14 & 58 & $9^{\mathrm{u}}$ & $25(3)$ & & & 500 & 5.5 & 2 & 390 & 0.47 & $4.6,250^{\mathrm{w}}$ & (35) \\
\hline sec-butoxide & water & ethanol $^{\mathrm{n}}$ & $\mathrm{C}_{16} \mathrm{TMA}^{+}$ & 232 & 0.07 & 25 & $9^{\mathrm{u}}$ & $25(3)$ & & & 500 & 5.5 & 2 & 370 & 0.4 & $4.1,400^{w}$ & (35) \\
\hline sec-butoxide & water & ethanol $^{\mathrm{n}}$ & $\mathrm{C}_{16} \mathrm{TMA}^{+}$ & 238 & 0.13 & 58 & $9^{\mathrm{u}}$ & $58(3)$ & & & 500 & 5.5 & 2 & 470 & 0.47 & 3.9 & (35) \\
\hline sec-butoxide & water & ethanol $^{\mathrm{n}}$ & $\mathrm{C}_{16} \mathrm{TMA}^{+}$ & 230 & 0.13 & 25 & $9^{\mathrm{u}}$ & $25(3)$ & & & 500 & 5.5 & 2 & 450 & 0.76 & 6.4 & (35) \\
\hline sec-butoxide & water & ethanol $^{\mathrm{n}}$ & $\mathrm{C}_{16} \mathrm{TMA}^{+}$ & 230 & 0.13 & 58 & $9^{\mathrm{u}}$ & $25(3)$ & & & 500 & 5.5 & 2 & 470 & 0.58 & 4.7 & (35) \\
\hline sec-butoxide & water & ethanol $^{\circ}$ & $\mathrm{C}_{16} \mathrm{TMA}^{+}$ & 35 & 0.14 & 25 & $9^{u}$ & $25(3)$ & & & 500 & 5.5 & 2 & 390 & 0.53 & 5.1 & $(35)$ \\
\hline sec-butoxide & water & ethanol $^{\mathrm{n}}$ & $\mathrm{C}_{16} \mathrm{TMA}^{+}$ & 252 & 0.14 & 25 & $5^{\mathrm{v}}$ & $25(3)$ & & & 500 & 5.5 & 2 & 290 & 0.37 & 4.8 & (35) \\
\hline sec-butoxide & 1-butanol & & $\mathrm{C}_{16} \mathrm{TMA}^{+}$ & 2 & 0.5 & 25 & & $150(24)$ & & & 500 & 4 & 2 & 401 & 0.46 & $4.8^{x}$ & (84) \\
\hline sec-butoxide & 1-butanol & & $\mathrm{C}_{12} \mathrm{TMA}^{+}$ & 2 & 0.5 & 25 & & $100(24)$ & & & 500 & 4 & 2 & 429 & 0.44 & $4.5^{x}$ & (84) \\
\hline sec-butoxide & 1-butanol & & $\mathrm{C}_{14} \mathrm{TMA}^{+}$ & 2 & 0.5 & 25 & & $100(24)$ & & & 500 & 4 & 2 & 357 & 0.68 & $6.5^{x}$ & $(84)$ \\
\hline sec-butoxide & 1-butanol & & $\mathrm{C}_{16} \mathrm{TMA}^{+}$ & 2 & 0.5 & 25 & & $30(24)$ & & & 500 & 4 & 2 & 310 & 0.46 & $7.2^{x}$ & (84) \\
\hline sec-butoxide & 1-butanol & & $\mathrm{C}_{16} \mathrm{TMA}^{+}$ & 2 & 0.5 & 25 & & $100(24)$ & & & 500 & 4 & 2 & 337 & 0.46 & $6.7^{x}$ & (84) \\
\hline sec-butoxide & 1-butanol & & $\mathrm{C}_{16} \mathrm{TMA}^{+}$ & 10 & 0.5 & 25 & & $150(24)$ & & & 500 & 4 & 2 & 290 & 0.88 & $9.6^{x}$ & (84) \\
\hline sec-butoxide & 1-butanol & & $\mathrm{C}_{16} \mathrm{TMA}^{+}$ & 20 & 0.5 & 25 & & $150(24)$ & & & 500 & 4 & 2 & 381 & 0.44 & $10.0^{\mathrm{x}}$ & (84) \\
\hline sec-butoxide & 1-butanol & & $\mathrm{C}_{12} \mathrm{TMA}^{+}$ & 2 & 0.5 & 25 & & $100(24)$ & & & 500 & 4 & & 429 & & 4.5 & (36) \\
\hline
\end{tabular}




\begin{tabular}{|c|c|c|c|c|c|c|c|c|c|c|c|c|c|c|c|c|c|}
\hline \multirow{3}{*}{ Al source } & \multirow{3}{*}{ solvent } & \multirow{3}{*}{ cosolvent } & \multirow{3}{*}{ surfactant $^{\mathrm{a}}$} & \multirow{3}{*}{$\mathrm{H}_{2} \mathrm{O}: \mathrm{Al}$} & \multirow{3}{*}{$\mathrm{S}^{+}: \mathrm{Al}$} & \multirow{3}{*}{\multicolumn{2}{|c|}{ temp. $\mathrm{pH}$}} & \multirow{3}{*}{$\begin{array}{l}\text { ageing } \\
{ }^{o} \mathrm{C}(h)\end{array}$} & \multicolumn{2}{|c|}{ decomposition $^{\mathrm{b}}$} & \multicolumn{3}{|c|}{ calcination $^{\mathrm{c}}$} & \multirow[b]{2}{*}{$\mathrm{S}_{\mathrm{BET}}$} & \multirow[b]{2}{*}{ pore vol. } & \multirow[b]{2}{*}{ pore size $^{\mathrm{d}}$} & \multirow{3}{*}{ Ref. } \\
\hline & & & & & & & & & temp. & ramp & temp. & time & ramp & & & & \\
\hline & & & & & & & & & ${ }^{\circ} \mathrm{C}$ & ${ }^{\circ} \mathrm{C} / \min$ & ${ }^{\circ} \mathrm{C}$ & $h$ & ${ }^{\circ} \mathrm{C} / \min$ & $\mathrm{m}^{2} / \mathrm{g}$ & $\mathrm{cm}^{3} / \mathrm{g}$ & $n m$ & \\
\hline sec-butoxide & 1-butanol & & $\mathrm{C}_{14} \mathrm{TMA}^{+}$ & 2 & 0.5 & 25 & & $100(24)$ & & & 500 & 4 & & 241 & & 6.5 & (36) \\
\hline sec-butoxide & 1-butanol & & $\mathrm{C}_{16} \mathrm{TMA}^{+}$ & 2 & 0.5 & 25 & & $100(24)$ & & & 500 & 4 & & 337 & & 6.7 & $(36)$ \\
\hline sec-butoxide & 1-butanol & & $\mathrm{C}_{16} \mathrm{TMA}^{+}$ & 2 & 0.5 & 25 & & $100(24)$ & & & 500 & 4 & & 401 & 0.46 & $4.8^{y}$ & $(25)$ \\
\hline sec-butoxide & 2-butanol & & $\mathrm{C}_{16} \mathrm{TMA}^{+}$ & 2 & 0.5 & 25 & & $100(24)$ & & & 500 & 4 & & 475 & 0.67 & $5.4^{\mathrm{y}}$ & $(25)$ \\
\hline sec-butoxide & 2-butanol & & $\mathrm{C}_{16} \mathrm{TMA}^{+}$ & 2 & 0.5 & 25 & & $100(24)$ & & & 500 & 4 & & 480 & 0.78 & $5.0^{y}$ & $(25)$ \\
\hline sec-butoxide & 2-butanol & & $\mathrm{C}_{16} \mathrm{TMA}^{+}$ & 2 & 0.3 & 25 & & $100(24)$ & & & 500 & 4 & & 506 & 0.83 & $6.5^{\mathrm{y}}$ & $(25)$ \\
\hline sec-butoxide & 2-butanol & & $\mathrm{C}_{16} \mathrm{TMA}^{+}$ & 2 & 0.1 & 25 & & $100(24)$ & & & 500 & 4 & & 460 & 0.68 & $5.9^{\mathrm{y}}$ & $(25)$ \\
\hline sec-butoxide & 2-butanol & & $\mathrm{C}_{16} \mathrm{TMA}^{+}$ & 2 & 0.5 & 25 & & $100(24)$ & & & 700 & 2 & & 356 & 0.68 & $7.7^{\mathrm{y}}$ & $(25)$ \\
\hline sec-butoxide & 2-butanol & & $\mathrm{C}_{16} \mathrm{TMA}^{+}$ & 2 & 0.5 & 25 & & $100(24)$ & & & 800 & 2 & & 258 & 0.63 & $8.1^{\mathrm{y}}$ & $(25)$ \\
\hline sec-butoxide & 1-butanol ${ }^{p}$ & & $\mathrm{C}_{16} \mathrm{TMA}^{+}$ & 2 & 0.5 & 25 & & $100(24)$ & & & 500 & 4 & & 370 & & 3.8 & (119) \\
\hline sec-butoxide & 1-butanol ${ }^{\mathrm{q}}$ & & $\mathrm{C}_{16} \mathrm{TMA}^{+}$ & 2 & 0.5 & 25 & & $100(24)$ & & & 500 & 4 & & 388 & & 3.7 & (119) \\
\hline sec-butoxide & 1-butanol ${ }^{\mathrm{r}}$ & & $\mathrm{C}_{16} \mathrm{TMA}^{+}$ & 2 & 0.5 & 25 & & $100(24)$ & & & 500 & 4 & & 404 & & 3 & (119) \\
\hline sec-butoxide & 1-butanol & & $\mathrm{C}_{16} \mathrm{TMA}^{+}$ & 2 & 0.5 & 25 & & $150(72)$ & & & 500 & 4 & & 400 & & & $(85)$ \\
\hline sec-butoxide & none & & $\mathrm{C}_{16} \mathrm{TMA}^{+}$ & 2 & 0.5 & 25 & & $150(72)$ & & & 500 & 4 & & 385 & 0.77 & 3.7 & (85) \\
\hline
\end{tabular}

${ }^{a}$ Surfactants are of the type $n$-alkyl $\left(\mathrm{C}_{\mathrm{x}}\right.$ indicates the chain length) trimethylammonium (TMA) bromide. ${ }^{\mathrm{b}}$ In nitrogen. ${ }^{\mathrm{c}}$ In air. ${ }^{\mathrm{d}}$ BJH pore size distribution. ${ }^{\mathrm{e}-\mathrm{i}}$ Chemically modified with triethanolamine (TEA); $\mathrm{H}_{2} \mathrm{O}$ :TEA $=7.4\left(\left(^{\mathrm{e}}\right), 11.1\left(^{\mathrm{f}}\right), 22.1\left(^{\mathrm{g}}\right), 34.8\left({ }^{\mathrm{h}}\right), 44.5\left(^{\mathrm{i}}\right) .{ }^{\mathrm{j}-\mathrm{o}} \mathrm{H}_{2} \mathrm{O}: \operatorname{cosolvent}=9.7\right.$ 
$\left(^{\mathrm{j}}\right), 11.9\left(^{\mathrm{k}}\right), 5.3\left({ }^{\mathrm{l}}\right), 29.7\left({ }^{\mathrm{m}}\right), 7.5\left({ }^{\mathrm{n}}\right), 0.4\left({ }^{\mathrm{o}}\right) .{ }^{\mathrm{p}-\mathrm{r}}$ Small amount of formamide added; formamide:Al $=0.1\left({ }^{\mathrm{p}}\right), 0.2\left({ }^{\mathrm{q}}\right), 0.45\left({ }^{\mathrm{r}}\right) .{ }^{\mathrm{s}}$ Addition of ammonium hydroxide and thermal decomposition of urea. ${ }^{\mathrm{t}}$ Addition of $\mathrm{NaOH} ; \mathrm{pH}$ not reported. ${ }^{\mathrm{u}}$ Addition of ammonium hydroxide. ${ }^{\mathrm{v}}$ Addition of hydrochloric acid. ${ }^{\mathrm{w}}$ Bimodal distribution: meso- and macropores. ${ }^{\mathrm{x}}$ From the $\mathrm{N}_{2}$ isotherm adsorption branch. ${ }^{\mathrm{y}}$ Mean pore diameter 
TABLE 3. Organized mesoporous aluminas templated by non-ionic $\left(\mathrm{N}^{0}\right)$ diblock copolymers

mesophase synthesis

\begin{tabular}{|c|c|c|c|c|c|c|c|c|c|}
\hline \multirow[t]{2}{*}{$\mathrm{Al}$ source } & \multirow[t]{2}{*}{ solvent } & \multicolumn{3}{|c|}{ surfactant } & \multirow[t]{2}{*}{$\mathrm{H}_{2} \mathrm{O}: \mathrm{Al}$} & \multirow[t]{2}{*}{$\mathrm{N}^{\mathrm{o}}: \mathrm{Al}$} & \multirow{2}{*}{$\begin{array}{l}\text { temp. } \\
{ }^{o} \mathrm{C}\end{array}$} & \multirow[t]{2}{*}{$\mathrm{pH}$} & \multirow{2}{*}{$\begin{array}{l}\text { ageing } \\
{ }^{o} C(h)\end{array}$} \\
\hline & & name & $\mathrm{n}^{\mathrm{a}}$ & HLB $^{b}$ & & & & & \\
\hline $\mathrm{Na}$ aluminate & water & Tergitol 15-S-5 & 5 & 10.6 & & 0.57 & 25 & $\mathrm{r}$ & $100(48)$ \\
\hline $\mathrm{Na}$ aluminate & water & Tergitol 15-S-7 & 7 & 12.0 & & 0.24 & 25 & r & $100(48)$ \\
\hline $\mathrm{Na}$ aluminate & water & Tergitol 15-S-7 & 7 & 12.0 & & 0.47 & 25 & $\mathrm{r}$ & $100(48)$ \\
\hline $\mathrm{Na}$ aluminate & water & Tergitol 15-S-7 & 7 & 12.0 & & 0.95 & 25 & $\mathrm{r}$ & $100(48)$ \\
\hline $\mathrm{Na}$ aluminate & water & Tergitol 15-S-7 & 7 & 12.0 & & 1.95 & 25 & r & $100(48)$ \\
\hline $\mathrm{Na}$ aluminate & water & Tergitol 15-S-7 & 7 & 12.0 & & 0.24 & 25 & $\mathrm{r}$ & $100(48)$ \\
\hline $\mathrm{Na}$ aluminate & water & Tergitol 15-S-7 & 7 & 12.0 & & 0.47 & 25 & $\mathrm{r}$ & $100(48)$ \\
\hline $\mathrm{Na}$ aluminate & water & Tergitol 15-S-7 & 7 & 12.0 & & 0.95 & 25 & $\mathrm{r}$ & $100(48)$ \\
\hline $\mathrm{Na}$ aluminate & water & Tergitol 15-S-7 & 7 & 12.0 & & 1.95 & 25 & r & $100(48)$ \\
\hline $\mathrm{Na}$ aluminate & water & Tergitol 15-S-9 & 9 & 13.6 & & 0.4 & 25 & $\mathrm{r}$ & $100(48)$ \\
\hline $\mathrm{Na}$ aluminate & water & Tergitol 15-S-12 & 12 & 14.3 & & 0.33 & 25 & r & $100(48)$ \\
\hline nitrate & water & Tergitol 15-S-12 & 12 & 14.3 & & 0.015 & 70 & $8^{s}$ & $100(24)$ \\
\hline nitrate & water & Tergitol 15-S-15 & 15 & 15.1 & & 0.015 & 70 & $8^{s}$ & $100(24)$ \\
\hline nitrate & water & Tergitol 15-S-20 & 20 & 16.3 & & 0.015 & 70 & $8^{\mathrm{s}}$ & $100(24)$ \\
\hline
\end{tabular}

template removal

textural properties

solvent decomposition $^{\mathrm{c}}$ calcination $^{\mathrm{c}}$

extraction temp. time ramp temp. time ramp $S_{\text {BET }}$ pore vol. pore size ${ }^{d}$ Ref.

${ }^{\circ} \mathrm{C} \quad h \quad{ }^{\circ} \mathrm{C} / \mathrm{min} \quad{ }^{\circ} \mathrm{C} \quad h \quad{ }^{\circ} \mathrm{C} / \mathrm{min} \quad \mathrm{m}^{2} / \mathrm{g} \quad \mathrm{cm}^{3} / \mathrm{g} \quad \mathrm{nm}$

\begin{tabular}{lllllllll}
\hline 500 & 20 & 2 & 371 & 1.89 & & $(78)$ \\
500 & 20 & 2 & 360 & 1.41 & & $(78)$ \\
500 & 20 & 2 & 376 & 1.62 & 12.0 & $(78)$ \\
500 & 20 & 2 & 347 & 1.95 & 15.0 & $(78)$ \\
500 & 20 & 2 & 373 & 1.19 & & $(78)$ \\
900 & 3 & & 179 & 1.13 & & $(78)$ \\
900 & 3 & & 199 & 1.41 & & $(78)$ \\
900 & 3 & & 189 & 1.55 & & $(78)$ \\
900 & 3 & & 184 & 1.13 & & $(78)$ \\
500 & 20 & 2 & 360 & 1.63 & & $(78)$ \\
500 & 20 & 2 & 352 & 1.67 & & $(78)$ \\
500 & 4 & & 254 & 0.39 & $5.5^{\mathrm{y}}$ & $(81)$ \\
500 & 4 & & 320 & 0.47 & $5.3^{\mathrm{y}}$ & $(81)$ \\
500 & 4 & & 302 & 0.47 & $6.0^{\mathrm{y}}$ & $(81)$ \\
& & & & & & \\
\\
500
\end{tabular}




\begin{tabular}{|c|c|c|c|c|c|c|c|c|c|c|c|c|c|c|c|c|c|c|c|c|}
\hline \multirow{3}{*}{ Al source } & \multirow{3}{*}{ solvent } & \multirow{2}{*}{\multicolumn{3}{|c|}{ surfactant }} & \multirow{3}{*}{$\mathrm{H}_{2} \mathrm{O}: \mathrm{Al}$} & \multirow{3}{*}{$\mathrm{N}^{\mathrm{o}}: \mathrm{Al}$} & \multirow{3}{*}{$\begin{array}{l}\text { temp. } \\
{ }^{o} \mathrm{C}\end{array}$} & \multirow{3}{*}{$\mathrm{pH}$} & \multirow{3}{*}{$\begin{array}{l}\text { ageing } \\
{ }^{o} C(h)\end{array}$} & \multirow{3}{*}{$\begin{array}{l}\text { solvent } \\
\text { extraction }\end{array}$} & \multicolumn{3}{|c|}{ decomposition $^{c}$} & \multicolumn{3}{|c|}{ calcination $^{\mathrm{c}}$} & \multirow{2}{*}{\multicolumn{2}{|c|}{$\mathrm{S}_{\mathrm{BET}}$ pore vol. }} & \multirow{3}{*}{ pore size ${ }^{\mathrm{d}}$} & \multirow{3}{*}{ Ref. } \\
\hline & & & & & & & & & & & temp. & time & ramp & temp & time & ramp & & & & \\
\hline & & name & $\mathrm{n}^{\mathrm{a}}$ & $\mathrm{HLB}^{\mathrm{b}}$ & & & & & & & ${ }^{\circ} \mathrm{C}$ & $h$ & ${ }^{\circ} \mathrm{C} / \mathrm{min}$ & ${ }^{\circ} \mathrm{C}$ & $h$ & ${ }^{\circ} \mathrm{C} / \mathrm{min}$ & $\mathrm{m}^{2} / \mathrm{g}$ & $\mathrm{cm}^{3} / \mathrm{g}$ & & \\
\hline nitrate & water & Tergitol 15-S-30 & 30 & 17.0 & & 0.015 & 70 & $8^{s}$ & $100(24)$ & & & & & 500 & 4 & & 297 & 0.43 & $6.0^{y}$ & $(81)$ \\
\hline sec-butoxide & water & Brij 56 & 10 & 13.0 & & 0.5 & 70 & $\mathrm{t}$ & $80(24)$ & ethanol $^{\mathrm{w}}$ & & & & & & & 381 & 0.68 & $3.0^{\mathrm{z}}$ & $(83)$ \\
\hline sec-butoxide & water & Brij 56 & 10 & 13.0 & & 0.5 & 70 & $\mathrm{t}$ & $80(24)$ & ethanol $^{\mathrm{w}}$ & & & & 300 & 1 & & 400 & 0.74 & $3.0^{\mathrm{z}}$ & $(83)$ \\
\hline sec-butoxide & water & Brij 56 & 10 & 13.0 & & 0.5 & 70 & $\mathrm{t}$ & $80(24)$ & ethanol $^{\mathrm{w}}$ & & & & 400 & 1 & & 428 & 0.79 & $3.0^{\mathrm{z}}$ & $(83)$ \\
\hline sec-butoxide & water & Brij 56 & 10 & 13.0 & & 0.5 & 70 & $\mathrm{t}$ & $80(24)$ & ethanol $^{\mathrm{w}}$ & & & & 500 & 1 & & 424 & 1.01 & $8.8^{\mathrm{z}}$ & $(83)$ \\
\hline sec-butoxide & water & Brij 56 & 10 & 13.0 & & 0.5 & 70 & $\mathrm{t}$ & $80(0.5)^{\mathrm{v}}$ & ethanol ${ }^{\mathrm{w}}$ & & & & & & & 469 & 0.92 & $4.7^{z}$ & $(83)$ \\
\hline sec-butoxide & water & Brij 56 & 10 & 13.0 & & 0.5 & 70 & $\mathrm{t}$ & $80(0.5)^{\mathrm{v}}$ & ethanol ${ }^{\mathrm{w}}$ & & & & 300 & 1 & & 454 & 1.02 & $5.9^{z}$ & $(83)$ \\
\hline sec-butoxide & water & Brij 56 & 10 & 13.0 & & 0.5 & 70 & $\mathrm{t}$ & $80(0.5)^{\mathrm{v}}$ & ethanol $^{\mathrm{w}}$ & & & & 400 & 1 & & 684 & 1.50 & $6.4^{\mathrm{z}}$ & $(83)$ \\
\hline sec-butoxide & water & Brij 56 & 10 & 13.0 & & 0.5 & 70 & $\mathrm{t}$ & $80(0.5)^{\mathrm{v}}$ & ethanol $^{\mathrm{w}}$ & & & & 500 & 1 & & 435 & 0.98 & $7.2^{z}$ & (83) \\
\hline chloride & ethanol & KLE-type & 86 & 11.5 & 23.2 & 0.007 & 25 & u & $25(360)$ & & 300 & 12 & 50 & 700 & 0,5 & 5 & 403 & 0.56 & $13^{z ; \S}$ & (63) \\
\hline chloride & ethanol & KLE-type & 86 & 11.5 & 23.2 & 0.007 & 25 & u & $25(360)$ & & 300 & 12 & 50 & 900 & 0,5 & 5 & 134 & 0.34 & $12.5^{z ; \S}$ & (63) \\
\hline sec-butoxide & 2-butanol ${ }^{1}$ & Triton X-114 & $7-8$ & 12.4 & 2 & 0.1 & 25 & & $95(6)$ & ethanol $^{\mathrm{w}}$ & & & & 550 & 4 & 2 & 521 & 0.66 & & $(42)$ \\
\hline sec-butoxide & 2-butanol ${ }^{\mathrm{m}}$ & Triton X-114 & $7-8$ & 12.4 & 2 & 0.1 & 25 & & $95(6)$ & ethanol ${ }^{\mathrm{w}}$ & & & & 550 & 4 & 2 & 518 & 0.72 & & $(42)$ \\
\hline sec-butoxide & 2-butanol ${ }^{1}$ & Triton X-114 & $7-8$ & 12.4 & 2 & 0.1 & 25 & & $95(6)$ & ethanol $^{\mathrm{w}}$ & & & & 600 & 3 & 2 & 334 & 0.60 & & $(42)$ \\
\hline sec-butoxide & 2-butanol ${ }^{\mathrm{m}}$ & Triton X-114 & $7-8$ & 12.4 & 2 & 0.1 & 25 & & $95(6)$ & ethanol $^{\mathrm{w}}$ & & & & 600 & 3 & 2 & 303 & 0.65 & & $(42)$ \\
\hline sec-butoxide & 2-butanol ${ }^{1}$ & Triton X-114 & $7-8$ & 12.4 & 2 & 0.1 & 25 & & $95(6)$ & ethanol ${ }^{\mathrm{w}}$ & & & & 700 & 3 & 2 & 242 & $\begin{array}{c}0.56 \\
\text { (cont }\end{array}$ & ed) & $(42)$ \\
\hline
\end{tabular}




\begin{tabular}{|c|c|c|c|c|c|c|c|c|c|c|c|c|c|c|c|c|c|c|c|}
\hline \multirow{3}{*}{ Al source } & \multirow{3}{*}{ solvent } & \multirow{2}{*}{\multicolumn{3}{|c|}{ surfactant }} & \multirow{3}{*}{$\mathrm{H}_{2} \mathrm{O}: \mathrm{Al}$} & \multirow{3}{*}{$\mathrm{N}^{\mathrm{o}}: \mathrm{Al}$} & \multirow{3}{*}{ temp. $\mathrm{pH}$} & \multirow{3}{*}{$\begin{array}{l}\text { ageing } \\
{ }^{o} \mathrm{C}(h)\end{array}$} & \multirow{3}{*}{$\begin{array}{c}\text { solvent } \\
\text { extraction }\end{array}$} & \multicolumn{3}{|c|}{ decomposition $^{c}$} & \multicolumn{3}{|c|}{ calcination $^{\mathrm{c}}$} & \multirow{2}{*}{\multicolumn{2}{|c|}{$\mathrm{S}_{\mathrm{BET}}$ pore vol. }} & \multirow[b]{2}{*}{ pore size ${ }^{\mathrm{d}}$} & \multirow{3}{*}{ Ref. } \\
\hline & & & & & & & & & & temp. & time & ramp & temp. & time & ramp & & & & \\
\hline & & & & & & & & & & ${ }^{\circ} \mathrm{C}$ & $h$ & ${ }^{\circ} \mathrm{C} / \mathrm{min}$ & ${ }^{\circ} \mathrm{C}$ & $h$ & ${ }^{\circ} \mathrm{C} / \min$ & $\mathrm{m}^{2} / \mathrm{g}$ & $\mathrm{cm}^{3} / \mathrm{g}$ & $n m$ & \\
\hline sec-butoxide & 2-butanol ${ }^{\mathrm{m}}$ & Triton X-114 & $7-8$ & 12.4 & 2 & 0.1 & 25 & $95(6)$ & ethanol $^{\mathrm{w}}$ & & & & 700 & 3 & 2 & 230 & 0.60 & & $(42)$ \\
\hline sec-butoxide & 2-butanol & Triton X-114 & $7-8$ & 12.4 & 2 & 0.1 & 25 & $95(6)$ & ethanol $^{\mathrm{w}}$ & & & & 700 & 3 & 2 & 267 & 0.81 & & $(42)$ \\
\hline sec-butoxide & 2-butanol & Triton X-114 & $7-8$ & 12.4 & 2 & 0.1 & 25 & $95(6)$ & ethanol ${ }^{\mathrm{w}}$ & & & & 550 & 4 & 2 & 519 & 0.88 & 5.0 & $(42,43)$ \\
\hline sec-butoxide & 2-butanol & Triton X-114 & $7-8$ & 12.4 & 2 & 0.1 & 25 & $95(6)$ & ethanol ${ }^{\mathrm{w}}$ & & & & 600 & 3 & 2 & 363 & 0.91 & 7.4 & $(42,43)$ \\
\hline sec-butoxide & 2-butanol & Triton X-114 & $7-8$ & 12.4 & 2 & 0.43 & 25 & $25(16)$ & & & & & 500 & 4 & & 460 & & 3.3 & (39) \\
\hline sec-butoxide & 2-butanol & Triton X-114 & $7-8$ & 12.4 & 2 & 0.1 & 25 & $25(24)$ & ethanol $^{\mathrm{w}}$ & 550 & 1 & 2 & 550 & 4 & 2 & 555 & 0.71 & 4.0 & (47) \\
\hline sec-butoxide & 2-butanol & Triton X-114 & $7-8$ & 12.4 & 2 & 0.1 & 25 & $95(24)$ & ethanol ${ }^{\mathrm{w}}$ & 550 & 1 & 2 & 550 & 4 & 2 & 510 & 0.71 & 3.8 & $(47)$ \\
\hline sec-butoxide & 2-butanol & Triton X-114 & $7-8$ & 12.4 & 2 & 0.1 & 25 & $25(24)$ & ethanol $^{\mathrm{w}}$ & 550 & 1 & 2 & 600 & 3 & 2 & 345 & 0.68 & 5.7 & (47) \\
\hline sec-butoxide & 2-butanol & Triton X-114 & $7-8$ & 12.4 & 2 & 0.1 & 25 & $95(24)$ & ethanol $^{\mathrm{w}}$ & 550 & 1 & 2 & 600 & 3 & 2 & 350 & 0.76 & 5.9 & (47) \\
\hline sec-butoxide & 2-butanol ${ }^{\mathrm{n}}$ & Triton X-114 & $7-8$ & 12.4 & 2 & 0.1 & 25 & $95(6)$ & ethanol ${ }^{\mathrm{w}}$ & & & & 550 & 4 & 2 & 480 & & 5.2 & (43) \\
\hline sec-butoxide & 2-butanol ${ }^{\circ}$ & Triton X-114 & $7-8$ & 12.4 & 2 & 0.1 & 25 & $95(6)$ & ethanol ${ }^{\mathrm{w}}$ & & & & 550 & 4 & 2 & 510 & & 6.0 & (43) \\
\hline sec-butoxide & 2-butanol ${ }^{p}$ & Triton X-114 & $7-8$ & 12.4 & 2 & 0.1 & 25 & $95(6)$ & ethanol w & & & & 550 & 4 & 2 & 500 & & 4.5 & (43) \\
\hline sec-butoxide & 2-butanol ${ }^{\mathrm{q}}$ & Triton X-114 & $7-8$ & 12.4 & 2 & 0.1 & 25 & $95(6)$ & ethanol ${ }^{\mathrm{w}}$ & & & & 550 & 4 & 2 & 530 & & 4.5 & $(43)$ \\
\hline sec-butoxide & 2-butanol ${ }^{\mathrm{n}}$ & Triton X-114 & $7-8$ & 12.4 & 2 & 0.1 & 25 & $95(6)$ & ethanol ${ }^{\mathrm{w}}$ & & & & 600 & 3 & 2 & 330 & & 6.6 & (43) \\
\hline sec-butoxide & 2-butanol ${ }^{o}$ & Triton X-114 & $7-8$ & 12.4 & 2 & 0.1 & 25 & $95(6)$ & ethanol $^{\mathrm{w}}$ & & & & 600 & 3 & 2 & 415 & & 6.7 & $(43)$ \\
\hline sec-butoxide & 2-butanol ${ }^{\mathrm{p}}$ & Triton X-114 & $7-8$ & 12.4 & 2 & 0.1 & 25 & $95(6)$ & ethanol ${ }^{\mathrm{w}}$ & & & & 600 & 3 & 2 & 330 & & 5.7 & $(43)$ \\
\hline
\end{tabular}




\begin{tabular}{|c|c|c|c|c|c|c|c|c|c|c|c|c|c|c|c|c|c|c|c|}
\hline \multirow{3}{*}{ Al source } & \multirow{3}{*}{ solvent } & \multirow{2}{*}{\multicolumn{3}{|c|}{ surfactant }} & \multirow{3}{*}{$\mathrm{H}_{2} \mathrm{O}: \mathrm{Al}$} & \multirow{3}{*}{$\mathrm{N}^{\mathrm{o}}: \mathrm{Al}$} & \multirow{3}{*}{ temp. $\mathrm{pH}$} & \multirow{3}{*}{$\begin{array}{l}\text { ageing } \\
{ }^{o} \mathrm{C}(h)\end{array}$} & \multirow{3}{*}{$\begin{array}{l}\text { solvent } \\
\text { extraction }\end{array}$} & \multicolumn{3}{|c|}{ decomposition $^{c}$} & \multicolumn{3}{|c|}{ calcination $^{\mathrm{c}}$} & \multirow{2}{*}{\multicolumn{2}{|c|}{$\mathrm{S}_{\mathrm{BET}}$ pore vol. }} & \multirow[b]{2}{*}{ pore size ${ }^{d}$} & \multirow{3}{*}{ Ref. } \\
\hline & & & & & & & & & & temp. & time & ramp & temp. & time & ramp & & & & \\
\hline & & & & & & & & & & ${ }^{\circ} \mathrm{C}$ & $h$ & ${ }^{\circ} \mathrm{C} / \mathrm{min}$ & ${ }^{\circ} \mathrm{C}$ & $h$ & ${ }^{\circ} \mathrm{C} / \mathrm{min}$ & $\mathrm{m}^{2} / \mathrm{g}$ & $\mathrm{cm}^{3} / \mathrm{g}$ & $n m$ & \\
\hline sec-butoxide & 2-butanol ${ }^{\mathrm{q}}$ & Triton X-114 & $7-8$ & 12.4 & 2 & 0.1 & 25 & $95(6)$ & ethanol $^{\mathrm{w}}$ & & & & 600 & 3 & 2 & 350 & & 6.5 & $(43)$ \\
\hline sec-butoxide ${ }^{\mathrm{e}}$ & 2-butanol & Triton X-114 & $7-8$ & 12.4 & 2 & 0.1 & 25 & $95(24)$ & ethanol $^{\mathrm{w}}$ & 550 & 1 & 2 & 550 & 4 & 2 & 530 & 0.39 & $3.0^{\mu, \$}$ & $(52)$ \\
\hline sec-butoxide ${ }^{f}$ & 2-butanol & Triton X-114 & $7-8$ & 12.4 & 2 & 0.1 & 25 & $115(24)$ & ethanol w $^{\mathrm{w}}$ & 550 & 1 & 2 & 550 & 4 & 2 & 285 & 0.13 & $\mu$ & $(52)$ \\
\hline sec-butoxide ${ }^{\mathrm{g}}$ & 2-butanol & Triton X-114 & $7-8$ & 12.4 & 2 & 0.1 & 25 & $95(24)$ & ethanol w $^{\mathrm{w}}$ & 550 & 1 & 2 & 550 & 4 & 2 & 110 & 0.07 & $\mu$ & $(52)$ \\
\hline sec-butoxide ${ }^{\mathrm{e}}$ & 2-butanol & Triton X-114 & $7-8$ & 12.4 & 2 & 0.1 & 25 & $95(24)$ & ethanol $^{\mathrm{w}}$ & 550 & 1 & 2 & 600 & 3 & 2 & 350 & 0.39 & $3.5^{\mu, \$}$ & $(52)$ \\
\hline sec-butoxide ${ }^{f}$ & 2-butanol & Triton X-114 & $7-8$ & 12.4 & 2 & 0.1 & 25 & $95(24)$ & ethanol $^{\mathrm{w}}$ & 550 & 1 & 2 & 600 & 3 & 2 & 280 & 0.23 & $3.5^{\mu, \$}$ & $(52)$ \\
\hline sec-butoxide ${ }^{f}$ & 2-butanol & Triton X-114 & $7-8$ & 12.4 & 2 & 0.1 & 25 & $115(24)$ & ethanol $^{\mathrm{w}}$ & 550 & 1 & 2 & 600 & 3 & 2 & 220 & 0.23 & $3.2^{\mu, *}$ & $(52)$ \\
\hline sec-butoxide ${ }^{\mathrm{g}}$ & 2-butanol & Triton X-114 & $7-8$ & 12.4 & 2 & 0.1 & 25 & $95(24)$ & ethanol $^{\mathrm{w}}$ & 550 & 1 & 2 & 600 & 3 & 2 & 220 & 0.22 & $3.2^{\mu, \$}$ & $(52)$ \\
\hline sec-butoxide ${ }^{f}$ & 2-butanol & Triton X-114 & $7-8$ & 12.4 & 2 & 0.1 & 25 & $95(24)$ & ethanol $^{\mathrm{w}}$ & 550 & 1 & 2 & 550 & 4 & 2 & 325 & 0.15 & $\mu$ & $(47)$ \\
\hline sec-butoxide ${ }^{\mathrm{h}}$ & 2-butanol & Triton X-114 & $7-8$ & 12.4 & 2 & 0.1 & 25 & $25(24)$ & ethanol $^{\mathrm{w}}$ & 550 & 1 & 2 & 550 & 4 & 2 & 550 & 0.49 & $3.5^{\mu, *}$ & $(52)$ \\
\hline sec-butoxide i & 2-butanol & Triton X-114 & $7-8$ & 12.4 & 2 & 0.1 & 25 & $25(24)$ & ethanol $^{\mathrm{w}}$ & 550 & 1 & 2 & 550 & 4 & 2 & 325 & 0.33 & $3.5^{\mu, \$}$ & $(52)$ \\
\hline sec-butoxide ${ }^{\mathrm{h}}$ & 2-butanol & Triton X-114 & $7-8$ & 12.4 & 2 & 0.1 & 25 & $95(24)$ & ethanol $^{\mathrm{w}}$ & 550 & 1 & 2 & 550 & 4 & 2 & 515 & 0.75 & $4.0^{\mu, *}$ & $(52)$ \\
\hline sec-butoxide i & 2-butanol & Triton X-114 & $7-8$ & 12.4 & 2 & 0.1 & 25 & $95(24)$ & ethanol $^{\mathrm{w}}$ & 550 & 1 & 2 & 550 & 4 & 2 & 460 & 0.52 & $3.5^{\mu, \sharp}$ & $(52)$ \\
\hline sec-butoxide ${ }^{h}$ & 2-butanol & Triton X-114 & $7-8$ & 12.4 & 2 & 0.1 & 25 & $25(24)$ & ethanol $^{\mathrm{w}}$ & 550 & 1 & 2 & 600 & 3 & 2 & 365 & 0.47 & $4.0^{\mu}$ & $(52)$ \\
\hline sec-butoxide ${ }^{\mathrm{h}}$ & 2-butanol & Triton X-114 & $7-8$ & 12.4 & 2 & 0.1 & 25 & $95(24)$ & ethanol $^{\mathrm{w}}$ & 550 & 1 & 2 & 600 & 3 & 2 & 355 & 0.75 & $6.4^{\mu, \sharp}$ & $(52)$ \\
\hline sec-butoxide $^{j}$ & 2-butanol & Triton X-114 & $7-8$ & 12.4 & 2 & 0.1 & 25 & $25(24)$ & ethanol $^{\mathrm{w}}$ & 550 & 1 & 2 & 550 & 4 & 2 & 505 & 0.32 & $\begin{array}{l}3.0^{\mu,:} \\
\mathrm{ed})\end{array}$ & $(52)$ \\
\hline
\end{tabular}




\begin{tabular}{|c|c|c|c|c|c|c|c|c|c|c|c|c|c|c|c|c|c|c|c|}
\hline \multirow{3}{*}{ Al source } & \multirow{3}{*}{ solvent } & \multirow{2}{*}{\multicolumn{3}{|c|}{ surfactant }} & \multirow{3}{*}{$\mathrm{H}_{2} \mathrm{O}: \mathrm{Al}$} & \multirow{3}{*}{$\mathrm{N}^{\mathrm{o}}: \mathrm{Al}$} & \multirow{3}{*}{ temp. $\mathrm{pH}$} & \multirow{3}{*}{$\begin{array}{l}\text { ageing } \\
{ }^{o} \mathrm{C}(h)\end{array}$} & \multirow{3}{*}{$\begin{array}{c}\text { solvent } \\
\text { extraction }\end{array}$} & \multicolumn{3}{|c|}{ decomposition $^{c}$} & \multicolumn{3}{|c|}{ calcination $^{\mathrm{c}}$} & \multirow[b]{2}{*}{$\mathrm{S}_{\mathrm{BET}}$} & \multirow[b]{2}{*}{ pore vol } & \multirow[b]{2}{*}{ pore size $^{d}$} & \multirow{3}{*}{ def. } \\
\hline & & & & & & & & & & temp. & time & ramp & temp. & time & ramp & & & & \\
\hline & & & & & & & & & & ${ }^{\circ} \mathrm{C}$ & $h$ & ${ }^{\circ} \mathrm{C} / \mathrm{min}$ & ${ }^{\circ} \mathrm{C}$ & $h$ & ${ }^{\circ} \mathrm{C} / \mathrm{min}$ & $m^{2} / g$ & $\mathrm{~cm}^{3} / \mathrm{g}$ & $n m$ & \\
\hline sec-butoxide ${ }^{j}$ & 2-butanol & Triton X-114 & $7-8$ & 12.4 & 2 & 0.1 & 25 & $95(24)$ & ethanol $^{\mathrm{w}}$ & 550 & 1 & 2 & 550 & 4 & 2 & 280 & 0.27 & $3.5^{\mu, \$}$ & (52) \\
\hline sec-butoxide ${ }^{k}$ & 2-butanol & Triton X-114 & $7-8$ & 12.4 & 2 & 0.1 & 25 & $95(24)$ & ethanol $^{\mathrm{w}}$ & 550 & 1 & 2 & 550 & 4 & 2 & 290 & 0.13 & $\mu$ & $(52)$ \\
\hline sec-butoxide ${ }^{j}$ & 2-butanol & Triton X-114 & $7-8$ & 12.4 & 2 & 0.1 & 25 & $25(24)$ & ethanol $^{\mathrm{w}}$ & 550 & 1 & 2 & 600 & 3 & 2 & 335 & 0.31 & $3.4^{\mu, \$}$ & $(52)$ \\
\hline sec-butoxide ${ }^{j}$ & 2-butanol & Triton X-114 & $7-8$ & 12.4 & 2 & 0.1 & 25 & $95(24)$ & ethanol $^{\mathrm{w}}$ & 550 & 1 & 2 & 600 & 3 & 2 & 295 & 0.36 & $4.0^{\mu, *}$ & (52) \\
\hline sec-butoxide ${ }^{k}$ & 2-butanol & Triton X-114 & $7-8$ & 12.4 & 2 & 0.1 & 25 & $25(24)$ & ethanol $^{\mathrm{w}}$ & 550 & 1 & 2 & 550 & 4 & 2 & 290 & 0.13 & $\mu$ & $(47)$ \\
\hline sec-butoxide & 2-butanol & Triton X-100 & $9-10$ & 13.5 & 2 & 0.53 & 25 & $25(16)$ & & & & & 500 & 4 & & 445 & & 3.6 & (39) \\
\hline sec-butoxide & 2-butanol & Tergitol 15-S-9 & 9 & 13.6 & 2 & 0.5 & 25 & $25(16)$ & & & & & 500 & 4 & & 490 & & 3.3 & (39) \\
\hline sec-butoxide & 2-butanol & Tergitol 15-S-9 & 9 & 13.6 & 2 & 0.1 & 25 & $25(24)$ & ethanol ${ }^{\mathrm{w}}$ & 550 & 1 & 2 & 550 & 4 & 2 & 485 & 0.56 & 3.8 & $(47)$ \\
\hline sec-butoxide & 2-butanol & Tergitol 15-S-9 & 9 & 13.6 & 2 & 0.1 & 25 & $25(24)$ & ethanol ${ }^{\mathrm{w}}$ & 550 & 1 & 2 & 600 & 3 & 2 & 335 & 0.64 & 5.8 & $(47)$ \\
\hline sec-butoxide & 2-butanol & Tergitol 15-S-9 & 9 & 13.6 & 2 & 0.1 & 25 & $95(6)$ & ethanol $^{\mathrm{w}}$ & & & & 550 & 4 & 2 & 420 & 0.70 & & $(42)$ \\
\hline sec-butoxide & 2-butanol & Tergitol 15-S-9 & 9 & 13.6 & 2 & 0.1 & 25 & $95(6)$ & ethanol $^{\mathrm{w}}$ & & & & 550 & 4 & 2 & 484 & 0.81 & 5.1 & $(42,43)$ \\
\hline sec-butoxide & 2-butanol & Tergitol 15-S-9 & 9 & 13.6 & 2 & 0.1 & 25 & $95(24)$ & ethanol $^{\mathrm{w}}$ & 550 & 1 & 2 & 550 & 4 & 2 & 515 & 0.64 & 3.9 & $(47)$ \\
\hline sec-butoxide & 2-butanol & Tergitol 15-S-9 & 9 & 13.6 & 2 & 0.1 & 25 & $95(6)$ & ethanol $^{\mathrm{w}}$ & & & & 600 & 3 & 2 & 312 & 0.71 & & $(42)$ \\
\hline sec-butoxide & 2-butanol & Tergitol 15-S-9 & 9 & 13.6 & 2 & 0.1 & 25 & $95(6)$ & ethanol ${ }^{\mathrm{w}}$ & & & & 600 & 3 & 2 & 326 & 0.77 & 7.4 & $(42,43)$ \\
\hline sec-butoxide & 2-butanol & Tergitol 15-S-9 & 9 & 13.6 & 2 & 0.1 & 25 & $95(24)$ & ethanol ${ }^{\mathrm{w}}$ & 550 & 1 & 2 & 600 & 3 & 2 & 380 & 0.68 & 5.2 & $(47)$ \\
\hline sec-butoxide & 2-butanol & Tergitol 15-S-9 & 9 & 13.6 & 2 & 0.1 & 25 & $95(6)$ & ethanol ${ }^{\mathrm{w}}$ & & & & 700 & 3 & 2 & 244 & $\begin{array}{r}0.72 \\
\text { (cont }\end{array}$ & ed) & $(42)$ \\
\hline
\end{tabular}




solvent decomposition ${ }^{c} \quad$ calcination $^{c}$

\begin{tabular}{|c|c|c|c|c|c|c|c|c|c|c|c|c|c|c|c|c|c|c|c|}
\hline Al source & solvent & surfac & & & $\mathrm{H}_{2} \mathrm{O}: \mathrm{Al}$ & $\mathrm{N}^{\mathrm{o}}: \mathrm{Al}$ & temp. $\mathrm{pH}$ & ageing & extraction & temp. & time & ramp & temp. & time & ramp & $\mathrm{S}_{\mathrm{BET}}$ & pore vol. & pore size $^{\mathrm{d}}$ & Ref. \\
\hline & & & & & & & ${ }^{\circ} \mathrm{C}$ & ${ }^{\circ} \mathrm{C}(h)$ & & ${ }^{\circ} \mathrm{C}$ & $h$ & ${ }^{\circ} \mathrm{C} / \mathrm{min}$ & ${ }^{\circ} \mathrm{C}$ & $h$ & ${ }^{o} \mathrm{C} / \mathrm{min}$ & $\mathrm{m}^{2} / \mathrm{g}$ & $\mathrm{cm}^{3} / \mathrm{g}$ & $n m$ & \\
\hline sec-butoxide & 2-butanol ${ }^{1}$ & Tergitol 15-S-9 & 9 & 13.6 & 2 & 0.1 & 25 & $95(6)$ & ethanol $^{\mathrm{w}}$ & & & & 550 & 4 & 2 & 512 & 0.72 & & (42) \\
\hline sec-butoxide & 2-butanol ${ }^{1}$ & Tergitol 15-S-9 & 9 & 13.6 & 2 & 0.1 & 25 & $95(6)$ & ethanol $^{\mathrm{w}}$ & & & & 550 & 4 & 2 & 534 & 0.80 & & (42) \\
\hline sec-butoxide & 2-butanol ${ }^{1}$ & Tergitol 15-S-9 & 9 & 13.6 & 2 & 0.1 & 25 & $95(6)$ & ethanol ${ }^{\mathrm{w}}$ & & & & 600 & 3 & 2 & 317 & 0.64 & & (42) \\
\hline sec-butoxide & 2-butanol ${ }^{1}$ & Tergitol 15-S-9 & 9 & 13.6 & 2 & 0.1 & 25 & $95(6)$ & ethanol $^{\mathrm{w}}$ & & & & 600 & 3 & 2 & 315 & 0.66 & & (42) \\
\hline sec-butoxide & 2-butanol ${ }^{1}$ & Tergitol 15-S-9 & 9 & 13.6 & 2 & 0.1 & 25 & $95(6)$ & ethanol $^{\mathrm{w}}$ & & & & 700 & 3 & 2 & 236 & 0.61 & & (42) \\
\hline sec-butoxide & 2-butanol ${ }^{1}$ & Tergitol 15-S-9 & 9 & 13.6 & 2 & 0.1 & 25 & $95(6)$ & ethanol $^{\mathrm{w}}$ & & & & 700 & 3 & 2 & 243 & 0.65 & & (42) \\
\hline sec-butoxide & 2-butanol ${ }^{\mathrm{m}}$ & Tergitol 15-S-9 & 9 & 13.6 & 2 & 0.1 & 25 & $95(6)$ & ethanol $^{\mathrm{w}}$ & & & & 550 & 4 & 2 & 465 & 0.69 & & (42) \\
\hline sec-butoxide & 2-butanol ${ }^{\mathrm{m}}$ & Tergitol 15-S-9 & 9 & 13.6 & 2 & 0.1 & 25 & $95(6)$ & ethanol $^{\mathrm{w}}$ & & & & 550 & 4 & 2 & 480 & 0.62 & & $(42)$ \\
\hline sec-butoxide & 2-butanol ${ }^{\mathrm{m}}$ & Tergitol 15-S-9 & 9 & 13.6 & 2 & 0.1 & 25 & $95(6)$ & ethanol $^{\mathrm{w}}$ & & & & 600 & 3 & 2 & 306 & 0.61 & & (42) \\
\hline sec-butoxide & 2-butanol ${ }^{\mathrm{m}}$ & Tergitol 15-S-9 & 9 & 13.6 & 2 & 0.1 & 25 & $95(6)$ & ethanol $^{\mathrm{w}}$ & & & & 600 & 3 & 2 & 320 & 0.57 & & (42) \\
\hline sec-butoxide & 2-butanol ${ }^{\mathrm{m}}$ & Tergitol 15-S-9 & 9 & 13.6 & 2 & 0.1 & 25 & $95(6)$ & ethanol $^{\mathrm{w}}$ & & & & 700 & 3 & 2 & 229 & 0.57 & & (42) \\
\hline sec-butoxide & 2-butanol ${ }^{\mathrm{m}}$ & Tergitol 15-S-9 & 9 & 13.6 & 2 & 0.1 & 25 & $95(6)$ & ethanol ${ }^{\mathrm{w}}$ & & & & 700 & 3 & 2 & 237 & 0.53 & & (42) \\
\hline sec-butoxide & 2-butanol ${ }^{\circ}$ & Tergitol 15-S-9 & 9 & 13.6 & 2 & 0.1 & 25 & $95(6)$ & ethanol $^{\mathrm{w}}$ & & & & 550 & 4 & 2 & 565 & & 5.0 & (43) \\
\hline sec-butoxide & 2-butanol ${ }^{\mathrm{q}}$ & Tergitol 15-S-9 & 9 & 13.6 & 2 & 0.1 & 25 & $95(6)$ & ethanol $^{\mathrm{w}}$ & & & & 550 & 4 & 2 & 535 & & 4.2 & (43) \\
\hline sec-butoxide & 2-butanol ${ }^{\circ}$ & Tergitol 15-S-9 & 9 & 13.6 & 2 & 0.1 & 25 & $95(6)$ & ethanol $^{\mathrm{w}}$ & & & & 600 & 3 & 2 & 380 & & 6.5 & (43) \\
\hline sec-butoxide & 2-butanol ${ }^{\mathrm{q}}$ & Tergitol 15-S-9 & 9 & 13.6 & 2 & 0.1 & 25 & $95(6)$ & ethanol ${ }^{\mathrm{w}}$ & & & & 600 & 3 & 2 & 375 & & 5.3 & (43) \\
\hline
\end{tabular}




\begin{tabular}{|c|c|c|c|c|c|c|c|c|c|c|c|c|c|c|c|c|c|c|c|}
\hline \multirow{3}{*}{ Al source } & \multirow{3}{*}{ solvent } & \multirow{2}{*}{\multicolumn{3}{|c|}{ surfactant }} & \multirow{3}{*}{$\mathrm{H}_{2} \mathrm{O}: \mathrm{Al}$} & \multirow{3}{*}{$\mathrm{N}^{\mathrm{o}}: \mathrm{Al}$} & \multirow{3}{*}{ temp. $\mathrm{pH}$} & \multirow{3}{*}{$\begin{array}{l}\text { ageing } \\
{ }^{o} \mathrm{C}(h)\end{array}$} & \multirow{3}{*}{$\begin{array}{l}\text { solvent } \\
\text { extraction }\end{array}$} & \multicolumn{3}{|c|}{ decomposition $^{c}$} & \multicolumn{3}{|c|}{ calcination $^{\mathrm{c}}$} & \multirow{2}{*}{\multicolumn{2}{|c|}{$\mathrm{S}_{\mathrm{BET}}$ pore vol. }} & \multirow[b]{2}{*}{ pore size ${ }^{d}$} & \multirow{3}{*}{ Ref. } \\
\hline & & & & & & & & & & temp. & time & ramp & temp. & time & ramp & & & & \\
\hline & & & & & & & & & & ${ }^{\circ} \mathrm{C}$ & $h$ & ${ }^{\circ} \mathrm{C} / \mathrm{min}$ & ${ }^{\circ} \mathrm{C}$ & $h$ & ${ }^{\circ} \mathrm{C} / \mathrm{min}$ & $\mathrm{m}^{2} / \mathrm{g}$ & $\mathrm{cm}^{3} / \mathrm{g}$ & $n m$ & \\
\hline sec-butoxide ${ }^{f}$ & 2-butanol & Tergitol 15-S-9 & 9 & 13.6 & 2 & 0.1 & 25 & $95(24)$ & ethanol ${ }^{\mathrm{w}}$ & 550 & 1 & 2 & 550 & 4 & 2 & 305 & 0.14 & $\mu$ & (47) \\
\hline sec-butoxide ${ }^{f}$ & 2-butanol & Tergitol 15-S-9 & 9 & 13.6 & 2 & 0.1 & 25 & $95(24)$ & ethanol $^{\mathrm{w}}$ & 550 & 1 & 2 & 600 & 3 & 2 & 205 & 0.19 & $3.2^{\mu, \sharp}$ & $(52)$ \\
\hline sec-butoxide & 2-butanol & Tergitol 15-S-12 & 12 & 14.3 & 3 & 0.4 & 25 & $45(40)$ & & & & & 500 & 6 & & 391 & 0.48 & 5.0 & $(40)$ \\
\hline sec-butoxide & 2-butanol & Tergitol 15-S-12 & 12 & 14.3 & 2 & 0.4 & 25 & $25(16)$ & & & & & 500 & 4 & & 425 & & 3.5 & (39) \\
\hline sec-butoxide & 2-butanol & Tergitol 15-S-12 & 12 & 14.3 & 2.2 & 0.1 & 25 & & 2-butanol ${ }^{\mathrm{x}}$ & & & & 540 & 6 & 1 & 285 & 0.53 & 6.7 & $(60)$ \\
\hline sec-butoxide & 2-butanol & Tergitol 15-S-12 & 12 & 14.3 & 2.2 & 0.1 & 25 & & & & & & 540 & 6 & 1 & 287 & 0.54 & 5.5 & $(60)$ \\
\hline sec-butoxide & 2-butanol & Tergitol 15-S-12 & 12 & 14.3 & 3 & 0.4 & 25 & $45(40)$ & & & & & 600 & & & 267 & 0.31 & 5.5 & $(40)$ \\
\hline sec-butoxide & 2-butanol & Igepal RC-760 & 18 & 15.0 & 2 & 0.28 & 25 & $25(16)$ & & & & & 500 & 4 & & 420 & & 4.7 & (39) \\
\hline sec-butoxide & 2-butanol & Tergitol 15-S-15 & 15 & 15.1 & 2 & 0.1 & 25 & $25(24)$ & ethanol ${ }^{\mathrm{w}}$ & 550 & 1 & 2 & 550 & 4 & 2 & 520 & 0.62 & 3.9 & (47) \\
\hline sec-butoxide & 2-butanol & Tergitol 15-S-15 & 15 & 15.1 & 2 & 0.1 & 25 & $95(24)$ & ethanol ${ }^{\mathrm{w}}$ & 550 & 1 & 2 & 550 & 4 & 2 & 540 & 0.64 & 3.8 & (47) \\
\hline sec-butoxide & 2-butanol & Tergitol 15-S-15 & 15 & 15.1 & 2 & 0.1 & 25 & $25(24)$ & ethanol ${ }^{\mathrm{w}}$ & 550 & 1 & 2 & 600 & 3 & 2 & 380 & 0.65 & 5.2 & (47) \\
\hline sec-butoxide & 2-butanol & Tergitol 15-S-15 & 15 & 15.1 & 2 & 0.1 & 25 & $95(24)$ & ethanol ${ }^{\mathrm{w}}$ & 550 & 1 & 2 & 600 & 3 & 2 & 330 & 0.67 & 6.0 & (47) \\
\hline sec-butoxide ${ }^{f}$ & 2-butanol & Tergitol 15-S-15 & 15 & 15.1 & 2 & 0.1 & 25 & $95(24)$ & ethanol ${ }^{\mathrm{w}}$ & 550 & 1 & 2 & 550 & 4 & 2 & 310 & 0.14 & $\mu$ & $(47)$ \\
\hline sec-butoxide & 2-butanol & Tergitol 15-S-20 & 20 & 16.3 & 2 & 0.28 & 25 & $25(16)$ & & & & & 500 & 4 & & 535 & & 4.6 & (39) \\
\hline sec-butoxide & 1,4-dioxane & Triton X-114 & $7-8$ & 12.4 & 2 & 0.1 & 25 & $25(24)$ & ethanol $^{\mathrm{w}}$ & 550 & 1 & 2 & 550 & 4 & 2 & 550 & 0.44 & 3.5 & (47) \\
\hline sec-butoxide & 1,4-dioxane & Triton X-114 & $7-8$ & 12.4 & 2 & 0.1 & 25 & $95(24)$ & ethanol ${ }^{\mathrm{w}}$ & 550 & 1 & 2 & 550 & 4 & 2 & 490 & 0.51 & 3.5 & $(47)$ \\
\hline
\end{tabular}




\begin{tabular}{|c|c|c|c|c|c|c|c|c|c|c|c|c|c|c|c|c|c|c|c|}
\hline \multirow{3}{*}{ Al source } & \multirow{3}{*}{ solvent } & \multirow{2}{*}{\multicolumn{3}{|c|}{ surfactant }} & \multirow{3}{*}{$\mathrm{H}_{2} \mathrm{O}: \mathrm{Al}$} & \multirow{3}{*}{$\mathrm{N}^{\mathrm{o}}: \mathrm{Al}$} & \multirow{3}{*}{ temp. $\mathrm{pH}$} & \multirow{3}{*}{$\begin{array}{l}\text { ageing } \\
{ }^{o} \mathrm{C}(h)\end{array}$} & \multirow{3}{*}{$\begin{array}{l}\text { solvent } \\
\text { extraction }\end{array}$} & \multicolumn{3}{|c|}{ decomposition $^{c}$} & \multicolumn{3}{|c|}{ calcination $^{c}$} & \multirow{2}{*}{\multicolumn{2}{|c|}{$\mathrm{S}_{\mathrm{BET}}$ pore vol. }} & \multirow[b]{2}{*}{ pore size ${ }^{d}$} & \multirow{3}{*}{ Ref. } \\
\hline & & & & & & & & & & temp. & time & ramp & temp. & time & ramp & & & & \\
\hline & & & & & & & & & & ${ }^{\circ} \mathrm{C}$ & $h$ & ${ }^{\circ} \mathrm{C} / \mathrm{min}$ & ${ }^{\circ} \mathrm{C}$ & $h$ & ${ }^{\circ} \mathrm{C} / \mathrm{min}$ & $\mathrm{m}^{2} / \mathrm{g}$ & $\mathrm{cm}^{3} / \mathrm{g}$ & $n m$ & \\
\hline sec-butoxide & 1,4-dioxane & Triton X-114 & $7-8$ & 12.4 & 2 & 0.1 & 25 & $25(24)$ & ethanol $^{\mathrm{w}}$ & 550 & 1 & 2 & 600 & 3 & 2 & 370 & 0.50 & 4.1 & $(47)$ \\
\hline sec-butoxide & 1,4-dioxane & Triton X-114 & $7-8$ & 12.4 & 2 & 0.1 & 25 & $95(24)$ & ethanol ${ }^{\mathrm{w}}$ & 550 & 1 & 2 & 600 & 3 & 2 & 350 & 0.60 & 4.2 & $(47)$ \\
\hline sec-butoxide ${ }^{f}$ & 1,4-dioxane & Triton X-114 & $7-8$ & 12.4 & 2 & 0.1 & 25 & $95(24)$ & ethanol $^{\mathrm{w}}$ & 550 & 1 & 2 & 600 & 3 & 2 & 210 & 0.22 & $3.2^{\mu, \$}$ & $(52)$ \\
\hline sec-butoxide ${ }^{f}$ & 1,4-dioxane & Triton X-114 & $7-8$ & 12.4 & 2 & 0.1 & 25 & $95(24)$ & ethanol $^{\mathrm{w}}$ & 550 & 1 & 2 & 550 & 4 & 2 & 290 & 0.13 & $\mu$ & $(47)$ \\
\hline sec-butoxide & 1,4-dioxane & Tergitol 15-S-9 & 9 & 13.6 & 2 & 0.1 & 25 & $25(24)$ & ethanol ${ }^{\mathrm{w}}$ & 550 & 1 & 2 & 550 & 4 & 2 & 500 & 0.75 & 4.8 & $(47)$ \\
\hline sec-butoxide & 1,4-dioxane & Tergitol 15-S-9 & 9 & 13.6 & 2 & 0.1 & 25 & $95(24)$ & ethanol $^{\mathrm{w}}$ & 550 & 1 & 2 & 550 & 4 & 2 & 525 & 0.71 & 4.0 & $(47)$ \\
\hline sec-butoxide & 1,4-dioxane & Tergitol 15-S-9 & 9 & 13.6 & 2 & 0.1 & 25 & $25(24)$ & ethanol $^{\mathrm{w}}$ & 550 & 1 & 2 & 600 & 3 & 2 & 350 & 0.76 & 6.5 & $(47)$ \\
\hline sec-butoxide & 1,4-dioxane & Tergitol 15-S-9 & 9 & 13.6 & 2 & 0.1 & 25 & $95(24)$ & ethanol $^{\mathrm{w}}$ & 550 & 1 & 2 & 600 & 3 & 2 & 355 & 0.72 & 5.8 & $(47)$ \\
\hline sec-butoxide ${ }^{f}$ & 1,4-dioxane & Tergitol 15-S-9 & 9 & 13.6 & 2 & 0.1 & 25 & $95(24)$ & ethanol ${ }^{\mathrm{w}}$ & 550 & 1 & 2 & 600 & 3 & 2 & 225 & 0.24 & $3.2^{\mu, *}$ & $(52)$ \\
\hline sec-butoxide ${ }^{f}$ & 1,4-dioxane & Tergitol 15-S-9 & 9 & 13.6 & 2 & 0.1 & 25 & $95(24)$ & ethanol ${ }^{\mathrm{w}}$ & 550 & 1 & 2 & 550 & 4 & 2 & 360 & 0.16 & $\mu$ & (47) \\
\hline sec-butoxide & 1,4-dioxane & Tergitol 15-S-15 & 15 & 15.1 & 2 & 0.1 & 25 & $25(24)$ & ethanol $^{\mathrm{w}}$ & 550 & 1 & 2 & 550 & 4 & 2 & 445 & 0.78 & 5.2 & $(47)$ \\
\hline sec-butoxide & 1,4-dioxane & Tergitol 15-S-15 & 15 & 15.1 & 2 & 0.1 & 25 & $95(24)$ & ethanol $^{\mathrm{w}}$ & 550 & 1 & 2 & 550 & 4 & 2 & 510 & 0.71 & 4.5 & $(47)$ \\
\hline sec-butoxide & 1,4-dioxane & Tergitol 15-S-15 & 15 & 15.1 & 2 & 0.1 & 25 & $25(24)$ & ethanol $^{\mathrm{w}}$ & 550 & 1 & 2 & 600 & 3 & 2 & 355 & 0.85 & 7.1 & $(47)$ \\
\hline sec-butoxide & 1,4-dioxane & Tergitol 15-S-15 & 15 & 15.1 & 2 & 0.1 & 25 & $95(24)$ & ethanol ${ }^{\mathrm{w}}$ & 550 & 1 & 2 & 600 & 3 & 2 & 375 & 0.74 & 6.0 & (47) \\
\hline sec-butoxide ${ }^{f}$ & 1,4-dioxane & Tergitol 15-S-15 & 15 & 15.1 & 2 & 0.1 & 25 & $95(24)$ & ethanol ${ }^{\mathrm{w}}$ & 550 & 1 & 2 & 550 & 4 & 2 & 400 & 0.19 & & $(47)$ \\
\hline sec-butoxide & none & Brij-type & 2 & 5.3 & 2 & 0.5 & 25 & $150(72)$ & & & & & 500 & 4 & & 445 & 0.73 & 3.0 & $(85)$ \\
\hline
\end{tabular}


${ }^{a}$ Diblock copolymers R-(EO) : R stands for hydrophobic hydrocarbon tail and (EO) $)_{\mathrm{n}}$ for hydrophilic poly(ethylene oxide) chain. ${ }^{\mathrm{b}}$ Hydrophiliclipophilic balance: $\mathrm{HLB}=\mathrm{wt} \%\left[(\mathrm{EO})_{\mathrm{n}}\right] / 5 .{ }^{\mathrm{c}}$ Decomposition in nitrogen and calcination in air. ${ }^{\mathrm{d}} \mathrm{BJH}$ pore size distribution. ${ }^{\mathrm{e}-\mathrm{g}}$ Chemically modified with ethyl acetoacetate; modifier:Al $=0.1\left({ }^{\mathrm{e}}\right), 0.5\left({ }^{\mathrm{f}}\right), 0.8\left({ }^{\mathrm{g}}\right) .{ }^{\mathrm{h}-\mathrm{i}}$ Chemically modified with ethyleneglycol; modifier:Al $=0.1\left({ }^{\mathrm{h}}\right), 0.35\left({ }^{\mathrm{i}}\right) .{ }^{\mathrm{j}-\mathrm{k}}$ Chemically modified with triethanolamine; modifier: $\mathrm{Al}=0.1\left({ }^{\mathrm{j}}\right), 0.2\left({ }^{\mathrm{k}}\right) \cdot{ }^{\mathrm{l}-\mathrm{q}}$ Small amount of amine added: dipropylamine $\left({ }^{\mathrm{l}, \mathrm{m}}\right)$, propylamine $\left({ }^{\mathrm{n}}\right)$, hexylamine $\left({ }^{\mathrm{o}}\right)$, dodecylamine $\left({ }^{\mathrm{p}}\right)$, hexadecylamine $\left({ }^{\mathrm{q}}\right)$; amine:Al $=0.1\left({ }^{1, \mathrm{n}-\mathrm{q}}\right), 0.25\left({ }^{\mathrm{m}}\right) \cdot{ }^{\mathrm{r}}$ Addition of acetic acid; $\mathrm{pH}$ not reported. ${ }^{\mathrm{s}}$ Addition of ammonium hydroxide. ${ }^{\mathrm{t}}$ Addition of sulfuric acid; $\mathrm{pH}$ not reported. ${ }^{\mathrm{u}}$ Addition of ammonium hydroxide; $\mathrm{pH}$ not reported. ${ }^{\mathrm{v}}$ Microwave heating. ${ }^{\mathrm{w}}$ Soxhlet extraction. ${ }^{\mathrm{x}}$ Washed with 2-butanol. ${ }^{\mathrm{y}}$ From the $\mathrm{N}_{2}$ isotherms desorption branch. Contains micropores. ${ }^{\mathrm{z}}$ From the $\mathrm{N}_{2}$ isotherms desorption branch. ${ }^{\mu}$ Contains micropores. ${ }^{\ddagger}$ Mean pore diameter. ${ }^{\S} 3 \mathrm{D}$ ordered structure. 
TABLE 4. Organized mesoporous aluminas templated by non-ionic $\left(\mathrm{N}^{\circ}\right)$ triblock copolymers

mesophase synthesis

\begin{tabular}{|c|c|c|c|c|c|c|c|c|c|}
\hline \multirow[t]{2}{*}{ Al source } & \multirow[t]{2}{*}{ solvent } & \multicolumn{3}{|c|}{ surfactant $^{\mathrm{a}}$} & \multirow[t]{2}{*}{$\mathrm{H}_{2} \mathrm{O}: \mathrm{Al}$} & \multicolumn{2}{|c|}{$\mathrm{N}^{\mathrm{o}}:$ Al temp. } & \multirow[t]{2}{*}{$\mathrm{pH}$} & \multirow{2}{*}{$\begin{array}{l}\text { ageing } \\
{ }^{\circ} \mathrm{C}(h)\end{array}$} \\
\hline & & name & & HLB & & & ${ }^{\circ} \mathrm{C}$ & & \\
\hline nitrate & water & Pluronic P-123 & $(\mathrm{EO})_{20}(\mathrm{PO})_{70}(\mathrm{EO})_{20}$ & 8 & & 0,015 & 40 & $8^{d}$ & $100(24)$ \\
\hline nitrate & water & Pluronic P-84 & $(\mathrm{EO})_{19}(\mathrm{PO})_{39}(\mathrm{EO})_{19}$ & 14 & & 0,015 & 70 & $8^{d}$ & \\
\hline nitrate & water & Pluronic P-84 & $(\mathrm{EO})_{19}(\mathrm{PO})_{39}(\mathrm{EO})_{19}$ & 14 & & 0,015 & 70 & $8^{d}$ & $100(24)$ \\
\hline chloride & water & Pluronic P-84 & $(\mathrm{EO})_{19}(\mathrm{PO})_{39}(\mathrm{EO})_{19}$ & 14 & & 0,015 & 70 & $8^{d}$ & $100(24)$ \\
\hline chloride & water & Pluronic P-84 & $(\mathrm{EO})_{19}(\mathrm{PO})_{39}(\mathrm{EO})_{19}$ & 14 & & 0,015 & 70 & $8^{d}$ & \\
\hline nitrate & water & Pluronic $64 \mathrm{~L}$ & $(\mathrm{EO})_{13}(\mathrm{PO})_{30}(\mathrm{EO})_{13}$ & 15 & & 0,015 & 50 & $8^{d}$ & $100(24)$ \\
\hline nitrate & water & Pluronic P-65 & $(\mathrm{EO})_{19}(\mathrm{PO})_{30}(\mathrm{EO})_{19}$ & 17 & & 0,015 & 70 & $8^{d}$ & $100(24)$ \\
\hline chloride & water & Pluronic P-84 & $(\mathrm{EO})_{19}(\mathrm{PO})_{39}(\mathrm{EO})_{19}$ & 14 & & & 80 & e & $100(24)$ \\
\hline Al13 Keggin & water & Pluronic P-84 & $(\mathrm{EO})_{19}(\mathrm{PO})_{39}(\mathrm{EO})_{19}$ & 14 & 10 & 0,01 & 80 & e & $100(24)$ \\
\hline Al13 Keggin & water & Pluronic P-84 & $(\mathrm{EO})_{19}(\mathrm{PO})_{39}(\mathrm{EO})_{19}$ & 14 & & 0,011 & 70 & $8^{d}$ & $100(24)$ \\
\hline Al13 Keggin & water & Pluronic P-84 & $(\mathrm{EO})_{19}(\mathrm{PO})_{39}(\mathrm{EO})_{19}$ & 14 & & 0,011 & 45 & $8^{d}$ & \\
\hline Al13 Keggin & water & Pluronic P-84 & $(\mathrm{EO})_{19}(\mathrm{PO})_{39}(\mathrm{EO})_{19}$ & 14 & & 0,011 & 60 & $8^{d}$ & \\
\hline Al13 Keggin & water & Pluronic P-84 & $(\mathrm{EO})_{19}(\mathrm{PO})_{39}(\mathrm{EO})_{19}$ & 14 & & 0,011 & 70 & $8^{d}$ & \\
\hline Al13 Keggin & water & Pluronic P-84 & $(\mathrm{EO})_{19}(\mathrm{PO})_{39}(\mathrm{EO})_{19}$ & 14 & & 0,011 & 90 & $8^{d}$ & \\
\hline
\end{tabular}

template removal

textural properties

solvent calcination $^{\mathrm{b}}$

extraction temp. time ramp $\mathrm{S}_{\mathrm{BET}}$ pore vol. pore size $^{\mathrm{c}}$ Ref. ${ }^{\circ} \mathrm{C} \quad h \quad{ }^{\circ} \mathrm{C} / \mathrm{min} \quad \mathrm{m}^{2} / \mathrm{g} \quad \mathrm{Cm}^{3} / \mathrm{g} \quad \mathrm{nm}$ 


\begin{tabular}{|c|c|c|c|c|c|c|c|c|c|c|c|c|c|c|c|c|c|}
\hline \multirow{3}{*}{ Al source } & \multirow{3}{*}{ solvent } & & \multirow{3}{*}{ surfactant $^{\text {a }}$} & & \multirow{3}{*}{$\mathrm{H}_{2} \mathrm{O}: \mathrm{Al}$} & \multirow{3}{*}{$\mathrm{N}^{\mathrm{o}}: \mathrm{Al}$} & \multirow{3}{*}{$\begin{array}{l}\text { temp. } \\
{ }^{\circ} \mathrm{C}\end{array}$} & \multirow{3}{*}{$\mathrm{pH}$} & \multirow{3}{*}{$\begin{array}{l}\text { ageing } \\
{ }^{o} \mathrm{C}(h)\end{array}$} & \multirow{3}{*}{$\begin{array}{c}\text { solvent } \\
\text { extraction }\end{array}$} & \multicolumn{3}{|c|}{ calcination $^{\mathrm{b}}$} & \multirow{3}{*}{$\begin{array}{l}\mathrm{S}_{\mathrm{BET}} \\
\mathrm{m}^{2} / \mathrm{g}\end{array}$} & \multirow{3}{*}{$\begin{array}{l}\text { pore vol. } \\
\qquad \mathrm{cm}^{3} / \mathrm{g}\end{array}$} & \multirow{3}{*}{$\begin{array}{c}\text { pore size }{ }^{c} \\
n m\end{array}$} & \multirow{3}{*}{ Ref. } \\
\hline & & & & & & & & & & & temp. & time & ramp & & & & \\
\hline & & & & & & & & & & & ${ }^{\circ} \mathrm{C}$ & $h$ & ${ }^{\circ} \mathrm{C} / \mathrm{min}$ & & & & \\
\hline A113 Keggin & water & Pluronic $64 \mathrm{~L}$ & $(\mathrm{EO})_{13}(\mathrm{PO})_{30}(\mathrm{EO})_{13}$ & 15 & & 0,016 & 70 & $8^{d}$ & $100(24)$ & & 500 & 4 & & 307 & 0,53 & $5,1^{\mathrm{m}}$ & (81) \\
\hline Al13 Keggin & water & Pluronic 64 L & $(\mathrm{EO})_{13}(\mathrm{PO})_{30}(\mathrm{EO})_{13}$ & 15 & & 0,016 & 70 & $8^{\mathrm{d}}$ & & & $550^{\mathrm{k}}$ & 4 & & 310 & 0,57 & $5,1^{\mathrm{m}}$ & (81) \\
\hline Al13 Keggin & water & Pluronic 64 L & $(\mathrm{EO})_{13}(\mathrm{PO})_{30}(\mathrm{EO})_{13}$ & 15 & & & 80 & e & $100(24)$ & & $550^{\mathrm{k}}$ & 4 & & 307 & 0,53 & $4,4^{\mathrm{m}}$ & (80) \\
\hline A113 Keggin & water & Pluronic P-65 & $(\mathrm{EO})_{19}(\mathrm{PO})_{30}(\mathrm{EO})_{19}$ & 17 & & 0,014 & 70 & $8^{d}$ & $100(24)$ & & 500 & 4 & & 309 & 0,73 & $5,8^{\mathrm{m}}$ & (81) \\
\hline A113 Keggin & water & Pluronic P-65 & $(\mathrm{EO})_{19}(\mathrm{PO})_{30}(\mathrm{EO})_{19}$ & 17 & & 0,014 & 70 & $8^{d}$ & & & $550^{\mathrm{k}}$ & 4 & & 319 & 0,53 & $6,1^{\mathrm{m}}$ & $(81)$ \\
\hline tert-butoxide & ethanol & Pluronic P-123 & $(\mathrm{EO})_{20}(\mathrm{PO})_{70}(\mathrm{EO})_{20}$ & 8 & 6 & 0,017 & 40 & f & $40(72)$ & & $400^{1}$ & 4 & 1,5 & 410 & 0,80 & 6,7 & (61) \\
\hline chloride & ethanol & Pluronic P-123 & $(\mathrm{EO})_{20}(\mathrm{PO})_{70}(\mathrm{EO})_{20}$ & 8 & & 0,02 & 25 & & 40 & & 400 & 5 & & 300 & 0,61 & 14,0 & (56) \\
\hline sec-butoxide & 2-butanol & Pluronic P-123 & $(\mathrm{EO})_{20}(\mathrm{PO})_{70}(\mathrm{EO})_{20}$ & 8 & 2,2 & 0,12 & 25 & & 25 & 2-butanol ${ }^{\mathrm{g}}$ & 540 & 6 & 1 & 451 & 1,32 & 8,5 & (60) \\
\hline sec-butoxide & 2-butanol & Pluronic P-123 & $(\mathrm{EO})_{20}(\mathrm{PO})_{70}(\mathrm{EO})_{20}$ & 8 & 2,2 & 0,12 & 25 & & 25 & 2-butanol ${ }^{g}$ & 540 & 6 & 1 & 431 & 1,36 & 8,9 & (60) \\
\hline sec-butoxide & 2-butanol & Pluronic P-123 & $(\mathrm{EO})_{20}(\mathrm{PO})_{70}(\mathrm{EO})_{20}$ & 8 & 2,2 & 0,12 & 25 & & 25 & & 540 & 6 & 1 & 385 & 1,20 & 7,8 & $(60)$ \\
\hline sec-butoxide & 2-butanol & Pluronic P-123 & $(\mathrm{EO})_{20}(\mathrm{PO})_{70}(\mathrm{EO})_{20}$ & 8 & 2,2 & 0,12 & 25 & & 25 & & 540 & 6 & 1 & 450 & 1,26 & 7,7 & $(60)$ \\
\hline sec-butoxide & 2-butanol & Pluronic P-123 & $(\mathrm{EO})_{20}(\mathrm{PO})_{70}(\mathrm{EO})_{20}$ & 8 & 2,2 & 0,12 & 25 & & 25 & water $^{\mathrm{h}}$ & 540 & 6 & 1 & 389 & 0,90 & 5,7 & $(60)$ \\
\hline sec-butoxide & 2-butanol & Pluronic P-123 & $(\mathrm{EO})_{20}(\mathrm{PO})_{70}(\mathrm{EO})_{20}$ & 8 & & & 80 & & $100(24)$ & & $550^{\mathrm{k}}$ & 4 & & 370 & 1,51 & $13.0^{\mathrm{m}}$ & $(80)$ \\
\hline sec-butoxide & 2-butanol & Pluronic P-84 & $(\mathrm{EO})_{19}(\mathrm{PO})_{39}(\mathrm{EO})_{19}$ & 14 & & & 80 & & $100(24)$ & & $550^{\mathrm{k}}$ & 4 & & 306 & 1,15 & $9.0^{\mathrm{m}}$ & $(80)$ \\
\hline sec-butoxide & butanol & Pluronic 64 L & $(\mathrm{EO})_{13}(\mathrm{PO})_{30}(\mathrm{EO})_{13}$ & 15 & 2 & 0,1 & 25 & & $25(16)$ & & 500 & 4 & 5 & 470 & 1,10 & $8,7^{\mathrm{n}}$ & $(58)$ \\
\hline sec-butoxide & butanol & Pluronic 64 L & $(\mathrm{EO})_{13}(\mathrm{PO})_{30}(\mathrm{EO})_{13}$ & 15 & 2 & 0,1 & 25 & & $25(16)$ & & 500 & 6 & 5 & 390 & 1,00 & $10.0^{\mathrm{n}}$ & $(58)$ \\
\hline
\end{tabular}




\begin{tabular}{|c|c|c|c|c|c|c|c|c|c|c|c|c|c|c|c|c|}
\hline \multirow{3}{*}{ Al source } & \multirow{3}{*}{ solvent } & & \multirow{3}{*}{ surfactant $^{\text {a }}$} & & \multirow{3}{*}{$\mathrm{H}_{2} \mathrm{O}: \mathrm{Al}$} & \multirow{3}{*}{$\mathrm{N}^{\mathrm{o}}: \mathrm{Al}$} & \multirow[b]{2}{*}{ temp. $\mathrm{pH}$} & \multirow[b]{2}{*}{ ageing } & \multirow{3}{*}{$\begin{array}{c}\text { solvent } \\
\text { extraction }\end{array}$} & \multicolumn{3}{|c|}{ calcination $^{\mathrm{b}}$} & \multirow{3}{*}{$\begin{array}{l}\mathrm{S}_{\mathrm{BET}} \\
\mathrm{m}^{2} / \mathrm{g}\end{array}$} & \multirow{3}{*}{$\begin{array}{l}\text { pore vol. } \\
\qquad \mathrm{cm}^{3} / \mathrm{g}\end{array}$} & \multirow{3}{*}{$\begin{array}{c}\text { pore size }{ }^{c} \\
n m\end{array}$} & \multirow{3}{*}{ Ref. } \\
\hline & & & & & & & & & & temp. & time & ramp & & & & \\
\hline & & & & & & & ${ }^{\circ} \mathrm{C}$ & ${ }^{\circ} \mathrm{C}(h)$ & & ${ }^{\circ} \mathrm{C}$ & $h$ & ${ }^{\circ} \mathrm{C} / \mathrm{min}$ & & & & \\
\hline sec-butoxide & 2-butanol & Pluronic $64 \mathrm{~L}$ & $(\mathrm{EO})_{13}(\mathrm{PO})_{30}(\mathrm{EO})_{13}$ & 15 & 2 & 0,1 & 25 & $25(16)$ & & 500 & 4 & & 430 & & 2,4 & (39) \\
\hline sec-butoxide & butanol & Pluronic $64 \mathrm{~L}$ & $(\mathrm{EO})_{13}(\mathrm{PO})_{30}(\mathrm{EO})_{13}$ & 15 & 2 & 0,1 & 25 & $50(16)$ & & 500 & 6 & 5 & 320 & 0,65 & & $(58)$ \\
\hline sec-butoxide & butanol & Pluronic $64 \mathrm{~L}$ & $(\mathrm{EO})_{13}(\mathrm{PO})_{30}(\mathrm{EO})_{13}$ & 15 & 2 & 0,1 & 25 & $70(16)$ & & 500 & 6 & 5 & 400 & 0,84 & & $(58)$ \\
\hline sec-butoxide & butanol & Pluronic $64 \mathrm{~L}$ & $(\mathrm{EO})_{13}(\mathrm{PO})_{30}(\mathrm{EO})_{13}$ & 15 & 2 & 0,1 & 25 & $90(16)$ & & 500 & 6 & 5 & 370 & 0,63 & & $(58)$ \\
\hline sec-butoxide & butanol & Pluronic $64 \mathrm{~L}$ & $(\mathrm{EO})_{13}(\mathrm{PO})_{30}(\mathrm{EO})_{13}$ & 15 & 2 & 0,1 & 25 & $25(16)$ & & 600 & 2 & 5 & 400 & 1,00 & $9,7^{\mathrm{n}}$ & (58) \\
\hline sec-butoxide & butanol & Pluronic $64 \mathrm{~L}$ & $(\mathrm{EO})_{13}(\mathrm{PO})_{30}(\mathrm{EO})_{13}$ & 15 & 2 & 0,1 & 25 & $50(16)$ & & 600 & 2 & 5 & 390 & 0,82 & & $(58)$ \\
\hline sec-butoxide & butanol & Pluronic $64 \mathrm{~L}$ & $(\mathrm{EO})_{13}(\mathrm{PO})_{30}(\mathrm{EO})_{13}$ & 15 & 2 & 0,1 & 25 & $70(16)$ & & 600 & 2 & 5 & 450 & 0,85 & & $(58)$ \\
\hline sec-butoxide & butanol & Pluronic 64 L & $(\mathrm{EO})_{13}(\mathrm{PO})_{30}(\mathrm{EO})_{13}$ & 15 & 2 & 0,1 & 25 & $90(16)$ & & 600 & 2 & 5 & 400 & 0,63 & & $(58)$ \\
\hline sec-butoxide & butanol & Pluronic $64 \mathrm{~L}$ & $(\mathrm{EO})_{13}(\mathrm{PO})_{30}(\mathrm{EO})_{13}$ & 15 & 2 & 0,1 & 25 & $25(16)$ & & 700 & 2 & 5 & 350 & 0,97 & $10.0^{\mathrm{n}}$ & (58) \\
\hline sec-butoxide & butanol & Pluronic $64 \mathrm{~L}$ & $(\mathrm{EO})_{13}(\mathrm{PO})_{30}(\mathrm{EO})_{13}$ & 15 & 2 & 0,1 & 25 & $50(16)$ & & 700 & 2 & 5 & 360 & 0,79 & & $(58)$ \\
\hline sec-butoxide & butanol & Pluronic $64 \mathrm{~L}$ & $(\mathrm{EO})_{13}(\mathrm{PO})_{30}(\mathrm{EO})_{13}$ & 15 & 2 & 0,1 & 25 & $70(16)$ & & 700 & 2 & 5 & 360 & 0,75 & & $(58)$ \\
\hline sec-butoxide & butanol & Pluronic $64 \mathrm{~L}$ & $(\mathrm{EO})_{13}(\mathrm{PO})_{30}(\mathrm{EO})_{13}$ & 15 & 2 & 0,1 & 25 & $90(16)$ & & 700 & 2 & 5 & 330 & 0,52 & & $(58)$ \\
\hline sec-butoxide & butanol & Pluronic $64 \mathrm{~L}$ & $(\mathrm{EO})_{13}(\mathrm{PO})_{30}(\mathrm{EO})_{13}$ & 15 & 2 & 0,1 & 25 & $25(16)$ & & 800 & 2 & 5 & 300 & 0,89 & $11.0^{\mathrm{n}}$ & $(58)$ \\
\hline sec-butoxide & butanol & Pluronic 64 L & $(\mathrm{EO})_{13}(\mathrm{PO})_{30}(\mathrm{EO})_{13}$ & 15 & 2 & 0,1 & 25 & $50(16)$ & & 800 & 2 & 5 & 310 & 0,65 & & $(58)$ \\
\hline sec-butoxide & butanol & Pluronic 64 L & $(\mathrm{EO})_{13}(\mathrm{PO})_{30}(\mathrm{EO})_{13}$ & 15 & 2 & 0,1 & 25 & $70(16)$ & & 800 & 2 & 5 & 380 & 0,71 & & $(58)$ \\
\hline sec-butoxide & butanol & Pluronic $64 \mathrm{~L}$ & $(\mathrm{EO})_{13}(\mathrm{PO})_{30}(\mathrm{EO})_{13}$ & 15 & 2 & 0,1 & 25 & $90(16)$ & & 800 & 2 & 5 & 350 & 0,53 & & $(58)$ \\
\hline
\end{tabular}




\begin{tabular}{|c|c|c|c|c|c|c|c|c|c|c|c|c|c|c|c|c|c|}
\hline \multirow{3}{*}{ Al source } & \multirow{3}{*}{ solvent } & \multirow{3}{*}{\multicolumn{2}{|c|}{ surfactant ${ }^{a}$}} & & \multirow{3}{*}{$\mathrm{H}_{2} \mathrm{O}: \mathrm{Al}$} & \multirow{2}{*}{\multicolumn{2}{|c|}{$\mathrm{N}^{\mathrm{o}}$ :Al temp. }} & \multirow{3}{*}{$\mathrm{pH}$} & \multirow{3}{*}{$\begin{array}{l}\text { ageing } \\
{ }^{o} \mathrm{C}(h)\end{array}$} & \multirow{3}{*}{$\begin{array}{l}\text { solvent } \\
\text { extraction }\end{array}$} & \multicolumn{3}{|c|}{ calcination $^{\mathrm{b}}$} & \multirow{3}{*}{$\begin{array}{l}\mathrm{S}_{\mathrm{BET}} \\
\mathrm{m}^{2} / g\end{array}$} & \multirow{3}{*}{$\begin{array}{l}\text { pore vol. } \\
\mathrm{cm}^{3} / \mathrm{g}\end{array}$} & \multirow{3}{*}{$\begin{array}{c}\text { pore size }{ }^{\mathrm{c}} \\
n m\end{array}$} & \multirow{3}{*}{ Ref. } \\
\hline & & & & & & & & & & & temp. & time & ramp & & & & \\
\hline & & & & & & & ${ }^{\circ} \mathrm{C}$ & & & & ${ }^{\circ} \mathrm{C}$ & $h$ & ${ }^{\circ} \mathrm{C} / \mathrm{min}$ & & & & \\
\hline sec-butoxide & acetonitrile & Pluronic PE10400 & $(\mathrm{EO})_{25}(\mathrm{PO})_{56}(\mathrm{EO})_{25}$ & 13 & 4,1 & 0,04 & 25 & e & 25 & acetonitrile $^{i}$ & 540 & 6 & 1 & 286 & 0,58 & 6,0 & $(60)$ \\
\hline sec-butoxide & acetonitrile & Pluronic PE10400 & $(\mathrm{EO})_{25}(\mathrm{PO})_{56}(\mathrm{EO})_{25}$ & 13 & 4,1 & 0,04 & 25 & e & 25 & & 540 & 6 & 1 & 277 & 0,49 & 5,3 & $(60)$ \\
\hline sec-butoxide & acetonitrile & Pluronic PE10400 & $(\mathrm{EO})_{25}(\mathrm{PO})_{56}(\mathrm{EO})_{25}$ & 13 & 4,1 & 0,04 & 25 & e & 25 & ethanol $^{\mathrm{j}}$ & 540 & 6 & 1 & 303 & 0,57 & 5,5 & $(60)$ \\
\hline sec-butoxide & acetonitrile & Pluronic P-123 & $(\mathrm{EO})_{20}(\mathrm{PO})_{70}(\mathrm{EO})_{20}$ & 8 & 4,1 & 0,03 & 25 & e & 25 & acetonitrile $^{i}$ & 540 & 6 & 1 & 272 & 0,64 & 7,4 & $(60)$ \\
\hline sec-butoxide & acetonitrile & Pluronic P-123 & $(\mathrm{EO})_{20}(\mathrm{PO})_{70}(\mathrm{EO})_{20}$ & 8 & 4,1 & 0,03 & 25 & e & 25 & & 540 & 6 & 1 & 285 & 0,54 & 4,8 & $(60)$ \\
\hline sec-butoxide & acetonitrile & Pluronic P-123 & $(\mathrm{EO})_{20}(\mathrm{PO})_{70}(\mathrm{EO})_{20}$ & 8 & 4,1 & 0,03 & 25 & e & $120(24)$ & & 540 & 6 & 1 & 284 & 0,53 & 4,8 & $(60)$ \\
\hline sec-butoxide & acetonitrile & Pluronic P-123 & $(\mathrm{EO})_{20}(\mathrm{PO})_{70}(\mathrm{EO})_{20}$ & 8 & 4,1 & 0,03 & 25 & e & $120(24)$ & ethanol $^{\mathrm{j}}$ & 540 & 6 & 1 & 293 & 0,57 & 4,3 & $(60)$ \\
\hline
\end{tabular}

${ }^{\mathrm{a}}$ Triblock copolymers $(\mathrm{EO})_{\mathrm{n}}(\mathrm{PO})_{\mathrm{m}}(\mathrm{EO})_{\mathrm{n}}$ : $(\mathrm{EO})_{\mathrm{n}}$ stands for hydrophilic poly(ethylene oxide) chain and $(\mathrm{PO})_{\mathrm{n}}$ for hydrophobic poly(propylene oxide) chain. ${ }^{\mathrm{b}}$ In air. ${ }^{\mathrm{c}} \mathrm{BJH}$ pore size distribution. ${ }^{\mathrm{d}}$ Addition of ammonium hydroxide. ${ }^{\mathrm{e}}$ Addition of ammonium hydroxide; $\mathrm{pH}$ not reported. ${ }^{\mathrm{f}}$ Addition of hydrochloric acid; $\mathrm{pH}$ not reported. ${ }^{\mathrm{g}}$ Washed with 2-butanol. ${ }^{\mathrm{h}}$ Washed with water overnight. ${ }^{\mathrm{i}}$ Washed with acetonitrile. ${ }^{\mathrm{j}}$ Soxhlet extraction. ${ }^{\mathrm{k}}$ With a previous treatment in air at $325{ }^{\circ} \mathrm{C}$ for $3 \mathrm{~h} .{ }^{1}$ In oxygen. ${ }^{\mathrm{m}}$ From the $\mathrm{N}_{2}$ isotherm desorption branch. ${ }^{\mathrm{n}}$ Mean pore diameter. 
TABLE 5. Organized mesoporous aluminas templated by non-surfactant compounds and via nanocasting.

mesophase synthesis

\begin{tabular}{|c|c|c|c|c|c|c|c|c|}
\hline Al source & solvent & Cosolvent & template & $\mathrm{H}_{2} \mathrm{O}: \mathrm{A}$ & template:Al & temp. & $\mathrm{pH}$ & agein \\
\hline & & & & & & ${ }^{\circ} \mathrm{C}$ & & ${ }^{\circ} \mathrm{C}(\mathrm{h}$ \\
\hline pseudoboehmite & water & & DL-malic acid & 55 & 0.5 & 30 & $\mathrm{~h}$ & 100 \\
\hline pseudoboehmite & water & & tartaric acid & 55 & 0.5 & 30 & $\mathrm{~h}$ & 100 \\
\hline pseudoboehmite & water & & lactic acid & 55 & 1 & 30 & $\mathrm{~h}$ & 100 \\
\hline pseudoboehmite & water & & citric acid & 55 & 0.5 & 30 & $\mathrm{~h}$ & 100 \\
\hline pseudoboehmite & water & & citric acid & 55 & 1 & 30 & $\mathrm{~h}$ & 30 \\
\hline pseudoboehmite & water & & citric acid & 55 & 1 & 30 & $\mathrm{~h}$ & 100 \\
\hline pseudoboehmite & water & & citric acid & 55 & 1 & 30 & $\mathrm{~h}$ & 150 \\
\hline pseudoboehmite & water & & citric acid & 55 & 2 & 30 & $\mathrm{~h}$ & 100 \\
\hline pseudoboehmite & water & & citric acid & 55 & 3 & 30 & $\mathrm{~h}$ & 100 \\
\hline pseudoboehmite & water & & citric acid & 55 & 4 & 30 & $\mathrm{~h}$ & 100 \\
\hline chloride & water & & $\mathrm{C}_{8} \mathrm{mimCl}^{\mathrm{c}}$ & 48 & 0.17 & 25 & $\mathrm{i}$ & $90(72$ \\
\hline chloride & water & & $\mathrm{C}_{8} \mathrm{mimCl}^{\mathrm{c}}$ & 48 & 0.3 & 25 & $\mathrm{i}$ & $90(72$ \\
\hline chloride & water & & $\mathrm{C}_{8} \mathrm{mimCl}^{\mathrm{c}}$ & 48 & 0.08 & 25 & $\mathrm{i}$ & $90(72$ \\
\hline isopropoxide & water & & glucose & 75 & 1 & 25 & $4.5^{\mathrm{j}}$ & 100 \\
\hline
\end{tabular}

template removal

textural properties

solvent decomp. calcination $^{\mathrm{a}}$

extraction temp. time temp. time ramp $\mathrm{S}_{\mathrm{BET}}$ pore vol. pore size ${ }^{\mathrm{b}}$ Ref.

$$
{ }^{\circ} \mathrm{C} \quad h \quad{ }^{\circ} \mathrm{C} \quad h \quad{ }^{\circ} \mathrm{C} / \mathrm{min} \quad \mathrm{m}^{2} / \mathrm{g} \quad \mathrm{cm}^{3} / \mathrm{g} \quad \mathrm{nm}
$$

$\begin{array}{ccccccc}500 & 4 & 1 & 314 & 0.45 & 4.4 & (70) \\ 500 & 4 & 1 & 291 & 0.42 & 4.5 & (70) \\ 500 & 4 & 1 & 374 & 0.42 & 4 & (70) \\ 500 & 4 & 1 & 321 & 0.43 & 4 & (70) \\ 500 & 4 & 1 & 313 & 0.45 & 4.7,27^{\mathrm{n}} & (70) \\ 500 & 4 & 1 & 320 & 0.44 & 4.1 & (70) \\ 500 & 4 & 1 & 381 & 0.30 & 3.3,0.7^{\mathrm{n}, \mathrm{o}} & (70) \\ 500 & 4 & 1 & 298 & 0.32 & 4.1 & (70) \\ 500 & 4 & 1 & 266 & 0.25 & 3.3 & (70) \\ 500 & 4 & 1 & 269 & 0.30 & 5.1 & (70) \\ 560 & 12 & 1 & 269 & 0.25 & 3.8^{\mathrm{p}} & (72) \\ 560 & 12 & 1 & 262 & 0.26 & 3.9^{\mathrm{p}} & (72) \\ 560 & 12 & 1 & 226 & 0.75 & & (72) \\ 600 & 6 & & 337 & 0.43 & 3.8^{\mathrm{p}} & (71) \\ & & & & (\text { continued }) & \\ & & & & & & \\ 5\end{array}$




\begin{tabular}{|c|c|c|c|c|c|c|c|c|c|c|c|c|c|c|c|c|c|c|}
\hline \multirow{3}{*}{ Al source } & \multirow{3}{*}{ solvent } & \multirow{3}{*}{ Cosolvent } & \multirow{3}{*}{ template } & \multirow{3}{*}{$\mathrm{H}_{2} \mathrm{O}: \mathrm{Al}$} & \multirow{3}{*}{ template:Al } & \multirow{3}{*}{$\begin{array}{l}\text { temp. } \\
{ }^{o} \mathrm{C}\end{array}$} & \multirow{3}{*}{$\mathrm{pH}$} & \multirow{3}{*}{$\begin{array}{l}\text { ageing } \\
{ }^{o} C(h)\end{array}$} & \multirow{3}{*}{$\begin{array}{l}\text { solvent } \\
\text { extraction }\end{array}$} & \multicolumn{2}{|c|}{ decomp. } & \multicolumn{3}{|c|}{ calcination $^{\mathrm{a}}$} & \multirow[b]{2}{*}{$\mathrm{S}_{\mathrm{BET}}$} & \multirow[b]{2}{*}{ pore vol. } & \multirow{3}{*}{ pore size ${ }^{b}$} & \multirow{3}{*}{ Ref. } \\
\hline & & & & & & & & & & temp. & time & temp. & time & ramp & & & & \\
\hline & & & & & & & & & & ${ }^{\circ} \mathrm{C}$ & $h$ & ${ }^{\circ} \mathrm{C}$ & $h$ & ${ }^{\circ} \mathrm{C} / \mathrm{min}$ & $\mathrm{m}^{2} / \mathrm{g}$ & $\mathrm{cm}^{3} / \mathrm{g}$ & & \\
\hline isopropoxide & water & & glucose & 75 & 1 & 25 & $5.0^{j}$ & 100 & & & & 600 & 6 & & 422 & 0.66 & $5.1^{p}$ & (71) \\
\hline isopropoxide & water & & glucose & 75 & 1 & 25 & $5.5^{\mathrm{j}}$ & 100 & & & & 600 & 6 & & 378 & 0.53 & $4.4^{p}$ & (71) \\
\hline isopropoxide & water & & glucose & 75 & 1 & 25 & $5.0^{\mathrm{j}}$ & 100 & & & & 800 & 4 & & 225 & 0.51 & $7.2^{p}$ & (71) \\
\hline sec-butoxide & ethanol & & DB-L-TARH $2^{d}$ & 52 & & & & & $\mathrm{THF}^{\mathrm{k}}$ & & & 400 & 5 & 1 & 453 & 0.56 & 3.8 & (69) \\
\hline sec-butoxide & ethanol & & DB-L-TARH2 ${ }^{d}$ & 52 & & & & & $\mathrm{THF}^{\mathrm{k}}$ & & & 600 & 5 & 1 & 294 & 0.53 & 5.1 & (69) \\
\hline sec-butoxide & ethanol & & DB-L-TARH2 ${ }^{d}$ & 52 & & & & & $\mathrm{THF}^{\mathrm{k}}$ & & & 800 & 5 & 1 & 192 & 0.48 & 6.9 & (69) \\
\hline sec-butoxide & ethanol & & DB-L-TARH2 ${ }^{d}$ & 52 & & & & & $\mathrm{THF}^{\mathrm{k}}$ & & & 1000 & 5 & 1 & 134 & 0.42 & 9 & (69) \\
\hline isopropoxide & isooctane & n-propanol & PEG $200^{\mathrm{e}}$ & 300 & & 25 & & $150(24)$ & & $500^{1}$ & 2 & 500 & & & 263 & 0.86 & $11.0^{\mathrm{q}}$ & (66) \\
\hline isopropoxide & isooctane & n-propanol & PEG $200^{\mathrm{e}}$ & 300 & & 25 & & $150(24)$ & & $500^{1}$ & 2 & 500 & & & 252 & 0.32 & $3.6^{\mathrm{q}}$ & (66) \\
\hline isopropoxide & ethanol & 2-propanol & $\mathrm{PG} 4^{\mathrm{f}}$ & 2 & 1 & 40 & & $160(3)$ & & & & 600 & 6 & & 430 & & $4.7^{p}$ & (67) \\
\hline isopropoxide & ethanol & 2-propanol & PG4 ${ }^{f}$ & 2 & 1 & 40 & & $160(4.7)$ & & & & 600 & 6 & & 427 & & $5.1^{\mathrm{p}}$ & (67) \\
\hline isopropoxide & ethanol & 2-propanol & PG4 ${ }^{f}$ & 2 & 1 & 40 & & $160(6.3)$ & & & & 600 & 6 & & 420 & & $5.3^{p}$ & (67) \\
\hline isopropoxide & ethanol & 2-propanol & PG4 ${ }^{\mathrm{f}}$ & 2 & 1 & 40 & & $160(8)$ & & & & 600 & 6 & & 409 & & $5.4^{\mathrm{p}}$ & (67) \\
\hline isopropoxide & ethanol & 2-propanol & PG4 ${ }^{f}$ & 2 & 1 & 40 & & $160(10)$ & & & & 600 & 6 & & 379 & & $5.7^{\mathrm{p}}$ & (67) \\
\hline isopropoxide & ethanol & 2-propanol & PG4 ${ }^{\mathrm{f}}$ & 2 & 1 & 40 & & $120(4)$ & & & & 600 & 6 & & 526 & & $3.8^{p}$ & (67) \\
\hline isopropoxide & ethanol & 2-propanol & PG4 ${ }^{\mathrm{f}}$ & 2 & 1 & 40 & & $120(7)$ & & & & 600 & 6 & & 511 & & $4.2^{p}$ & (67) \\
\hline
\end{tabular}




\begin{tabular}{|c|c|c|c|c|c|c|c|c|c|c|c|c|c|c|c|c|c|}
\hline \multirow{3}{*}{$\mathrm{Al}$ source } & \multirow{3}{*}{ solvent } & \multirow{3}{*}{ Cosolvent } & \multirow{3}{*}{ template } & \multirow{3}{*}{$\mathrm{H}_{2} \mathrm{O}: \mathrm{Al}$} & \multirow{3}{*}{ template:Al } & \multirow{3}{*}{$\begin{array}{l}\text { temp. } \\
{ }^{\circ} \mathrm{C}\end{array}$} & \multirow{3}{*}{$\mathrm{pH}$} & \multirow{3}{*}{$\begin{array}{l}\text { ageing } \\
{ }^{\circ} \mathrm{C}(h)\end{array}$} & \multirow{3}{*}{$\begin{array}{c}\text { solvent } \\
\text { extraction }\end{array}$} & decomp. & \multicolumn{3}{|c|}{ Calcination $^{\mathrm{a}}$} & \multirow{3}{*}{$\begin{array}{l}\mathrm{S}_{\mathrm{BET}} \\
m^{2} / g\end{array}$} & \multirow{3}{*}{$\begin{array}{l}\text { pore vol. } \\
\qquad \mathrm{cm}^{3} / \mathrm{g}\end{array}$} & \multirow{3}{*}{$\begin{array}{c}\text { pore size }{ }^{b} \\
n m\end{array}$} & \multirow{3}{*}{ Ref. } \\
\hline & & & & & & & & & & temp. time & temp. & time & ramp & & & & \\
\hline & & & & & & & & & & ${ }^{\circ} \mathrm{C}$ & ${ }^{\circ} \mathrm{C}$ & $h$ & ${ }^{\circ} \mathrm{C} / \mathrm{min}$ & & & & \\
\hline isopropoxide & ethanol & 2-propanol & PG4 ${ }^{\mathrm{f}}$ & 2 & 1 & 40 & & $120(10)$ & & & 600 & 6 & & 462 & & $4.5^{p}$ & (67) \\
\hline isopropoxide & ethanol & 2-propanol & PG4 ${ }^{\mathrm{f}}$ & 2 & 1 & 40 & & $120(12)$ & & & 600 & 6 & & 451 & & $4.6^{p}$ & (67) \\
\hline isopropoxide & ethanol & 2-propanol & PG4 ${ }^{\mathrm{f}}$ & 2 & 1 & 40 & & $120(15)$ & & & 600 & 6 & & 432 & & $4.8^{p}$ & (67) \\
\hline isopropoxide & ethanol & 2-propanol & PG4 ${ }^{\mathrm{f}}$ & 2 & 1 & 40 & & $120(4)$ & & & 600 & 6 & & 468 & & $4.0^{p}$ & (67) \\
\hline isopropoxide & ethanol & 2-propanol & PG4 ${ }^{f}$ & 2 & 1 & 40 & & $120(6)$ & & & 600 & 6 & & 466 & & $4.2^{p}$ & (67) \\
\hline isopropoxide & ethanol & 2-propanol & PG4 ${ }^{\mathrm{f}}$ & 2 & 1 & 40 & & $120(9)$ & & & 600 & 6 & & 423 & & $4.8^{p}$ & (67) \\
\hline isopropoxide & ethanol & 2-propanol & PG4 ${ }^{\mathrm{f}}$ & 2 & 1 & 40 & & $120(11)$ & & & 600 & 6 & & 394 & & $5.2^{p}$ & (67) \\
\hline isopropoxide & ethanol & 2-propanol & PG4 ${ }^{f}$ & 2 & 1 & 40 & & $120(4)$ & & & 700 & 6 & & 414 & & $4.5^{p}$ & (67) \\
\hline secbutoxide & propanol & & $\mathrm{C}_{16} \mathrm{mimCl}^{\mathrm{c}}$ & 6.4 & 0.5 & 60 & 10 & $120(48)$ & & & 550 & 2 & 2 & 471 & 1.46 & 9.9 & (73) \\
\hline secbutoxide & propanol & & $\mathrm{C}_{16} \mathrm{mimCl}^{\mathrm{c}}$ & 6.4 & 0.5 & 60 & 10 & $120(48)$ & & & 700 & 2 & 2 & 401 & 1.42 & 10.5 & (73) \\
\hline secbutoxide & propanol & & $\mathrm{C}_{16} \operatorname{mimCl}^{\mathrm{c}}$ & 6.4 & 0.5 & 60 & 10 & $120(48)$ & & & 800 & 2 & 2 & 340 & 1.37 & 12.0 & (73) \\
\hline nitrate & water & & carbon aerogel & & $11.10^{\mathrm{g}}$ & & & & & & 600 & 8 & & 335 & 1.07 & $10.4,6.0^{\mathrm{n}}$ & (75) \\
\hline nitrate & water & & carbon aerogel & & $7.10^{\mathrm{g}}$ & & & & & & 600 & 8 & & 332 & 1.30 & $12.2,8.0^{\mathrm{n}}$ & (75) \\
\hline nitrate & water & & carbon aerogel & & $6.25^{\mathrm{g}}$ & & & & & & 600 & 8 & & 311 & 1.41 & $14.0,8.0^{\mathrm{n}}$ & (75) \\
\hline nitrate & water & & carbon aerogel & & $5.30^{\mathrm{g}}$ & & & & & & 600 & 8 & & 305 & 1.55 & $17.9,8.0^{\mathrm{n}}$ & (75) \\
\hline nitrate & water & & carbon aerogel & & $5.60^{\mathrm{g}}$ & & & & & & 600 & 8 & & 300 & 1.48 & $16.6,8.0^{\mathrm{n}}$ & (75) \\
\hline
\end{tabular}


Table 5 (continued)

mesophase synthesis

template removal

textural properties

\begin{tabular}{|c|c|c|c|c|c|c|c|c|c|c|c|c|c|c|c|c|}
\hline \multirow{3}{*}{ Al source } & \multirow{3}{*}{ solvent } & \multirow{3}{*}{ Cosolvent } & \multirow{3}{*}{ template } & \multirow{3}{*}{ template:Al } & \multirow{3}{*}{$\begin{array}{l}\text { temp. } \\
{ }^{o} \mathrm{C}\end{array}$} & \multirow{3}{*}{$\mathrm{pH}$} & \multirow{3}{*}{$\begin{array}{l}\text { ageing } \\
{ }^{\circ} C(h)\end{array}$} & \multirow{3}{*}{$\begin{array}{c}\text { solvent } \\
\text { extraction }\end{array}$} & \multirow{2}{*}{$\begin{array}{l}\text { decomp. } \\
\text { temp. time }\end{array}$} & \multicolumn{3}{|c|}{ Calcination $^{\mathrm{a}}$} & \multirow[b]{2}{*}{$\mathrm{S}_{\mathrm{BET}}$} & \multirow[b]{2}{*}{ pore vol. } & \multirow[b]{2}{*}{ pore size ${ }^{\mathrm{b}}$} & \multirow{3}{*}{ Ref. } \\
\hline & & & & & & & & & & temp. & time & ramp & & & & \\
\hline & & & & & & & & & ${ }^{\circ} \mathrm{C}$ & ${ }^{\circ} \mathrm{C}$ & $h$ & ${ }^{\circ} \mathrm{C} / \mathrm{min}$ & $\mathrm{m}^{2} / \mathrm{g}$ & $\mathrm{cm}^{3} / \mathrm{g}$ & $n m$ & \\
\hline nitrate & water & & carbon aerogel & $2.94^{\mathrm{g}}$ & & & & & & 600 & 8 & & 278 & 1.03 & $22.9,7.7^{\mathrm{n}}$ & $(75)$ \\
\hline nitrate & water & & carbon aerogel & $2.94^{\mathrm{g}}$ & & & & & & 600 & 8 & & 275 & 0.80 & $21.2,7.7^{\mathrm{n}}$ & $(75)$ \\
\hline nitrate & ethanol & & CMK-3 carbon & $3.20^{\mathrm{g}}$ & & $\mathrm{i}$ & & & $750^{\mathrm{m}}$ & 550 & & & 396 & 0.46 & $4.6^{\mathrm{p}, \mathrm{r}}$ & (77) \\
\hline
\end{tabular}

${ }^{\mathrm{a}}$ In air. ${ }^{\mathrm{b}} \mathrm{BJH}$ pore size distribution. ${ }^{\mathrm{c}} \mathrm{C}_{8}$ mimCl: 1-methyl-3-octylimidazolium chloride; $\mathrm{C}_{16}$ mimCl: 1-hexadecyl-3-methylimidazolium chloride. ${ }^{\mathrm{d}}$

Dibenzoyl-L-tartaric acid. ${ }^{\mathrm{e}}$ Polyethylene glycol 200. ${ }^{\mathrm{f}}$ Tetraethylene glycol. ${ }^{\mathrm{g}} \mathrm{C}$ :Al ratio. ${ }^{\mathrm{h}}$ Addition of nitric acid; $\mathrm{pH}$ not reported. ${ }^{\mathrm{i}}$ Addition of ammonium hydroxide; $\mathrm{pH}$ not reported. ${ }^{\mathrm{j}}$ Addition of nitric acid. ${ }^{\mathrm{k}}$ Soxhlet extraction with tetrahydrofuran. ${ }^{1}$ In argon. ${ }^{\mathrm{m}}$ In nitrogen. ${ }^{\mathrm{n}}$ Bimodal pore size distribution. ${ }^{\circ}$ Contains micropores. ${ }^{\mathrm{p}}$ From the $\mathrm{N}_{2}$ isotherm desorption branch. ${ }^{\mathrm{q}}$ Mean pore diameter. ${ }^{\mathrm{r}}$ 2D hexagonal arrangement of pore channels. 


\begin{tabular}{|c|c|c|c|c|c|}
\hline Substrate & \begin{tabular}{|l|}
$\mathrm{T}$ \\
solvent
\end{tabular} & Catalyst & Product & Yield $(\%) /$ reaction time & Selectivity (\%) \\
\hline 1-Decene & $\begin{array}{l}60^{\circ} \mathrm{C} \\
\text { neat }\end{array}$ & $\begin{array}{l}\text { Re/OMA3.5 } \\
\text { Re/OMA6.5 } \\
\text { Re/Condea } \\
\text { Re/Alcoa }\end{array}$ & 9-Octadecene & $\begin{array}{l}80 / 250 \mathrm{~min} \\
88 / 250 \mathrm{~min} \\
44 / 250 \mathrm{~min} \\
2.5 / 250 \mathrm{~min}\end{array}$ & $\begin{array}{c}96-98 \\
97 \\
93 \\
97 \\
\end{array}$ \\
\hline 1-Octadecene & $\begin{array}{l}60{ }^{\circ} \mathrm{C} \\
\text { neat }\end{array}$ & Re/OMA6.5 & 17-Tetratriacontene & $80 / 300 \mathrm{~min}$ & $97-98$ \\
\hline 2-Pentene & $\begin{array}{l}25^{\circ} \mathrm{C} \\
\text { neat }\end{array}$ & Re/OMA6.5 & 3-Hexene & $69 / 200 \mathrm{~min}$ & 95 \\
\hline 1,5-Hexadiene & $\begin{array}{l}25^{\circ} \mathrm{C} \\
\text { in toluene }\end{array}$ & $\begin{array}{l}\text { Re/OMA3.5 } \\
\text { Re/OMA6.5 } \\
\text { Re/Alcoa }\end{array}$ & $\begin{array}{l}\text { ADMET oligomers } \\
\mathrm{n}=2, \ldots 8 \\
\text { ADMET oligomers } \\
\mathrm{n}=2, \ldots 8 \\
\text { ADMET oligomers }\end{array}$ & $\begin{array}{l}96 / 390 \mathrm{~min} \\
95 / 300 \mathrm{~min} \\
4.2 / 300 \mathrm{~min}\end{array}$ & \\
\hline 1,9-Decadiene & $\begin{array}{l}40^{\circ} \mathrm{C} \\
\text { in toluene }\end{array}$ & $\begin{array}{l}\text { Re/OMA3.5 } \\
\text { Re/OMA6.5 } \\
\text { Re/Alcoa }\end{array}$ & $\begin{array}{l}\text { ADMET oligomers } \\
\mathrm{n}=2,3,4 \\
\text { ADMET oligomers } \\
\mathrm{n}=2,3,4 \\
\text { ADMET } \\
\text { Dimers+trimers }\end{array}$ & $\begin{array}{c}65 / 450 \mathrm{~min} \\
85 / 350 \mathrm{~min} \\
2.6 / 450\end{array}$ & $\begin{array}{l}95 \\
89\end{array}$ \\
\hline cyclooctene & $\begin{array}{l}40^{\circ} \mathrm{C} \\
\text { in toluene } \\
\end{array}$ & Re/OMA6.5 & polyoctenamer & $75 / 30 \mathrm{~min}$ & - \\
\hline
\end{tabular}


Table 7 Metathesis of oxygen containing substrates with Re(VII)oxide/mesoporous alumina catalysts

\begin{tabular}{|c|c|c|c|c|c|c|}
\hline Substrate & Conditions & Catalyst & Product & $\begin{array}{l}\mathrm{Y}(\%) / \\
\text { Reaction time (min) }\end{array}$ & Selectivity (\%) & TON \\
\hline & $\begin{array}{l}25^{\circ} \mathrm{C} \\
\text { Substrate } / \mathrm{Re}=40\end{array}$ & $\begin{array}{l}\text { Re/OMA3.5 } \\
\text { Re/OMA5 } \\
\text { Re/Condea } \\
\text { Re/Alcoa }\end{array}$ & -0 & $\begin{array}{c}59.7 / 300 \\
91.2 / 300 \\
80.3 / 300 \\
1.5 / 300\end{array}$ & $\begin{array}{l}98.5 \\
99.3 \\
99.7\end{array}$ & $\begin{array}{c}23.8 \\
36.5 \\
32.1 \\
0.6\end{array}$ \\
\hline & $\begin{array}{l}25^{\circ} \mathrm{C} \\
\text { Substrate } / \mathrm{Re}=100\end{array}$ & $\begin{array}{l}\text { Re/OMA3.5 } \\
\text { Re/OMA5 }\end{array}$ & o- & $\begin{array}{l}38.8 / 300 \\
78.5 / 300\end{array}$ & $\begin{array}{l}98.2 \\
99.8\end{array}$ & $\begin{array}{l}38.8 \\
78.5\end{array}$ \\
\hline$X_{\text {cooEt }}^{\text {COOEt }}$ & $\begin{array}{l}25^{\circ} \mathrm{C} \\
\text { Substrate } / \mathrm{Re}=40\end{array}$ & $\begin{array}{l}\text { Re/OMA3.5 } \\
\text { Re/OMA5 } \\
\text { Re/Condea } \\
\text { Re/Alcoa }\end{array}$ & t & $\begin{array}{l}52.3 / 150 \\
74.5 / 150 \\
71.5 / 150 \\
1.18 / 150\end{array}$ & $\begin{array}{l}100 \\
100 \\
100 \\
100\end{array}$ & $\begin{array}{c}20.9 \\
29.8 \\
28.6 \\
0.5\end{array}$ \\
\hline Methyl-undecenoate & $\begin{array}{l}40^{\circ} \mathrm{C} \\
\text { Substrate } / \mathrm{Re}=40\end{array}$ & Re/OMA5 & $\begin{array}{l}\mathrm{CH}-\left(\mathrm{CH}_{2}\right)_{8} \mathrm{COOCH}_{3} \\
\| \\
\mathrm{CH}-\left(\mathrm{CH}_{2}\right)_{8} \mathrm{COOCH}_{3}\end{array}$ & $40.2 / 30$ & 100 & 16.1 \\
\hline
\end{tabular}

catalyst loading 9 wt $\% \mathrm{Re}, \mathrm{Me}_{4} \mathrm{Sn} / \mathrm{Re}=1$, toluene; OMA3.5 = mesoporous alumina with pore diameter $=3.5 \mathrm{~nm}$. 
Figure captions

Figure 1. Models showing the layered structures of gibbsite $\left(\gamma-\mathrm{Al}(\mathrm{OH})_{3}\right)$ and boehmite $(\gamma-\mathrm{AlOOH}) . \mathrm{Al}, \mathrm{O}$ and $\mathrm{H}$ atoms are shown as light grey, dark grey and white spheres, respectively. Gibbsite sheets are formed by a single layer of corner sharing $\mathrm{Al}(\mathrm{OH})_{6}$ octahedra. A double layer of $\mathrm{AlO}_{4}(\mathrm{OH})_{2}$ octahedra, with $\mathrm{O}$ atoms shared by four octahedra and $\mathrm{OH}$ groups shared by two octahedra, forms the boehmite sheets. Layers are linked through H-bonding between hydroxyls (dotted lines).

Figure 2. X-ray diffraction pattern of organized mesoporous alumina after calcination at $420{ }^{\circ} \mathrm{C}(\mathrm{A}), 600{ }^{\circ} \mathrm{C}(\mathrm{B}), 800{ }^{\circ} \mathrm{C}(\mathrm{C})$, and $1000{ }^{\circ} \mathrm{C}$ (D). From ref. (29), reproduced by permission of The Royal Society of Chemistry.

Figure 3. TEM images of organized mesoporous alumina after calcination at $420{ }^{\circ} \mathrm{C}$ (A) and $1000{ }^{\circ} \mathrm{C}$ (D). From ref. (29), reproduced by permission of The Royal Society of Chemistry.

Figure 4. Possible bonding of poly (ethylene oxide) chains with the aluminum oxide hydroxide surface in a non-ionic block copolymer-templated alumina mesophase. Dotted lines show bonding of oxygen atoms of the PEO chain to coordinatively unsaturated aluminum atoms and H-bonding to hydroxyl groups.

Figure 5. Transmission electron microscopy image of a mesoporous alumina synthesized from Al sec-butoxide in 2-butanol solution, using Triton X-114 as template, and calcined at $550{ }^{\circ} \mathrm{C}$. Inset: High resolution TEM image of a selected area. Reprinted with permission from ref. (42). (C) Elsevier Science B.V.

Figure 6. Estimated surface area $\left(\mathrm{m}^{2} / \mathrm{g}\right.$ ) of a boehmite crystal (density $3.01 \mathrm{~g} / \mathrm{cm}^{3}$ ) with crystal dimensions $\mathrm{AxBxC}$. For simplicity, the $\mathrm{A} / \mathrm{C}$ crystal dimensions ratio is kept equal to the $\mathrm{a}_{0} / \mathrm{c}_{0}$ unit cell parameters ratio.

Figure 7. ${ }^{27} \mathrm{Al}$ MAS NMR spectra of aluminas synthesised in 1,4-dioxane solution using Tergitol 15-S-9 as template and Al sec-butoxide (a) and ethyl acetoacetate-modified Al sec-butoxide (b) as aluminum source. The samples were calcined at $550{ }^{\circ} \mathrm{C}$. Reprinted with permission from ref. (47). (C) Elsevier Science B.V.

Figure 8. 2-D experimental TEM images and 3-D reconstructed visual images of porous aluminas synthesized from Al sec-butoxide chemically modified with triethanolamine (A1) or ethyl acetoacetate (A2), in 2-butanol solution containing Triton X-114. Samples where calcined at $550{ }^{\circ} \mathrm{C}$ (A1 and A2) and $600{ }^{\circ} \mathrm{C}$ (A2-HT). Black color corresponds to void space and grey color to solid phase. Reprinted with permission from ref. (54). (C) Elsevier Science B.V.

Figure 9. ${ }^{27} \mathrm{Al}$ MAS NMR spectra of organized mesoporous alumina before (A) and after (B) calcination. Reprinted with permission from ref. (8). C) Elsevier Science B.V.

Figure 10. Hydrodesulfurization of thiophene over $\mathrm{MoO}_{3}$ catalyst supported on mesoporous and $\gamma$-aluminas (MA - mesoporous alumina, MA1 - pore size $3.3 \mathrm{~nm}$, MA2 - $5.5 \mathrm{~nm}, \mathrm{CIM}$ - conventional impregnation, TSM - thermal spreading method). Reprinted with permission from ref. (88). (C) Elsevier Science B.V. 
Figure 11. Comparison of metathesis activity of Re(VII) oxide supported on organized mesoporous aluminas with different pore sizes and conventional alumina in metathesis

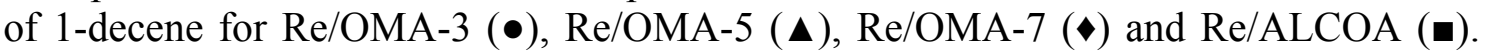
Catalyst loading $=12$ wt. $\%$ of $\mathrm{Re}$, reaction temperature $=60{ }^{\circ} \mathrm{C}$, numbers at experimental points give the reached selectivity. Reprinted with permission from ref. (94). (C) Springer.

Figure 12. 1-decene conversion vs. time curves for Re/OMA-6 catalyst with 4.5 wt. $\%$ of $\operatorname{Re}(\bullet), 9.5$ wt.\% of $\operatorname{Re}(\boldsymbol{\Delta})$ and 15 wt.\% of Re $(\diamond)$. Reaction temperature $60{ }^{\circ} \mathrm{C}$, numbers at experimental points give the reached selectivity, for 4.5 wt. $\%$ of $\mathrm{Re}$ conversion $89 \%$ and selectivity 0.95 were reached at reaction time $23 \mathrm{~h}$. Reprinted with permission from ref. (94). (C) Springer.

Figure 13. X-ray photoelectron spectra of Re in 12Re/OMA6.5 before activation (a), activated at $500{ }^{\circ} \mathrm{C}$ in argon stream for $30 \mathrm{~min}$ (b) and for $2 \mathrm{~h}$ (c). Reprinted with permission from ref. (101). (C) Elsevier Science B.V.

Figure 14. Fig. 7 Conversion curves for $p$-allylanisole with 9SMA-7-n, 9OMA-5-•, 9LMA-4) - $\mathbf{\Delta}$, 9OMA-3- $\boldsymbol{\nabla}$. Catalyst $30 \mathrm{mg}$, mol ratio $p$-allylanisole/ $\mathrm{Re} / \mathrm{Me}_{4} \mathrm{Sn}=$ 40/1/3, decane $1 \mathrm{ml}, 25{ }^{\circ} \mathrm{C}$ Reprinted with permission from ref. (103). (C) Elsevier Science B.V. 
Figure 1

Gibbsite

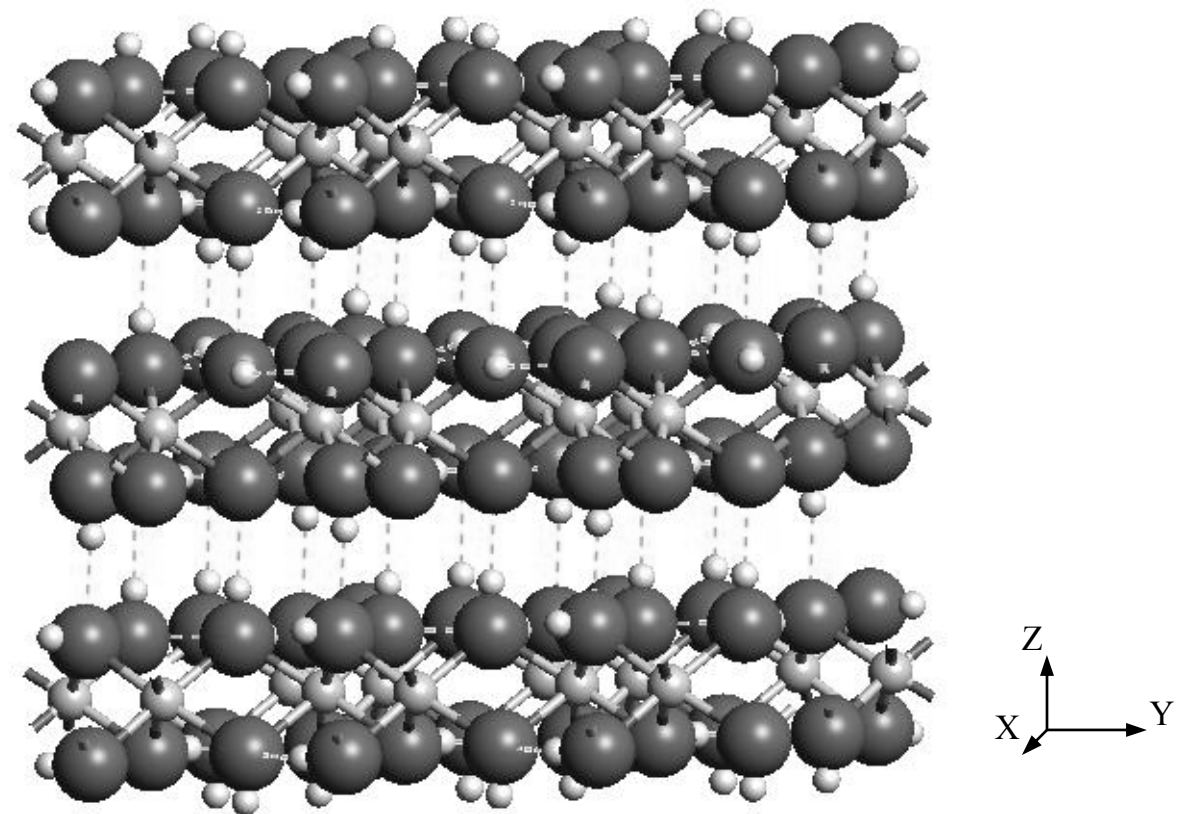

\section{Boehmite}

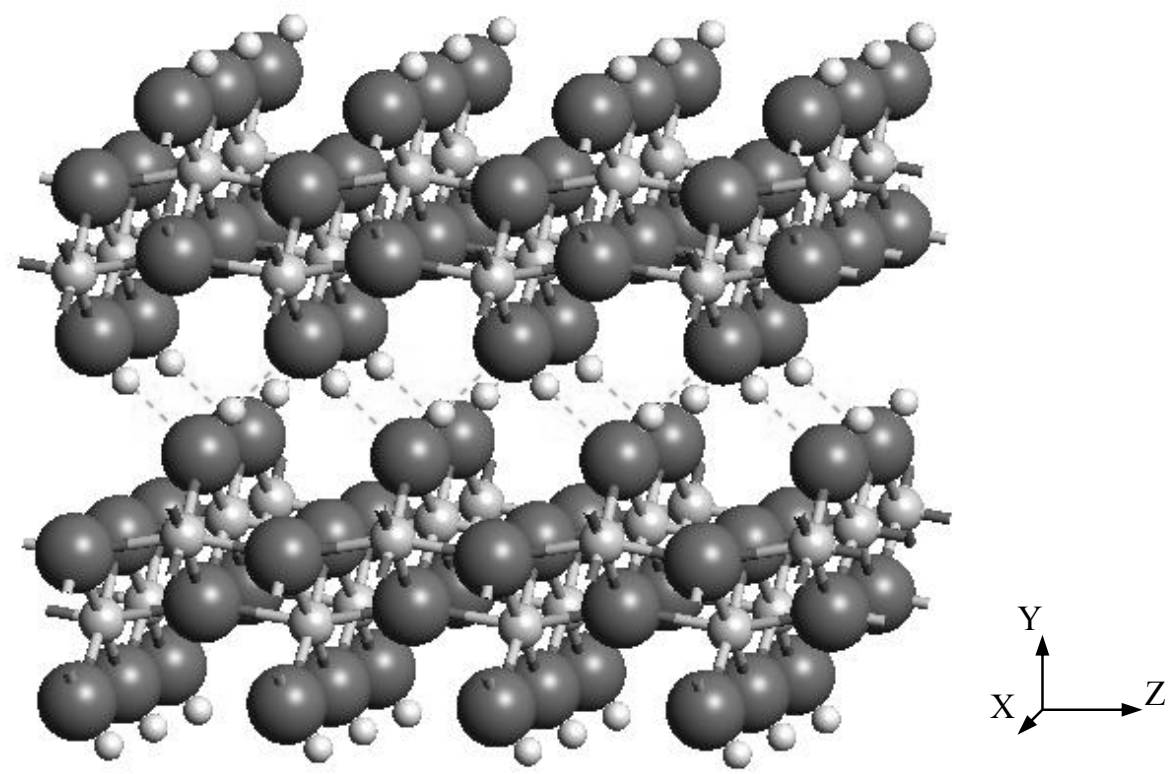


Figure 2

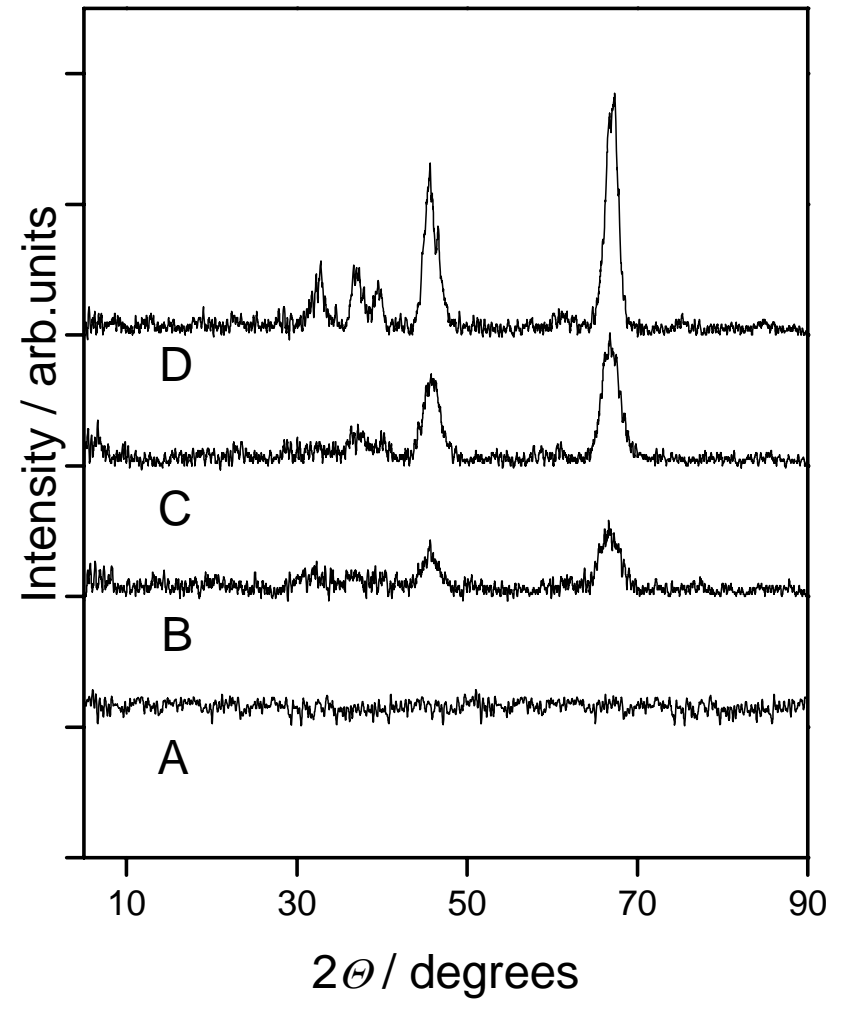


Fig. 3a

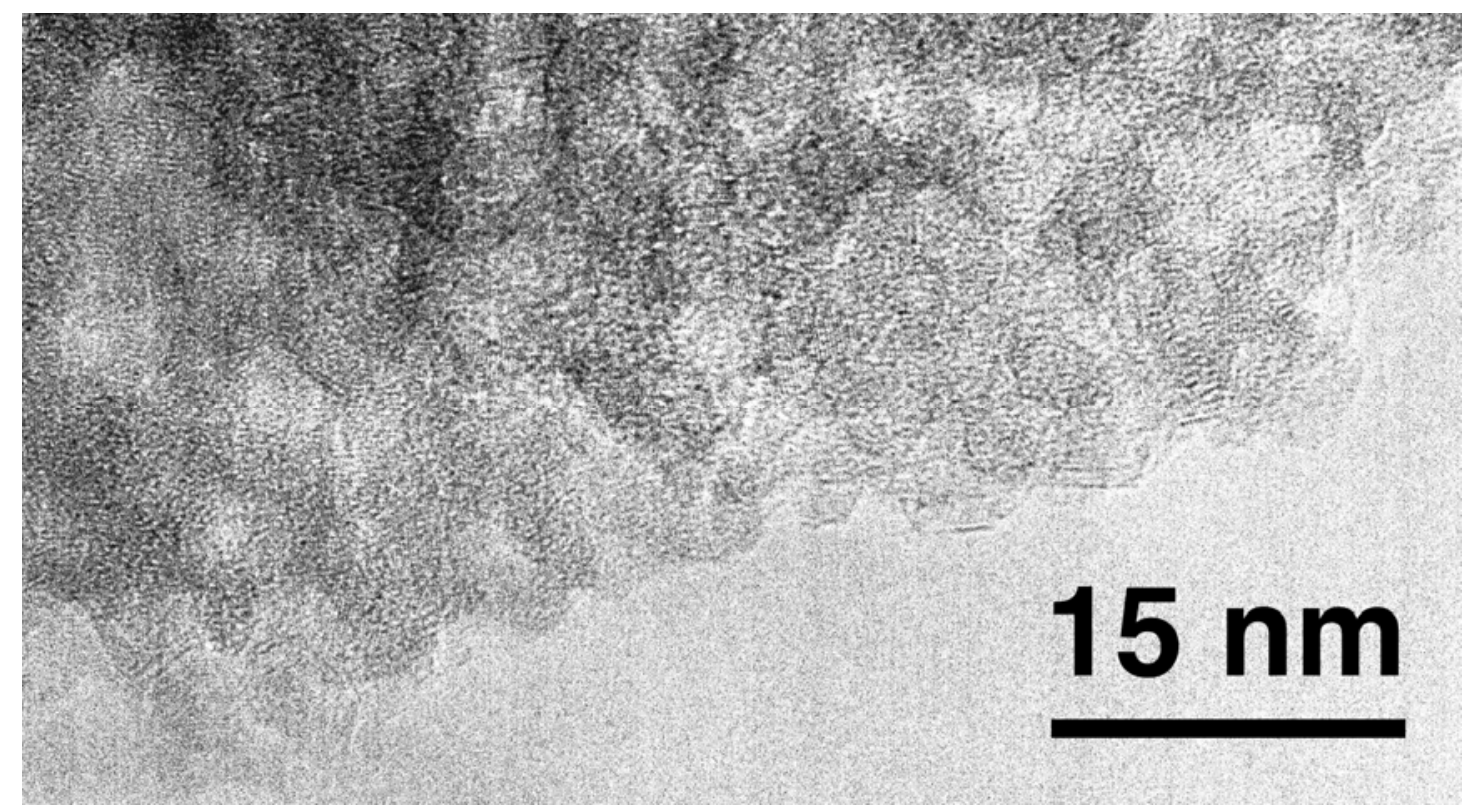

Fig. $3 b$

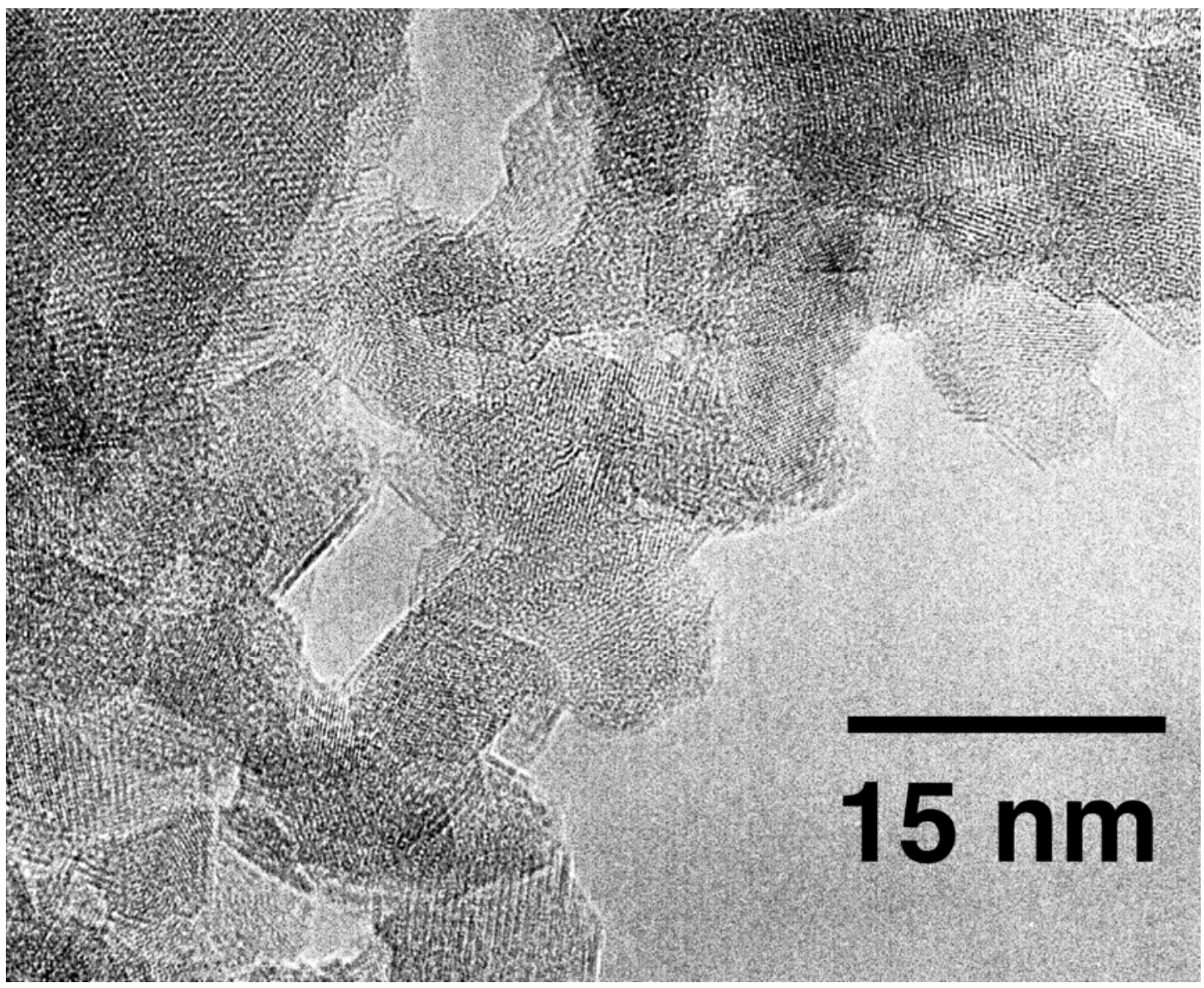


Figure 4

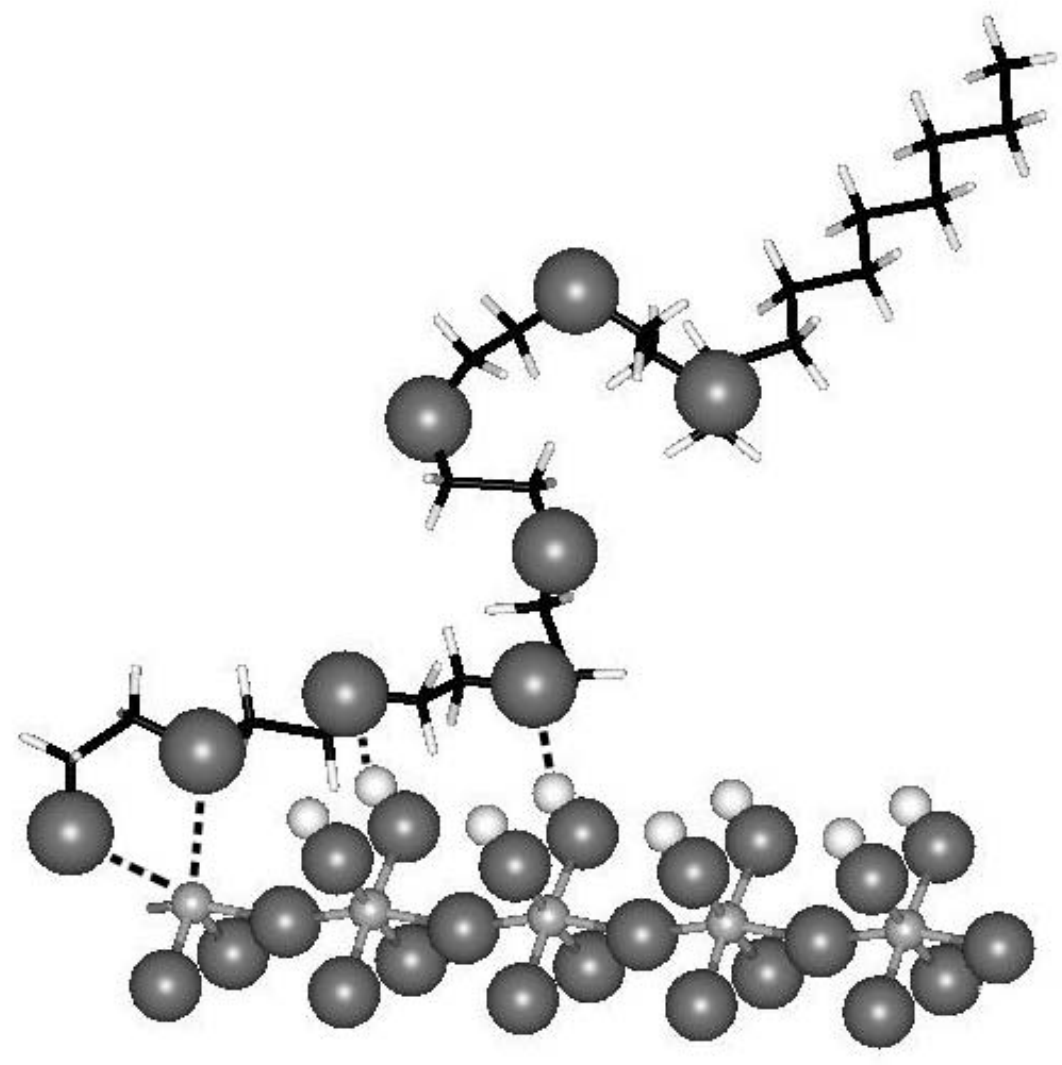


Figure 5

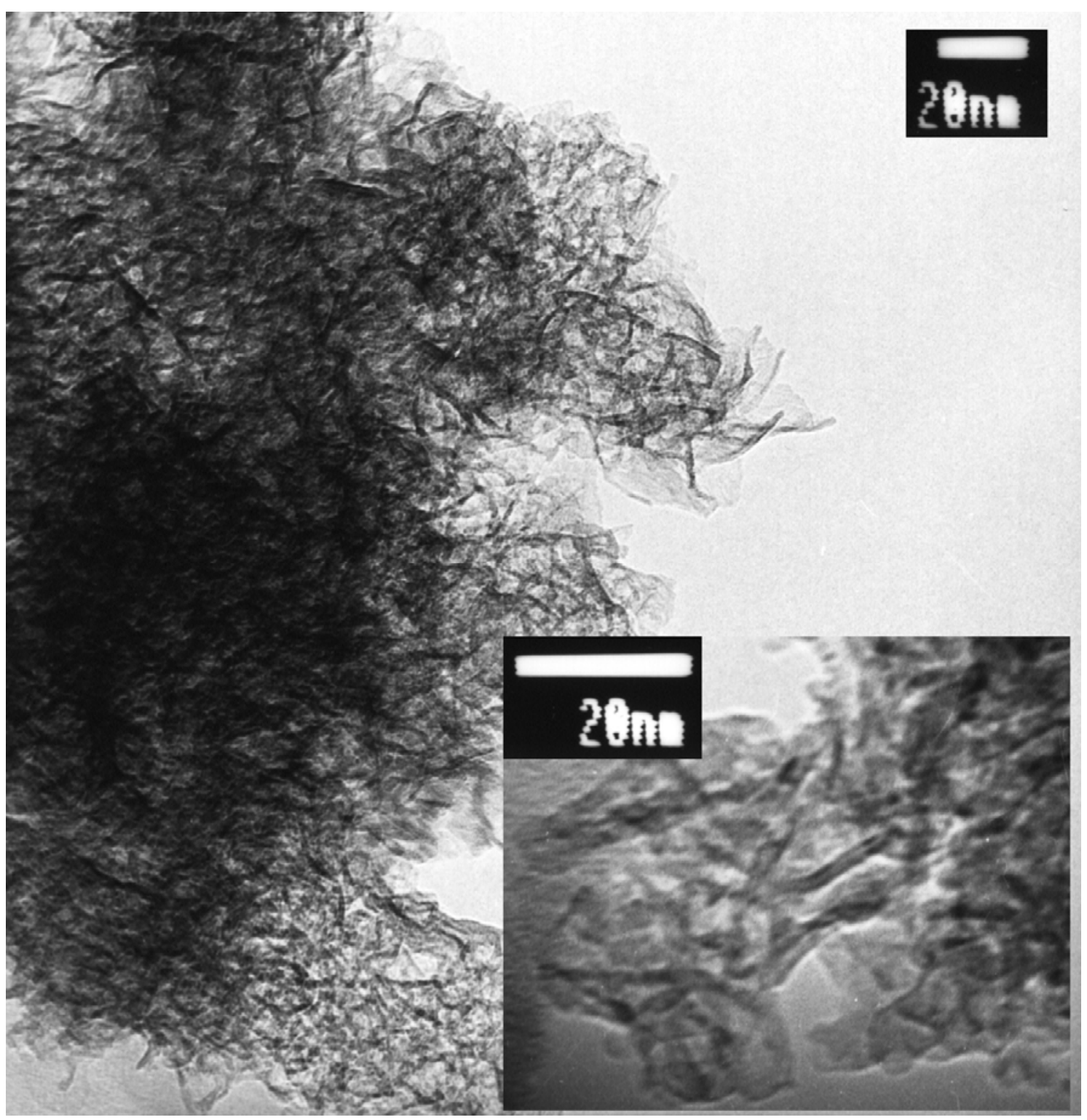


Figure 6

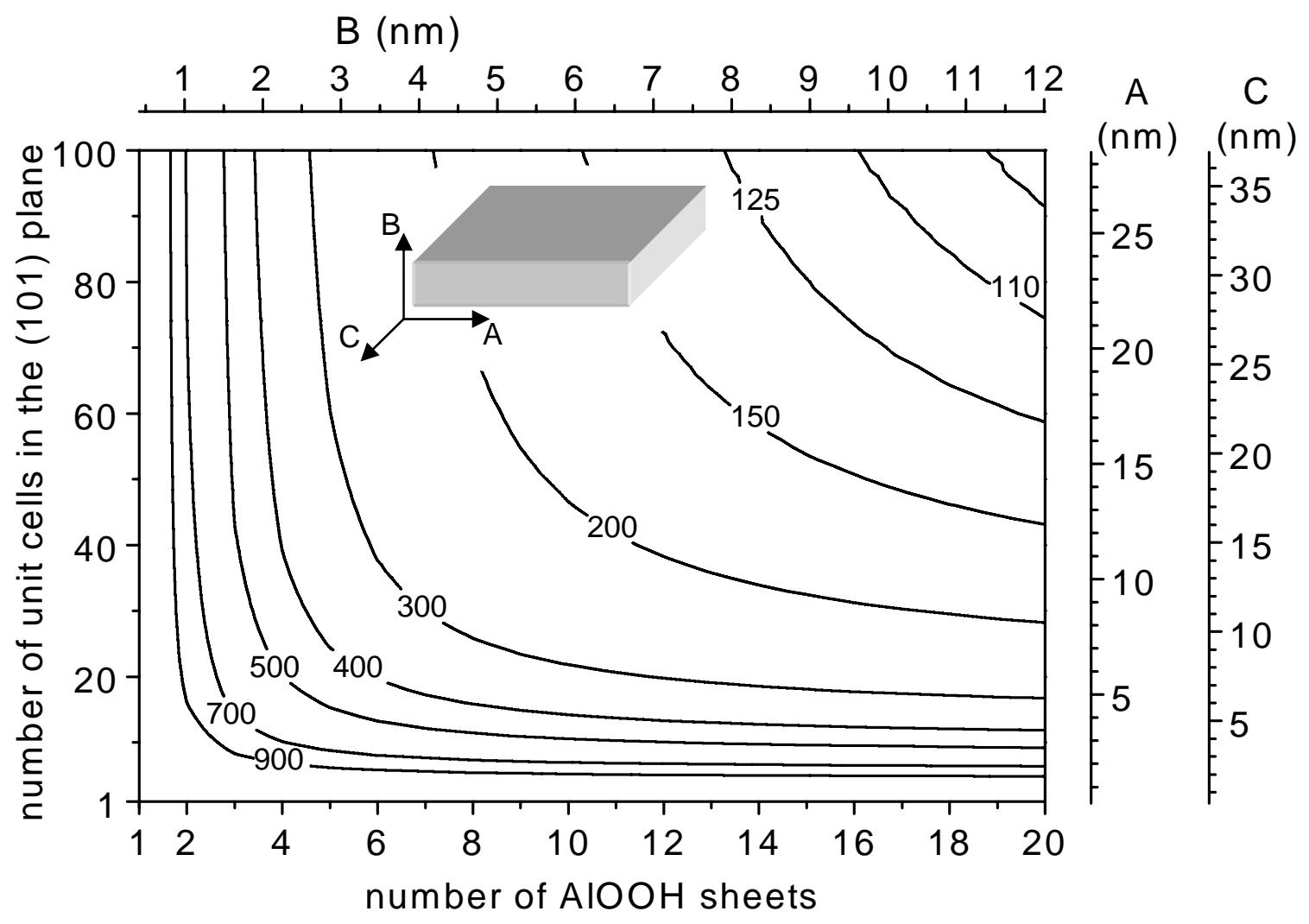


Figure 7

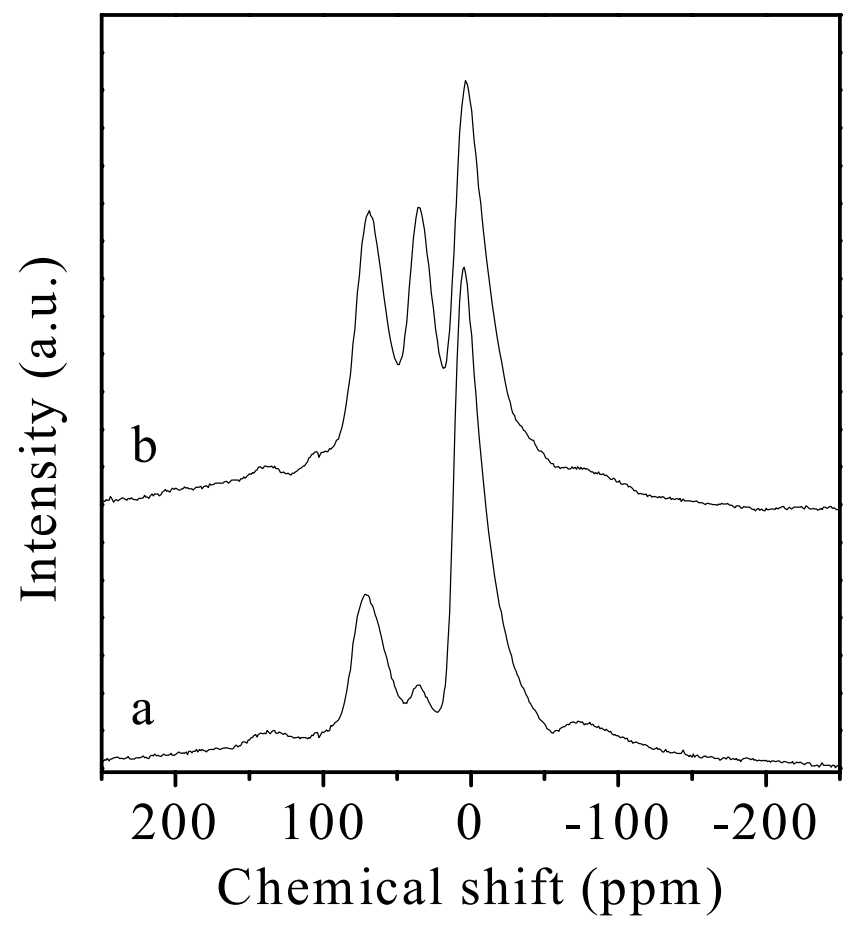


Figure 8

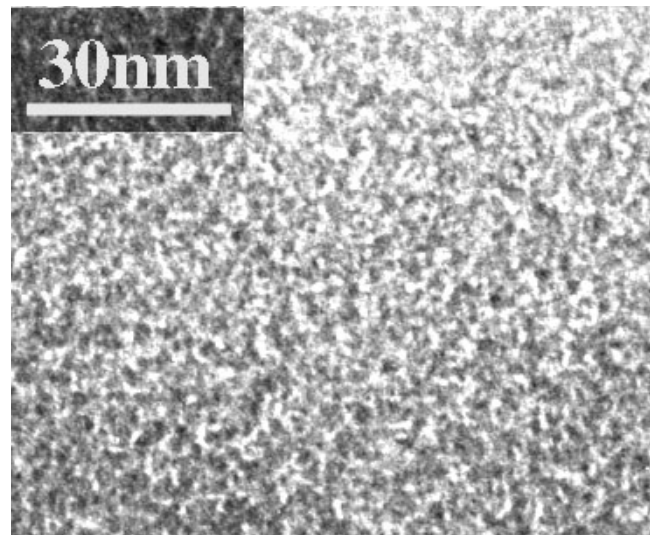

A1
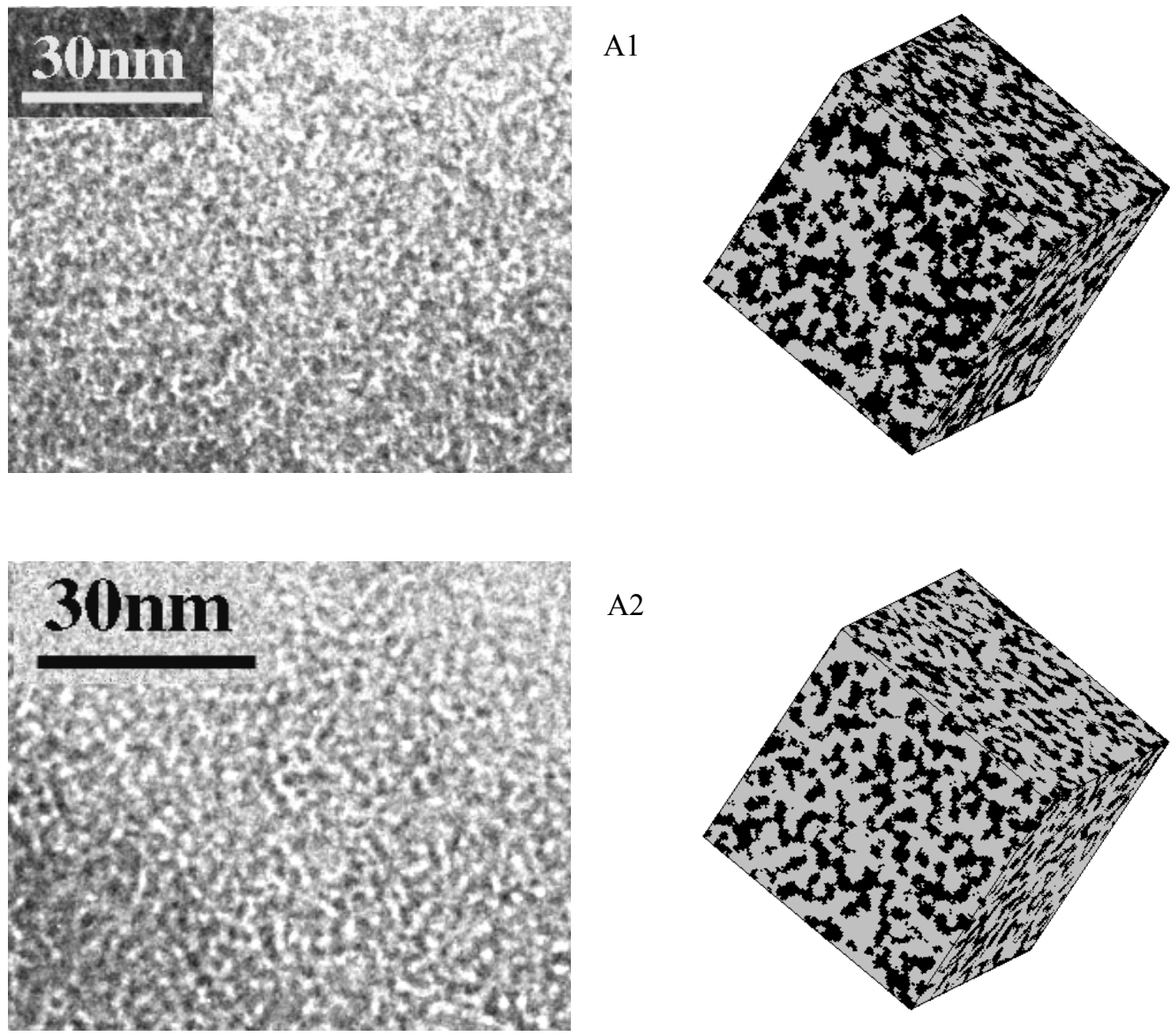

A2

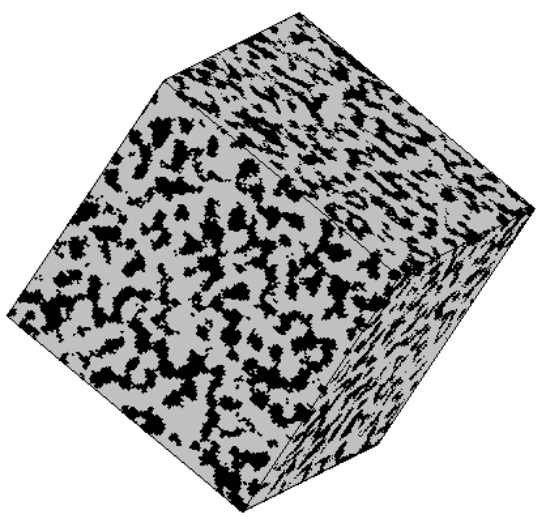

A2-HT

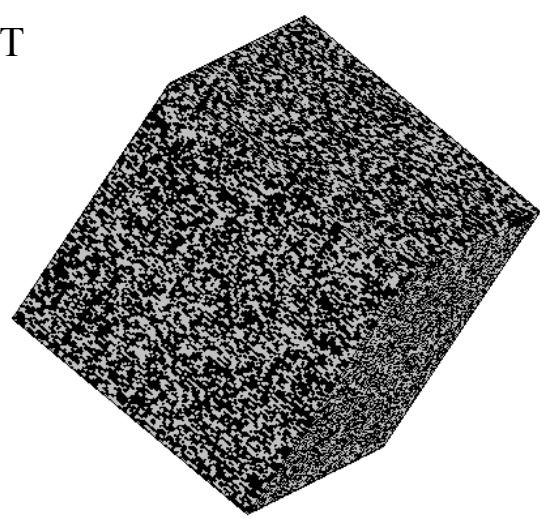


Figure 9

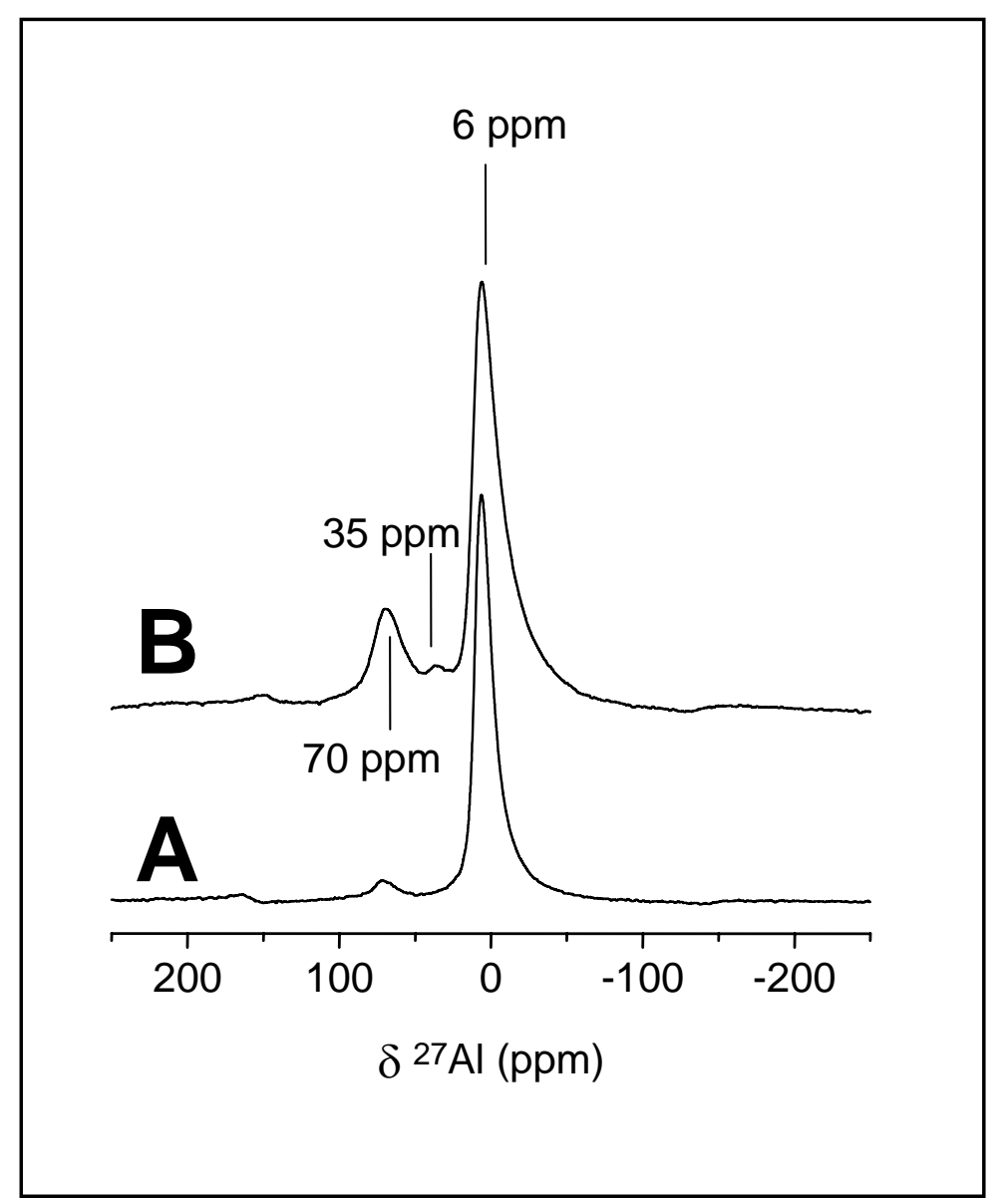


Figure 10

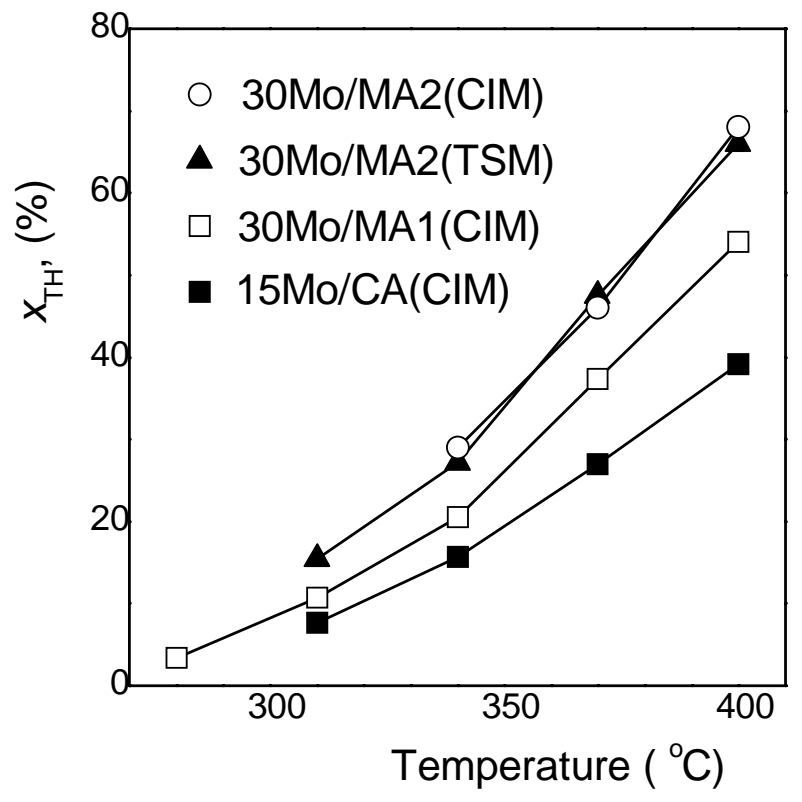


Figure 11

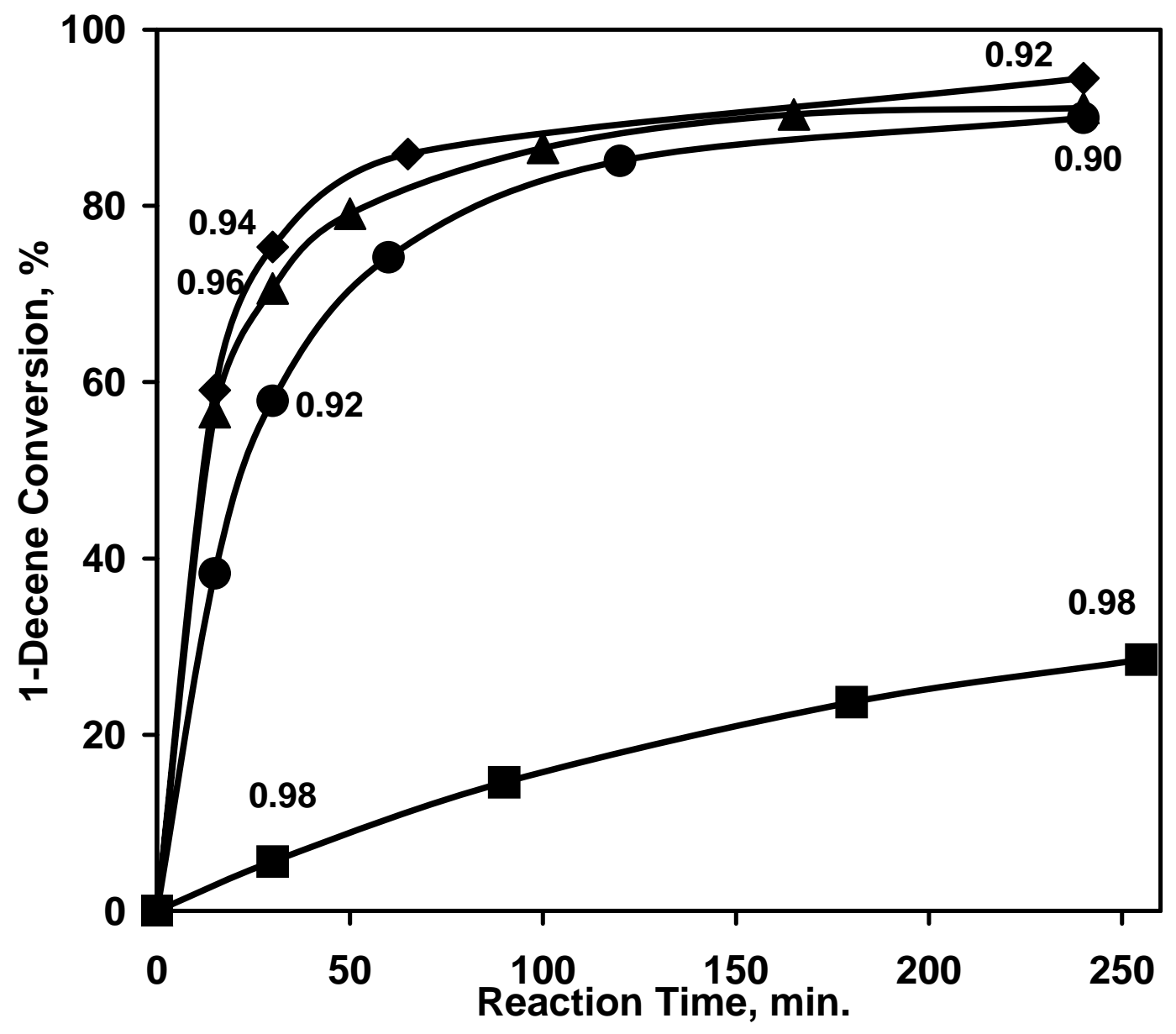


Figure 12

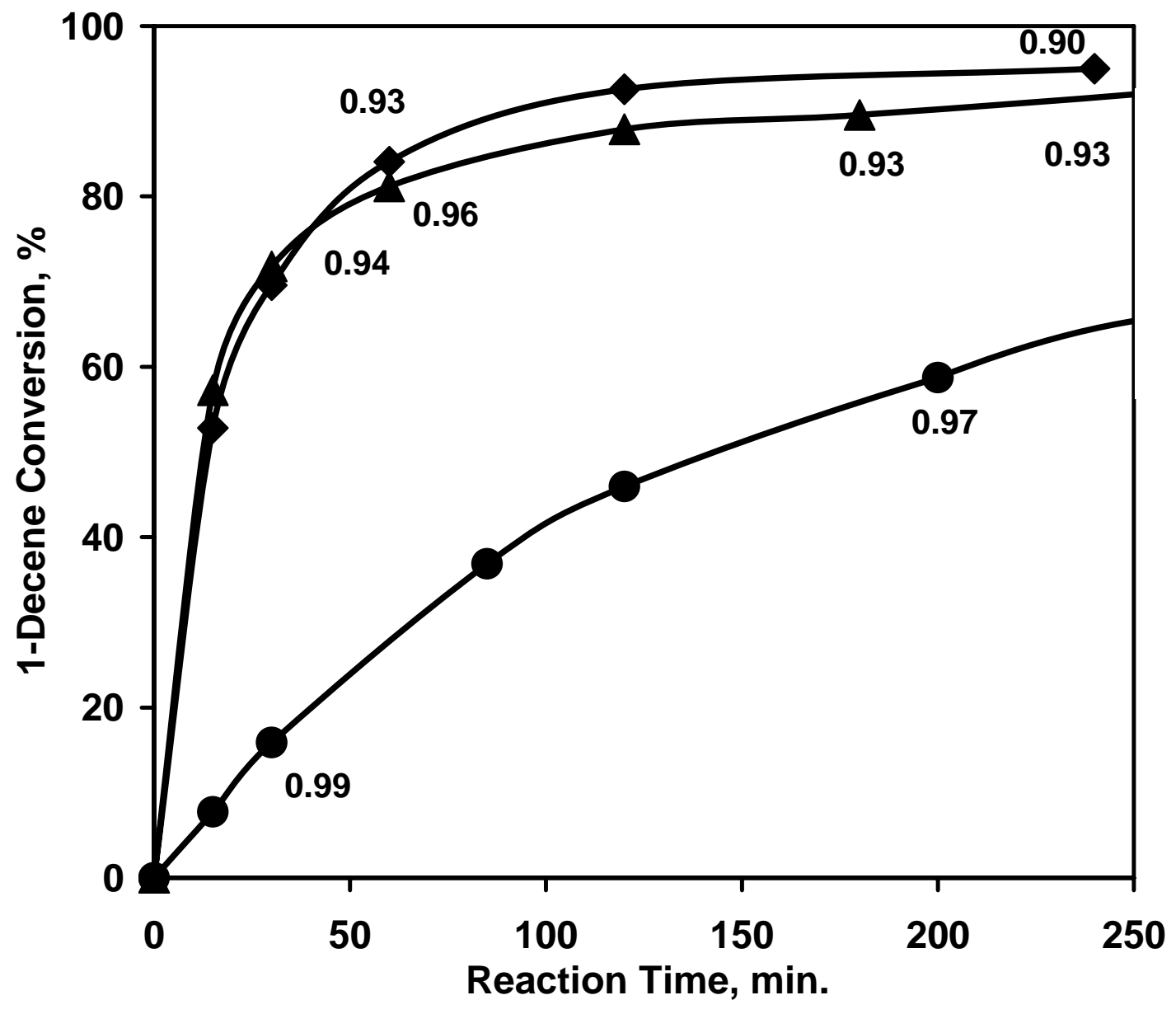


Figure 13

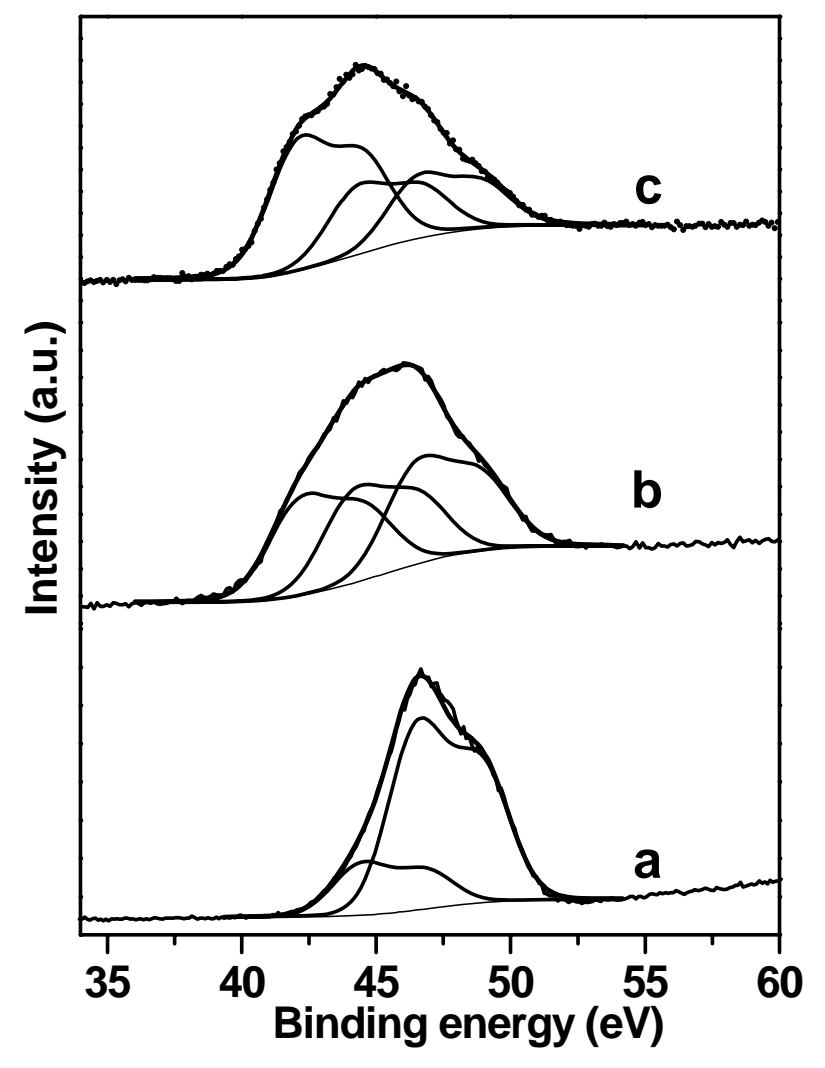


Figure 14

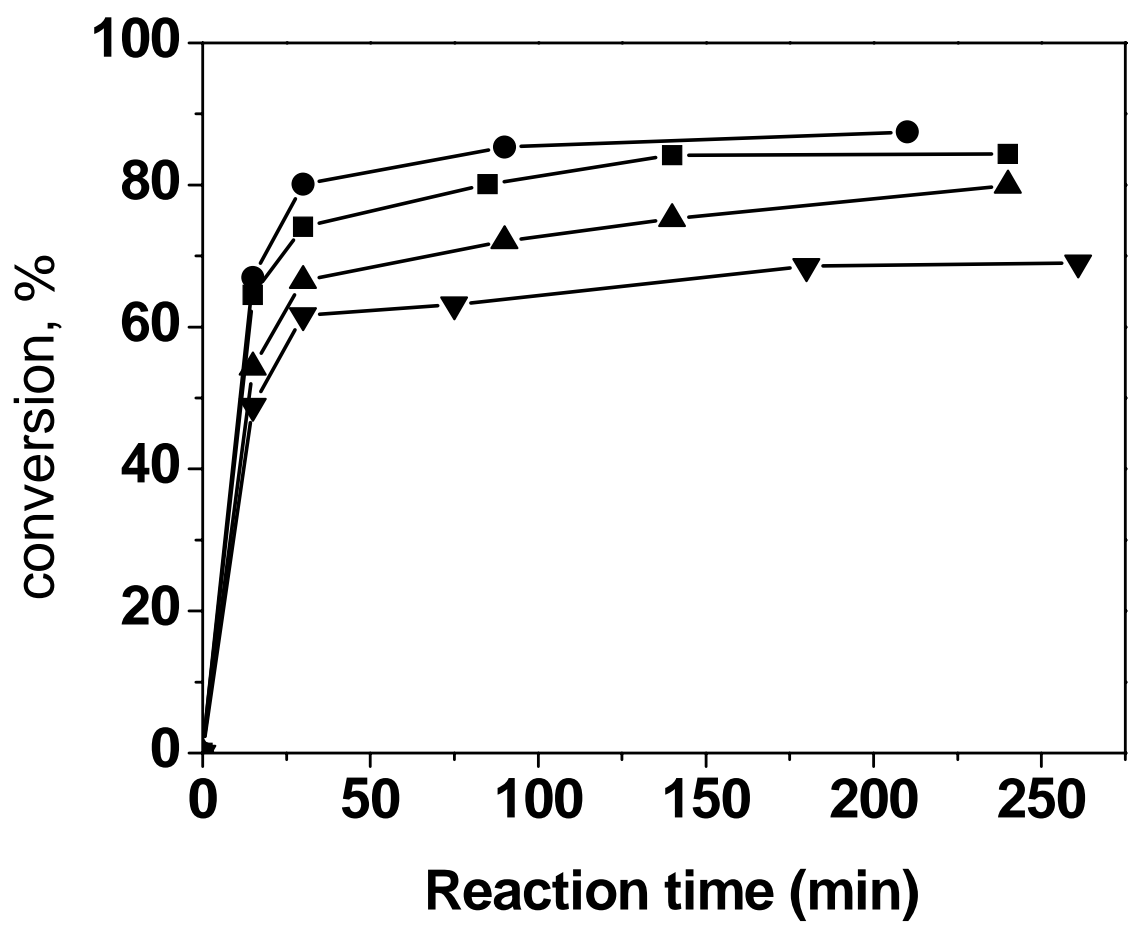

